\title{
Proceedings of the 2013 National Toxicology Program Satellite Symposium
}

\author{
Susan A. Elmore ${ }^{1}$, Michael C. Boyle ${ }^{1}$, Molly H. Boyle ${ }^{2}$, Michelle C. Cora ${ }^{1}$, Torrie A. Crabbs ${ }^{3}$, \\ Connie A. Cummings ${ }^{4}$, Margarita M. Gruebbel ${ }^{3}$, Crystal L. Johnson ${ }^{5}$, David E. Malarkey ${ }^{1}$, \\ Elizabeth F. McInnes ${ }^{6}$, Thomas Nolte ${ }^{7}$, Cynthia C. Shackelford ${ }^{3}$, and Jerrold M. Ward ${ }^{8}$
}

${ }^{1}$ National Toxicology Program, National Institute of Environmental Health Sciences, National Institutes of Health, Research Triangle Park, North Carolina ${ }^{2}$ Integrated Laboratory Systems, Inc., Research Triangle Park, North Carolina ${ }^{3}$ Experimental Pathology Laboratories, Inc., Research Triangle Park, North Carolina ${ }^{4}$ Ultrapath Imaging, Durham, North Carolina ${ }^{5}$ Charles River Laboratories, Pathology Associates, Durham, North Carolina ${ }^{6}$ Gribbles Healthscope, Glenside, Australia ${ }^{7}$ Boehringer Ingelheim Pharma GmbH \& Co. KG, Biberach/Riss, Germany ${ }^{8}$ Global VetPathology, Montgomery Village, Maryland

\begin{abstract}
The 2013 annual National Toxicology Program (NTP) Satellite Symposium, entitled "Pathology Potpourri" was held in Portland, Oregon in advance of the Society of Toxicologic Pathology's $32^{\text {nd }}$ annual meeting. The goal of the NTP Symposium is to present current diagnostic pathology or nomenclature issues to the toxicologic pathology community. This article presents summaries of the speakers' presentations, including diagnostic or nomenclature issues that were presented, along with select images that were used for audience voting and discussion. Some lesions and topics covered during the symposium included a caudal tail vertebra duplication in mice; nephroblastematosis in rats; ectopic $\mathrm{C}$ cell tumor in a hamster; granular cell aggregates/tumor in the uterus of a hamster; Pneumocystis carinii in the lung of a rat; iatrogenic chronic inflammation in the lungs of control rats; hepatoblastoma arising within an adenoma in a mouse; humoral hypercalcemia of benignancy in a transgenic mouse; acetaminophen induced hepatoxicity in rats; electron microscopy images of iatrogenic intraerythrocytic inclusions in transgenic mice; questionable hepatocellular degeneration/cell death/artifact in rats; atypical endometrial hyperplasia in rats; malignant mixed Müllerian tumors/carcinosarcomas in rats; differential diagnoses of proliferative lesions the intestine of rodents; and finally obstructive nephropathy caused by melamine poisoning in a rat.
\end{abstract}

\footnotetext{
Address correspondence to: Susan A. Elmore, National Toxicology Program, Cellular and Molecular Pathology Branch, National Institute of Environmental Health Sciences, National Institutes of Health, Research Triangle Park, NC 27709, USA; e-mail: elmore@niehs.nih.gov.

The author(s) declared no potential conflicts of interest with respect to the research, authorship, and/or publication of this article. The author(s) received no financial support for the research, authorship, and/or publication of this article.
} 


\section{Keywords}

NTP Satellite Symposium; duplicate vertebra; nephroblastematosis; granular cell aggregates; Pneumocystis carinii; bronchioloalveolar hyperplasia; hepatoblastoma; intraerythrocytic inclusions; hepatocellular apoptosis; atypical endometrial hyperplasia; malignant mixed Müllerian tumor; gastrointestinal diverticulum; obstructive nephropathy

\section{Introduction}

The National Toxicology Program (NTP) Satellite Symposium is a one-day meeting that is traditionally held in conjunction with the annual Society of Toxicologic Pathology (STP) meeting (Bach et al. 2010; Adams et al. 2011; Elmore et al. 2012). Attendance at the symposium has steadily increased since the first meeting in 2000 and this year there were 239 registered participants. The objective of this annual symposium is to provide continuing education on interpreting histopathology slides. This includes the presentation and discussion of diagnostically difficult, interesting, or rare lesions, or challenging nomenclature issues. The session is interactive in that each speaker presents images for audience voting via wireless keypads. Once the votes are tallied the results are displayed on the screen for all to view. The speaker generally provides his or her preferred diagnosis for comparison with some additional background information, after which lively and constructive discussion ensues.

The theme for the 2013 Symposium was "Pathology Potpourri" which allowed for a variety of topics to be presented. Species included rat, mouse, and hamster and organ systems included skeletal, renal, endocrine, reproductive, pulmonary, hepatobiliary, and gastrointestinal. Two cases using only transmission electron microscopy for voting were also included, one of which was a clinical pathology case. One speaker presented diagnostic challenges that the International Harmonization of Nomenclature and Diagnostic Criteria (INHAND) Gastrointestinal Organ Working Group had been considering. This article provides synopses of all presentations including the diagnostic or nomenclature issues, a selection of images presented for voting and discussion, voting choices, voting results, and major discussion points.

\section{An Unusual Bone Lesion in Mice}

The first presentation of the day was given by Dr. Margarita M. Gruebbel (Experimental Pathology Laboratories, Inc. Research Triangle Park, NC, USA). Dr. Gruebbel presented an unusual bone lesion noted incidentally in five adult B6C3F1 mice (one vehicle-control group male, three low-dose group males, and one mid-dose group female) from a 2-year carcinogenicity bioassay. All five mice were $770-773$ days of age at the end of the study. At terminal necropsy, all had grossly apparent, single, $1-3 \mathrm{~mm}$, pale nodules in the skin of the distal tail. Visual examination and plain radiographs of the residual fixed carcasses of all five mice did not reveal any additional developmental abnormalities in the tails or other parts of the skeleton. Due to a lack of clinical neurologic signs, the spinal cords had not been sectioned or examined by light microscopy in any of the five mice. 
Light microscopic images of transverse sections of normal distal tail from an unaffected mouse were presented, demonstrating that the distal caudal vertebrae (Figure 1A) are normally small and cylindrical, without arches, and with diminished or absent processes (Bab et al. 2007). Light microscopic images of representative examples of the grossly observed tail nodules (Figures 1B-F) were then presented, with the following voting choices: (1) tail - heterotopic bone, (2) tail - caudal vertebra, luxation, (3) tail - callus, (4) tail- caudal vertebra, duplication, (5) tail - osteoma, and (6) tail - hyperostosis. Most votes (60\%) were for caudal vertebra duplication, with $29 \%$ for heterotopic bone, $11 \%$ for osteoma, and $0 \%$ for the other voting choices. Thus, the majority consensus was that these tail findings consisted of a single redundant (duplicate) caudal vertebra located in the subcutis dorsal to the normal vertebra.

In all five mice, the duplicate vertebra (Figures 1B-F) was morphologically similar to, though sometimes slightly smaller than, the normal underlying vertebral body . Both the duplicate and normal vertebrae in the five affected mice were also similar to the distal caudal vertebrae of unaffected mice when collected from approximately the same level within the vertebral column (Figure 1A). In addition, the structure of the duplicate vertebra tended to "echo" that of the underlying normal vertebra. Thus, in one low-dose group male, both the duplicate and underlying normal vertebrae exhibited a central medullary cavity containing usual structures such as blood vessels and adipocytes (Figures1B-D). In the other four cases, the duplicate and normal vertebrae both had narrowed or absent medullary cavities (Figures 1E\&F)

The duplicate vertebrae were composed of well-differentiated bone, morphologically identical to that of the underlying normal vertebra, sometimes with peripheral cartilaginous zones (Figures 1B-D). The duplicate vertebrae were generally surrounded by a loose fibrous connective tissue capsule (Figures 1B-D), but were not associated with the usual tendons, nerves, or blood vessels, which were present around the underlying normal vertebra in affected mice [Figures 1B, C, E] and around normal caudal vertebrae in unaffected mice (Figure 1A).

In two affected mice (low-dose group males), the duplicate vertebrae were partly or completely displaced to the external surface of the tails through overlying skin ulcerations (Figure 1F); the normal vertebrae were also slightly dorsally displaced. These vertebrae exhibited inflammation, with necrotic debris and degenerate neutrophils in the narrowed medullary cavities; the adjacent subcutis exhibited fibrosis and mild inflammatory cell infiltrates. The epidermis bordering the ulcerations was hyperplastic and overlaid with an exudative crust composed of necrotic cell debris, proteinaceous fluid, and degenerate neutrophils. These secondary reactive changes were most likely due to bacterial contamination through the skin breach and were therefore not considered primary toxic effects.

Several differential diagnoses were considered for the tail lesions in these mice, including congenital heterotopic bone, luxation of one caudal vertebra dorsally over the immediately adjacent vertebra, or genetically or exogenously induced misalignment of consecutive vertebrae at abnormal angles. However, the uniform dorsal localization, homogeneous 
microscopic morphology within given animals, and non-tangential, full-face aspects of the both vertebrae in transverse sections of affected mice were not consistent with these possibilities. Also, no "kinks", "bends", or other deviations of normal tail anatomy were noted at gross necropsy, and there was no radiographic evidence of such abnormalities in the residual tails.

Therefore, the five cases presented here were considered duplicate caudal vertebrae, incidental and unrelated to treatment, and most likely arising as developmental anomalies. The occurrence of this finding in at least one vehicle-control mouse mitigates against the possibility that this was a test-article effect, however, the involvement of other environmental factors cannot be entirely ruled out. It is also possible that these duplicate vertebrae resulted from random, spontaneous mutation(s).

Numerous spontaneous and induced vertebral and tail malformations have been described in mice including grossly visible kinking, bending, curling, truncation, and/or agenesis of the tail as well as malformation, misalignment, hypoplasia, fusion, abnormal ossification, homeotic transformations, and/or reduction in number of the vertebrae (Barnett 1965; Doolittle et al. 1996; Greco et al. 1996; Klootwijk et al. 2000; Matsuura et al. 1997; Murakami and Kameyama 1963; Murakami and Kameyama 1964; Noel and Wright 1970; Padmanabhan 1998; Padmanabhan et al. 2008; Schrick et al. 1995; Sonoda et al. 1990; Torchinsky et al. 1995).

Despite this variety of tail defects, reports of duplicate vertebrae and/or tails in mice are few and often perfunctory, typically mentioned only as minor features in complex syndromes of multiorgan abnormalities (Center 1969; Rutledge et al. 1994; Theiler and GluecksohnWaelsch 1956).

Duplications of the spinal cord (often referred to as split cord malformations, diplomyelia or diastematomyelia) have long been recognized as congenital anomalies in humans, and usually occur with other abnormalities such as neural tube defects (Dias and Walker 1992; Pang et al. 1992) and/or caudal duplication syndromes (Dominguez et al. 1993). In domestic animals, duplication of the spinal cord is very rare, with most reported cases occurring in calves (Zani et al. 2010).

Abnormal vertebrae such as hemivertebrae, fused vertebrae, and butterfly vertebrae often occur with duplicate spinal cords and other spinal dysraphisms, to form malformed "hemivertebral" spinal columns (Dias and Walker 1992). In contrast, segmental spine doubling with essentially fully formed vertebrae is very rare. Some human patients with segmental spinal cord/vertebral column duplications also exhibit soft tissue malformations and other defects which result in severe clinical disease (Dominguez et al. 1993; Pathak et al. 1988), but other patients have few or no concurrent defects or clinical symptoms (Cebesoy et al. 2009).

Pang et al. (1992) proposed a "unified" theory of split cord malformations postulating that all such defects ultimately derive from a common error during gastrulation resulting in paired notochords and neural tubes. This could presumably lead to formation of duplicate vertebral columns (Dias and Walker 1992), since during embryogenesis, the notochord 
induces patterning and growth of the somites, from which the axial skeleton - including the tail -develops (Wellik 2009). Similar or analogous processes could occur during presumed post-gastrulation secondary development of the posterior body and tail in mammals (Handrigan 2003). Whether such mechanism(s) may have been involved in the formation of the duplicate caudal vertebrae in the mice in this presentation remains undetermined.

\section{Interstitial Infiltrates in The Rat Kidney}

Dr. Cynthia Shackelford (Experimental Pathology Laboratories, Inc., Research Triangle Park, NC, USA) presented three examples of a spontaneous renal lesion that is encountered sporadically in rats. All three examples were from NTP studies using Harlan SpragueDawley rats. It was noted that these lesions were observed in control and treated female rats ranging from $\sim 92$ to 250 days (3-9 mo.) of age at study termination. All three cases depicted a series of low and higher magnification photographs of the lesions located within the deep cortex of the kidney. The first case (Animal \#1) had a small, focal accumulation of basophilic cells and attempts at rosette-like structures within the renal interstitium (Figure $2 \mathrm{~A} \& \mathrm{~B}$ ). The second case (Animal \#2) contained a larger focal accumulation of intensely staining basophilic cells dispersed within the renal interstitium but did not exhibit rosette formation (Figure $2 \mathrm{C} \& \mathrm{D}$ ). The third case (Animal \#3) was characterized by a larger focal accumulation of basophilic cells within the interstitium, no rosette formation and no disruption of the overall structure and organization of the kidney, despite the size of the lesion (Figure 2E\&F).

After reviewing the series of representative photographs the attendees were presented with the following diagnostic choices: (1) nephropathy; (2) mononuclear cell infiltration; (3) interstitial cell hyperplasia; (4) hamartoma; (5) nephroblastematosis; (6) nephroblastoma; (7) malignant mesenchymal tumor; and (8) other. The correct response for all three examples was "nephroblastematosis" which was the option favored by the audience (54\% of respondents). "Nephroblastoma" (12\% of respondents) and "mononuclear cell infiltration" (10\% of respondents) are differential diagnoses for this lesion. However, other votes recorded were "interstitial cell hyperplasia" (7\% of respondents), "nephropathy" (3\% of respondents), "hamartoma" ( $2 \%$ of respondents) and "other" ( $1 \%$ of respondents).

The discussion then moved on to a review of the origin and histologic characteristics of nephroblastematosis and ultimately nephroblastoma in rats (Frazier, et. al. 2012). "Nephroblastematosis" (synonyms: nephroblastomatosis, blastemal rest, nephrogenic rest) of the kidney is considered a precursor lesion to spontaneous nephroblastoma (NB) encountered sporadically in specific colonies of rats, suggesting a predisposing genetic basis. Foci of nephroblastematosis appear to have the potential to develop into NB as they enlarge, and therefore may be regarded as pre-neoplastic lesions. The distinction between nephroblastematosis and NB appears arbitrary and would probably rest on size and degree of organoid differentiation (Beckwith, Kiviat, and Bonadio 1990; Mesfin 1999). Nephroblastematosis and early NB tumors occur in rats as early as 3 months of age and as late as 21 months of age in either sex, but are noted most often in females. These precursor lesions are not grossly detectable and begin as small, focal, multifocal or bilateral crowded interstitial accumulations of intensely basophilic immature (blastemal) cells with ill-defined 
cytoplasm and basophilic nuclei, which are clearly delineated from the normal renal tissue. The immature cells are presumed to originate from a remnant of developing metanephric blastema. The cells may have early organoid differentiation into epithelial rosettes. Occasional mitoses are observed within the blast cells and also in adjacent pars recta tubules (autocrine response to the blastema). The cell accumulations are exclusively located in the deep cortex near the corticomedullary junction, infiltrating between pars recta tubules, and can occasionally be seen in the presence of NB. These precursor lesions of NB, i.e. nephroblastematosis and even early tumors, do not overtly disrupt the overall structure and organization of the kidney. However, with increasing size the now neoplastic NB traps, compresses and displaces/replaces the existing renal tubules. The Upjohn Sprague-Dawley rat strain (Uph:TUC[SD]spf.nb) is considered to be genetically predisposed to NB. The precursor lesions have been designated "intralobular nephroblastematosis" because the lesions were interstitially infiltrative and the cells were blastemal (Mesfin 1999). The speaker addressed the term "intralobular" and noted that the kidney is divided into lobules and that each lobule consists of a cortex and medulla. Kidneys of all mammals and birds contain one or more lobules. The rat kidney has one lobule (unilobular) (Jamison 2002). Differential diagnoses of nephroblastematosis include "foci of lymphocyte accumulation" and "NB". "Foci of lymphocyte accumulation" consist of a more discrete, individualized population of cells, composed of mononuclear inflammatory cells and show no early epithelial rosette formation (Figure $2 \mathrm{G}$ ).

"Nephroblastoma (NB)" (synonyms: embryonal nephroma, renal adenosarcoma, embryonal carcinoma, Wolffian duct tumor, and Wilms' tumor [man]) of the kidneys occur rarely in rats. In rats, NBs have been observed as early as 5 months of age, but do not appear to occur as frequently as nephroblastematosis. These tumors generally appear as large grossly detectable, circumscribed, fleshy growths with invasion of the cortex and occasionally renal pelvis. Histologically, these tumors consist of discrete clusters of highly basophilic blast cells, sometimes surrounding mature renal ducts (Figure $2 \mathrm{H}$ ). The blast cells can also be arranged in trabecular, alveolar, papillary, or rarely, fascicular or cylindromatous patterns (Cardesa and Ribalta 1998; Hard 1985; Hard and Grasso 1976; Turusov, Alexandrov, and Timoshenko 1980). Organoid differentiation of the tumor cells is usually present as epithelial rosettes, primitive basophilic tubules, attempted glomerulus formation, or mature epithelial ducts (Figure 2I). The stroma varies from either delicate areolar tissue to welldeveloped fibrous connective tissue tracts. Evidence of mitotic activity is frequent in the blast cell clusters and the primitive tubules. Ultrastructurally, the neoplastic epithelial cells have abundant junctional complexes and poorly formed cytoplasmic organelles, and form narrow luminae with microvilli. Evidence of abundant external laminae with basilar infoldings may be found (Hara, et.al. 1982; Mesfin 1999). Differential diagnoses of NB are "renal mesenchymal tumor" which consists of neoplastic fibroblast-like spindle cells that sequester pre-existing renal tubules and "papillary variant of renal tubule carcinoma" which exhibits extensions of neoplastic tubule epithelial cells into epithelial sacs that mimic glomeruli formation.

While NB's reportedly have been chemically induced, one audience member inquired as to whether or not nephroblastematosis has been observed to be chemically induced as well. Chemically induced NB reportedly start as small aggregates of highly basophilic blastemal 
cells located in the superficial cortex in contrast to the spontaneous precursor lesions and tumors which are characteristically located in the deep cortex (Cardesa and Ribalta 1998; Hard 1985; Hard and Grasso 1976; Mesfin 1999; Turusov, Alexandrov, and Timoshenko 1980). Finally, one audience member commented on the trend for these precursor lesions being observed in animals as early as 3 months of age and then as late as 21 months of age, whether or not these lesions should actually be considered preneoplastic or even a precursor lesion to NB since the tumors reportedly tend to occur primarily earlier in life. After the symposium, the speaker noted a common discussion point amongst attendees who had experience seeing these lesions in different rat strains; the majority felt that these lesions of nephroblastematosis were most often detected within the central region of the longitudinally cut section of kidney.

\section{Interesting Background Lesions in Hamsters}

A presentation on interesting background lesions in hamsters, presented by Dr. Elizabeth F. McInnes (Gribbles Healthscope, Glenside, Australia) was a collaborative effort with Dr. Ernst Heinrich (Fraunhofer ITEM, Hannover, Germany). Two challenging cases were presented to the audience for voting. The first case was from a terminal sacrifice, male Syrian golden hamster of the strain Han:AURA which was from the untreated control group of a carcinogenicity study of 104 weeks. The hamster did not display any macroscopic findings in the larynx at necropsy. The audience was shown a series of three low and high magnification images of trachea with a luminal cellular mass extending through the lamina propria to the level of the tracheal cartilage, adjacent to the thyroid gland (Figures 3A-C). The mass was composed of sheets of medium-sized, polygonal to elongated cells with abundant eosinophilic, often vacuolated cytoplasm. The nuclei were predominantly mediumsized, round, and central with coarse chromatin and occasional mitotic figures.

The audience voting choices and results were (1) focus of epithelial hyperplasia (2\%), (2) carcinoma (3\%), (3) ectopic C cell tumor, benign (24\%), (4) tumor neuroendocrine cell, malignant (16\%), (5) tumor neuroendocrine cell, benign (41\%), (6) histiocytic aggregate (2\%), (7) C cell tumor, malignant (9\%), and (8) another diagnosis? (3\%). The majority of audience members voted for the diagnosis of tumor neuroendocrine cell, benign, which was not completely inaccurate. However, the diagnosis of ectopic $\mathrm{C}$ cell tumor, benign was the more specific diagnosis favored by the authors, as illustrated with immunohistochemical markers later in the presentation. The discussion points included why the term ectopic $\mathrm{C}$ cell tumor, benign was preferred over the term neuroendocrine cell tumor, benign and the history of the lesion in the literature. The presence of spontaneous ectopic C-cell tumors, neuroendocrine cell hyperplasia, or benign or malignant tumors in the larynx (Pour 1985) and trachea (Ernst et al.1995, McInnes, 2011) may be unique to hamsters. These lesions occur in the larynx and upper trachea in close proximity to the thyroid gland in hamsters and incidence increases with age.

Evidence was then presented to the audience of the neuroendocrine or $\mathrm{C}$ cell nature of the tumor. Neuroendocrine cells stain positive for calcitonin, calcitonin gene-related peptide (CGRP), neuron-specific enolase, serotonin and synaptophysin using immunohistochemistry (Ernst et al., 1995) and this is demonstrated in Figures 3D-H. In addition, neuroendocrine 
and ectopic $\mathrm{C}$ cells are positive with a silver stain (Grimelius) as shown in Figure 3I. Benign tumors of neuroendocrine cells do not display invasion, whereas malignant tumors demonstrate submucosal and luminal invasion and metastasis to the lung (Ernst et al., 1995). Since this tumor did not display invasion, the diagnosis of benign tumor was favored. The incidences of ectopic $\mathrm{C}$ cell hyperplasia and neoplasia in control animals in short and long term studies were presented, as shown in Table 1. Incidences of ectopic C cell hyperplasia ranged from 1/30-1/100 whereas incidences of neoplasia, benign or malignant, were 1/250.

The authors favor the term ectopic C-cell hyperplasia/adenoma/carcinoma rather than neuroendocrine cell hyperplasia/tumor since they consider the origin of these cells to be the C-cells from the thyroid. It is likely that these types of tumors arise from rests of C-cells, which fail to migrate to the thyroid. The site of origin at the laryngotracheal junction (adjacent to the thyroid gland), the tumor morphology, immunohistochemistry profile (positive for calcitonin and CGRP) and Grimelius silver stain positivity appear to support this hypothesis.

In conclusion, the authors stated that the presence of spontaneous ectopic C-cell hyperplasia and tumors in the larynx and trachea might be unique to hamsters. There are no obvious cytological differences between ectopic $\mathrm{C}$ cell hyperplasia and benign tumors at the laryngotracheal junction in hamsters and the diagnosis is largely based on size. Incidences of up to $8 \%$ in hamsters are reported (Ernst et al., 1995), but this incidence was not seen in present studies. The lesion could originate from solitary or clusters of neuroendocrine cells or it could originate from embryonic $\mathrm{C}$ cells (which is the hypothesis favored by the authors). Immunohistochemistry is needed to confirm the presence of ectopic $\mathrm{C}$ cells in the hamster upper respiratory tract.

The second case was a female Syrian golden hamster, untreated control of the strain Han:AURA. The hamster was a terminal sacrifice from a carcinogenicity study of 104 weeks and no macroscopic findings were observed in the female reproductive system of this animal at necropsy. The audience was shown two images (Figures $3 \mathrm{~J} \& \mathrm{~K}$ ), of a lesion at low and high magnification, demonstrating a focal group of large polygonal cells with abundant eosinophilic granular cytoplasm and small, eccentric nuclei with coarse chromatin in the lamina propria of the uterus. The audience voting choices and results were (1) carcinoma (0\%), (2) histiocytoma, benign (5\%), (3) histiocytoma, malignant (0\%), (4) histiocytic aggregates (3\%), (5) granular cell aggregates (14\%), (6) granular cell tumor (78\%), and (7) another diagnosis? $(0 \%)$.

The majority of the audience voted for the diagnosis of granular cell tumor based on the size of the lesion, distinct borders, and slight compression of surrounding tissue. The author's preferred term was granular cell aggregate (or focus, accumulation, or hyperplasia). The author did not consider this lesion a tumor because these lesions occur with increasing age in nearly all female Syrian hamsters, especially if lesions consisting of 2-3 cells are included. If one only counts the lesions that are visible at low magnification, the incidence can be as high as $81 \%$ (Kamino et al. 2001). The sizes of the lesions are variable, but rarely are they larger than the one presented here for voting. These lesions can show minimal compression, but no other tumor criteria. In the hamster, particularly in aging female hamsters, this is very 
a common, non-neoplastic, change with a multifocal distribution in the endometrium and muscular layer of the uterus.

Discussion then focused on the history and cellular features of granular cell aggregates and tumors in hamsters. Granular cell foci are found in the hamster uterus at an incidence of $54 \%$ (Kamino et al., 2001). In one report, granular cells resembling those of granular tumors were found scattered in the subserosa of the uterus in three female hamsters (Pour et al., 1976). Tumors composed of granular cells in the intestinal walls of white hamsters have been described by Pour and co-workers (1973) and granular cell tumors have also been observed in the peripheral nervous system (Pour et al., 1973).

The cell of origin of uterine granular cell tumors or aggregates has not been definitively determined although they are thought to be of myogenic (Veit et al., 2008), Schwann cell, or histiocytic origin (Markovits and Sahota, 2000a). The principle histomorphologic feature of granular tumor cells/aggregates in $\mathrm{B} 6 \mathrm{C} 3 \mathrm{~F} 1$ mice is the presence of abundant cytoplasmic eosinophilic granules that stain positive for periodic acid-Schiff with diastase resistance (Veit et al., 2008). Expression of S-100 and neuron specific enolase in rodent granular cell tumors/aggregates may be negative (Veit et al., 2008, Miyajima et al., 2000) or positive (Courtney et al., 1992; Markovits and Sahota, 2000a). Ultrastructurally, uterine granular cell tumors in mice demonstrate prominent electron-dense granules and contain secondary lysosomes (Veit et al., 2008).

Markovits and Sahota (2000a) reported that up to 23\% of control female Sprague Dawley rats from 9 carcinogenicity studies had granular cell lesions in the distal reproductive tract (Markovits and Sahota, 2000a). They described granular cell aggregates as lesions composed of typical granular cells that generally lacked collagen, were not space-occupying, and did not efface normal tissue architecture. Most were aggregates within the wall of the cervix/vagina but were also present in the adventitia.

Benign granular cell tumors were described as space occupying and expansile lesions composed of typical granular cells with variable but frequently abundant amounts of prominent interstitial collagen. Many were distinct nodules within the muscularis or extended into the adventitia. Others had indistinct borders and expanded along tissue planes and ligaments. Mitotic figures were not noted in benign tumors.

Study data in three 104-week studies in Syrian golden hamsters (strain Han:AURA), untreated controls were then presented. Granular cell aggregates were noted at an incidence of $23 \%, 62 \%$ and $64 \%$ in the uterus in these studies. The PAS-positivity of granular cell tumors was demonstrated (image not shown) and the cause of granular cell lesions was discussed. Although there was no direct evidence of an estrogenic effect on the Sprague Dawley granular cell lesions in the Markovits and Sahota (2000b) study, they did indicate a remarkable reduction in the incidence of granular cell aggregates and tumors after aromatase inhibitor treatment. Since these compounds prevent the conversion of androgenic steroids to corresponding estrogens, this may suggest a role for estrogen in the pathogenesis of these tumors (Markovits and Sahota, 2000b). 
The discussion ended with a brief summary of granular cell lesions including the fact that there is a high incidence of this lesion in hamsters on chronic 2-year toxicity studies, but a low incidence in 13 and 52-week studies. The cell of origin of granular cell tumors or aggregates has not been definitively described and may be myogenic, Schwann cell or histiocytic. Granular cell aggregates or tumors cause lesions with typical large cells with granular cytoplasm, that often contain eccentric nuclei and stain positive with PAS.

The generous contributions from Heinrich Ernst, Fraunhofer ITEM, Hannover, Germany and Paul-Georg Germann, Takeda, Germany are gratefully acknowledged.

\section{Lung Lesions in Control Rats From Gavage Studies}

Dr. Torrie A. Crabbs (Experimental Pathology Laboratories, Inc., Research Triangle Park, NC, USA) presented two cases, both of which involved lung lesions from control F344/N rats. The lesions had been encountered during a retrospective review in which Dr. Crabbs evaluated the lungs of control rats from chronic toxicity studies, comparing the presence of pulmonary lesions in association with route of administration, particularly oral gavage. Both of the presented cases were from oral gavage studies and all images were from routine sections of lung.

The first case presentation was from a male control F344/N rat; water served as the vehicle control. Knowledge concerning the length of the study (and thus age of the rat) was initially withheld, and the audience was asked to vote on the most likely etiology/etiologic diagnosis prior to receiving this information. The following voting choices were provided: (1) lymphoma; (2) rat respiratory virus; (3) Pneumocystis carinii; (4) Pneumocystis jiroveci; (5) Mycoplasma pulmonis; (6) idiopathic interstitial pneumonia; (7) infectious interstitial pneumonia; and (8) other. The lesion consisted of 2 components: (1) a dense perivascular infiltrate composed of lymphocytes admixed with lesser numbers of macrophages and (2) thickening of the adjacent alveolar septae by a lymphohistiocytic infiltrate (Figures 4A \& B). Based upon these histologic features, the presenter identified Pneumocystis carinii as the possible etiology. While $19 \%$ of the audience concurred with this diagnosis, the majority voted for either idiopathic interstitial pneumonia (28\%) or rat respiratory virus $(22 \%)$.

The distribution of votes was not surprising given that in younger rats, this entity has previously been described in the literature as "idiopathic interstitial pneumonia" and erroneously attributed to an unknown "rat respiratory virus." PCR, and histochemistry using silver stains, has recently identified the fungus $P$. carinii as one infectious agent responsible for producing these lesions in young rats (Livingston et al., 2011). Dr. Crabbs provided a brief review of pneumocystosis in rats, emphasizing the histologic differences between immunodeficient and immunocompetent rats. In immunodeficient rats, the lesions are characterized by an interstitial pneumonia in which alveolar septae are thickened by a mononuclear infiltrate and alveoli are distended by pneumocystis organisms. Histologically, these organisms appear as finely vacuolated eosinophilic material. Silver stains, such as GMS, can be utilized to highlight the organisms. In immunocompetent rats the lesions are characterized by perivascular infiltrates of macrophages and lymphocytes, which sometimes form dense lymphocytic cuffs, in addition to a lymphohistiocytic interstitial pneumonia. The 
lesion in immunocompetent rats has not been associated with route of administration, nor has it been demonstrated to exhibit a dose response (Elwell et al., 1997). More importantly, the lesion has not been reported to occur in animals from chronic studies; but rather resolve before adulthood (Elwell et al., 1997; Slaoui et al., 1998). At this point, Dr. Crabbs revealed that this case was from a chronic 2-year toxicity study, and stated that while the lesion fit the histologic diagnostic criteria established by Albers et al. (2009) for this entity, the etiologic agent was not definitely known. From this point on, Dr. Crabbs more accurately referred to the lesion in her case as presumptive or " $P$. carinii-like" and announced that there were plans to further evaluate for the presence of $P$. carinii through the use of silver stains and PCR for a definitive diagnosis. The audience was questioned as to whether others had seen lesions similar to these in older rats, and if anyone had additional insight or opinions on the etiology. It was suggested that immunohistochemistry for $P$. carinii might also be considered. Dr. Crabbs concluded by stating that within the particular gavage study in which this example was discovered, the lesion occurred quite frequently, and added that identical lesions were also present in control rats from an additional chronic inhalation study.

Images of lesions from two different rats were provided for the second case presentation. Both examples were from male control F344/N rats, and both rats were from the same chronic 2-year carcinogenicity study. The study was an oral gavage study in which corn oil served as the vehicle control. The lesions were consistently centered on the terminal bronchioles and alveolar ducts (centriacinar) and were composed of an infiltrate of large foamy macrophages, admixed with lesser numbers of neutrophils, lymphocytes, plasma cells, cellular debris, and epithelioid macrophages that at times contained linear, clear spaces (cholesterol/sterol clefts) (Figure 4C). Regions of type II alveolar epithelial hyperplasia and bronchiolar metaplasia of alveolar epithelium were often concurrent (Figure 4D). The audience was asked to vote on how they would record these lesions, and the following voting choices were provided (Table 2).

While the distribution of votes was quite varied, the majority of the audience voted for either option (6) infiltration cellular, histiocyte; type II epithelial hyperplasia; and bronchiolar metaplasia (34\%), option (4) infiltration cellular, histiocyte and bronchioloalveolar hyperplasia, mixed (27\%), or option (5) inflammation, chronic; type II epithelial hyperplasia; and bronchiolar metaplasia (17\%). Each of the remaining 3 options received $\$ 8 \%$ of the votes. Dr. Crabbs explained that while there were features of chronic inflammation, type II epithelial hyperplasia, and bronchiolar metaplasia present, a pathology working group (PWG) voted to record the lesion as "inflammation, chronic" (option 1) and then provide a description in the pathology narrative since it was not a treatment-related lesion; 7\% of the audience voted for option 1 . The PWG did not want to confuse this nontreatment related lesion with a similar appearing treatment-related one that had been previously recorded in rats exposed to similar compounds. Dr. Crabbs stated that she was not surprised by the voting results; she felt they reflected the same issues she had encountered during the retrospective review: when is it appropriate to lump diagnoses versus split them; when does an aggregate of cells signify inflammation versus a cellular infiltrate; and when should alveolar hyperplasia and bronchiolar metaplasia be recorded separately versus combining them under the INHAND suggested term "bronchioloalveolar hyperplasia, 
mixed" (Renne, R. et al., 2009). Dr. Crabbs stated that the examples she presented were from two of the more severe cases she had encountered during her retrospective review and commented that often times the lesions were much more subtle. A panel of images demonstrating the entire spectrum of lesions was projected. While in all instances the lesions were centriacinar (bronchioloalveolar) in distribution, the combination of the specific histologic features (chronic inflammation, epithelial hyperplasia, and bronchiolar metaplasia) differed. In some cases, only small numbers of histiocytes were present, while in others, the histiocytic component was much denser and admixed with additional inflammatory cells; the presence of alveolar epithelial hyperplasia and bronchiolar metaplasia was variable, and in some instances the only histologic features present.

At this point, Dr. Crabbs described the study design of the retrospective review in further detail and explained that while data interpretation was ongoing, she could still provide results from a subset of the data. The subset included data from 2 chronic gavage studies (both of which utilized corn oil as the vehicle control), one chronic feed study, and one chronic water study. All lung tissues were from control animals. The results are summarized in Table 3. Minimal to mild alveolar histiocytosis was present in approximately $50-60 \%$ of rats, irrespective of administration route. However, the distinct centriacinar lesions were present only in the rats from the chronic gavage studies. Since the centriacinar region is a common sight of injury to inhaled particles and toxicants, it was questioned why centriacinar lesions were being seen in control rats from non-inhalation studies. Dr. Crabbs explained that while it was not obvious in the previously projected photomicrographs, numerous pale yellow homogeneous droplets were present in many of the rats from the gavage studies Visibility of these droplets was enhanced by removing the condenser (Figure 4E). This finding was lacking in all animals from the water and feed studies. Therefore, it was suspected that the droplets represented small amounts of corn oil that had been aspirated during the gavage procedure, and that the centriacinar lesions had developed as a result. Sudan Black staining was performed on formalin fixed paraffin-embedded sections of lung from a few rats from each of the studies. This stain is primarily used for detection of neutral triglycerides and lipids on frozen sections and some lipoproteins on paraffin sections. The sections from the animals from the water and feed studies were negative for Sudan Black, with the exception of faint positive staining of the peribronchial fat (positive internal control). In contrast, the rats from the gavage studies exhibited intense positive staining throughout many of the alveolar spaces (Figure 4F), in addition to the faint staining of the peribronchial fat.

Dr. Crabbs concluded the presentation by stressing that 1) centriacinar lesions can and do occur in gavage studies, 2) they can be seen in both treated and control animals, depending upon the vehicle control and chemical properties of the test-article, and 3) dose responses can be seen (data not presented). Therefore, when centriacinar lesions are present in gavage studies, especially if a dose response is noted, particular attention should be paid to the presence of pale yellow homogenous droplets within the alveolar spaces and subtle changes in the controls animals, as these may suggest aspiration as the culprit. She emphasized that it is crucial that the distribution of lung lesions be taken into account when considering pathogenesis and suggested diagnostically distinguishing lesions that consistently occur at the junction of the terminal bronchioles and alveolar ducts; INHAND suggests incorporating 
the subanatomic modifier "bronchioloalveolar." This case generated a nice discussion on the varying opinions of lumping versus splitting diagnoses. Dr. Crabbs concluded the presentation by stating that when centriacinar lung lesions appear in animals from gavage studies, aspiration should be considered. Specific attention should be given to the presence of subtle centriacinar lesions within control animals, in addition to the presence of corn oil droplets within the alveolar spaces, when corn oil is used as the vehicle control.

\section{Top Shelf Quandaries}

Dr. Michael Boyle (NTP, NIEHS, Research Triangle Park, NC, USA) presented three cases on behalf of Dr. David Malarkey (NTP, NIEHS). These cases present a bit of "thinking out of the box"; not your conventional symposium cases, but some thought provoking examples of molecular pathology data providing insight into carcinogenic processes in rodent models. Not all images could be presented here due to the as yet unpublished status of the research.

The first case pairs molecular data kindly provided by Drs. Hiroki Nagai, Sachin Bhusari, and Mark Hoenerhoff with histological evidence that supports independent pathways occurring in the development of hepatoblastoma within pre-existing hepatocellular neoplasms. The audience was asked to diagnose the lesion(s) observed in several H\&E stained sections (Figures 5A-D). The choices were (1) cholangiocarcinoma, (2) metastatic carcinoma, (3) hepatocellular adenoma, (4) hepatocellular carcinoma, (5) hepatoblastoma, multiple, and (6) hepatoblastoma arising within an adenoma. The vast majority of participants correctly diagnosed hepatoblastoma arising within an adenoma (82\%), followed by cholangiocarcinoma (8\%) and metastatic carcinoma (5\%).

Mouse hepatoblastoma is a primitive, poorly differentiated neoplasm that is believed to be a variant of a hepatocellular neoplasm. Typically, hepatoblastoma consists of an expansile and well-demarcated, solid to cystic tumor that is often accompanied by necrosis and/or hemorrhage; however, these tumors may be invasive and/or metastatic (Turusov et al. 2002) (Figure 5A). Tumor cells are small and ovoid with basophilic cytoplasm, hyperchromatic nuclei and occasional mitotic figures (Figures 5B-D). Hepatoblastoma is an uncommon spontaneous neoplasm in male $\mathrm{B} 6 \mathrm{C} 3 \mathrm{~F} 1$ mice, and rare in female $\mathrm{B} 6 \mathrm{C} 3 \mathrm{~F} 1$ mice, and can be induced by a variety of rodent carcinogens. Hepatoblastoma is often observed to be arising from within a preexisting hepatocellular tumor (Figures 5A\&B) suggesting that it evolves via de-differentiation of a neoplastic hepatocyte. If so, one would expect the hepatoblastoma to harbor the same genetic mutations as its parent hepatocellular tumor. In the NTP Pathology Group, Dr. Hiroaki Nagai studied 30 mice with hepatoblastoma arising within a hepatocellular carcinoma for mutations in $\mathrm{H}$-ras or $\beta$-catenin. DNA was extracted from each tumor cell population by laser capture microdissection on paraffin sections. Eleven of the 30 mice had at least one point mutation in either H-ras and/or $\beta$-catenin (Table 4) while only a single pair of tumors from the 30 mice examined shared a mutation. In these cases, a shared mutation between the hepatoblastoma and the carcinoma from which it appeared to arise was an exception, rather than the rule. This suggests that hepatoblastomas do not arise from hepatocellular neoplasms. Further, Principle Component Analysis (PCA) revealed that not only are hepatoblastomas genomically distinct from hepatocellular carcinomas but mouse hepatoblastomas are genetically similar to human hepatoblastomas based on marked 
dysregulation of genes involving Wnt/ $\beta$-catenin pathway, embryonic stem cell pluripotency, and embryonic imprinting (data not shown).

The second case is the first reported example of PTHrP-mediated humoral hypercalcemia associated with benign neoplasms (papillomas) in an animal model, in this case the Tg.AC transgenic mouse (Hansen et al. 1998). Conference participants were shown several tables including those conveying data regarding tumor development (tumors were increased in those animals harboring the $\mathrm{A}^{\mathrm{VY}}$ mutation), decreases in body weight gain (decreased in body weight gain were concomitant with treatment), and serum calcium analysis between groups (Table 5). Upon revealing that mice containing the agouti variable yellow mutation $\left(\mathrm{A}^{\mathrm{VY}}\right)$ appeared to have hypercalcemia associated with neoplasm development, the participants were asked to choose one of the following explanations: (1) humoral hypercalcemia of malignancy, (2) humoral hypercalcemia of benignancy, (3) all values are within the range of normal, or (4) I don't know, ask a Clinical Pathologist. Humoral hypercalcemia of malignancy was the most popular choice at $42 \%$, followed closely by "I don't know, ask a Clinical Pathologist" at 32\%. Approximately 18\% of the audience correctly chose humoral hypercalcemia of benignancy.

In this study, $\mathrm{Tg}$.AC transgenic mice were crossed with an Agouti viable yellow mutant mouse (Avy) to determine the influence of agouti protein on skin papillomagenesis in an Agouti $\times$ Tg.AC mouse (Hansen et al. 1998). After 5 weeks of dermal treatment with 3 different doses of 12-O-tetradecanoylphorbol-13-acetate (TPA) $(1.25 \mu \mathrm{g}, 2.5 \mu \mathrm{g}$, and 5.0 $\mu \mathrm{g})$, papillomas began to develop. There was a dose-related papillomagenesis at a rate more numerous in Avy $\times \mathrm{Tg}$.AC mice with concomitant loss of body weight (up to $40 \%$ ). Beginning around week 9 , the time papillomas were really becoming more numerous, many mice were becoming cachexic and sacrificed due to morbidity. CBC and clinical chemistry were performed on survivors and revealed mice with moderate to severe elevations in serum calcium (13 - $20 \mathrm{mg} / \mathrm{dL}$; normal range $8.5-12.5 \mathrm{mg} / \mathrm{dl}$ ). Serum parathyroid hormone-related peptide (PTHrP), a mediator of humoral hypercalcemia, was detected in papilloma-bearing mice (courtesy of Dr. Andrew Stewart of VA Hospital, West Haven, CT) and serum levels correlated with the degree of hypercalcemia. In some cases, TPA exposure was discontinued, papillomas regressed, and serum calcium returned to normal. PTHrP is produced by epidermis and hair follicles, which is the proposed origin of cutaneous papillomas. This is the $1^{\text {st }}$ report of humoral hypercalcemia due to benign neoplasms. Numerous participants speculated that analysis of other tissues dependent upon calcium and phosphorus homeostasis, such as long bones, may be beneficial in these scenarios.

The last case posited how, in the case of acetaminophen toxicity, gene expression profiles may be more helpful at low dose levels than ultrastructural and light microscopic findings and are the basis of the newly proposed "NOTEL" (No Observable Transcriptomic Effect Level). At high doses, a variety of hepatotoxicants have an overwhelming proportion of altered gene transcripts in common, many of which are involved in oxidative stress, acute phase responses, hepatocyte degeneration, DNA damage, cell proliferation, cell cycle progression, energy loss, and repair. Symposium attendees were presented with a graph depicting the number of genes either up-regulated or down-regulated based on treatment and time following treatment (Table 6), and then asked to vote. Their choices were: (1) high- 
dose, but not low- and mid-dose, hepatoxicity is evident by H\&E, (2) mid-dose causes only ultrastructural lesions, (3) high-dose hepatotoxicity is evident by MRI, (4) NOTEL not reached, (5) this is probably acetaminophen toxicity, and (6) all of the above. A plurality of audience members (39\%) correctly identified that all of the answers were correct, and chose "All of the above." The next favorite answer was "high-dose, but not low- and mid-dose, hepatoxicity is evident by $\mathrm{H} \& \mathrm{E}^{*}(31 \%)$.

In this study, thirty 8-week-old male F344 rats were dosed with toxic and sub-toxic doses of acetaminophen and then monitored by MRI microscopy, light microscopy, and/or gene array profiling after 6, 24, or 48 hours (Heinloth et al. 2004). At low doses and early time points, changes were detected by gene array only. At mid-doses, toxicity was apparent by gene array and electron microscopy of mitochondrial damage. At high doses, there were severe histological alterations, hundreds of genes differentially expressed representing generic pathways induced by various hepatotoxicants, and MRI changes in the liver (Gerrish and Malarkey 2007). In conclusion, gene array was the most sensitive technique to detect hepatotoxicity and might be the basis for determining a newly proposed "NOTEL" (No Observable Transcriptomic Effect Level). Audience members rightly cautioned against heavily weighing low sensitivity points such as "NOTELs" in risk assessments as transcriptome levels plotted relative to treatment groups is not necessarily indicative of relevant biology, particularly in the absence of additional information such as species, strain, and animal-to-animal variability indices, statistical method selection including fold-change cutoff, and more rigorous association to treatments.

\section{Electron Microscopic Brain Teasers}

Two transmission electron microscopy (TEM) cases from Dr. Connie Cummings (UltraPath Imaging, Research Triangle Park, NC) were presented by Dr. Michelle Cora (NTP, NIEHS, Research Triangle Park, NC). The first case was an abnormality of erythrocytes from genetically engineered mice. The abnormality was observed on peripheral blood smears (Figure 6A) submitted to the Clinical Pathology Laboratory at the NIEHS. Electron microscopy was requested to further characterize the abnormality (Figures 6B \& $\mathrm{C}$ ). Photomicrographs of both the peripheral blood smears and EM images were shown to the audience. The voting choices and results were babesiosis (16\%), Heinz bodies (6\%), hepatozoonosis $(9 \%)$, normal erythrocytes $(11 \%)$, intracytoplasmic inclusions $(22 \%)$ and hereditary protein 4.1 deficiency $(35 \%)$. The correct answer was intracytoplasmic inclusions; these inclusions are crystalline-like and suspected to be hemoglobin crystals.

An overview of the other choices was briefly discussed. Babesia is a protozoal organism that is seen as piroplasms within erythrocytes and usually with a signet ring appearance sometimes in a Maltese cross formation (Homer et al. 2000). Heinz bodies are oxidation of hemoglobin that leads to precipitation of the hemoglobin and appears as electron dense (not crystalline) intracellular inclusions or projections from the erythrocyte cell wall (Barger 2010). In mammals, stages of Hepatozoon species are observed in circulating monocytes and neutrophils (not erythrocytes). The type of leukocyte infected is dependant upon the species and geographic distribution of the mammalian host. (Cummings et al 2005; Johnson et al. 2007). Protein 4.1 is a membrane protein associated with spectrin and F-actin (Smith et 
al. 1983). Deficiencies of protein 4.1 cause erythrocytic elliptocytosis, among other abnormal erythrocytic morphologies, but it does not result in intracellular inclusions.

Several hypotheses for the cause of the suspected hemoglobin crystals were next presented. The formation of the inclusions is thought to be preanalytical artifact due to one or more of the following factors: location of blood collection (e.g., retro-orbital, submandibular, cardiac), type of ethylenediaminetetraacetic acid (EDTA) utilized (e.g., $\mathrm{Na}_{2}$ EDTA, $\mathrm{K}_{2}$ EDTA, $\mathrm{K}_{3}$ EDTA), ratio of blood to EDTA, and potential constitutive differences in the blood vials. Thus far, preliminary studies do support preanalytical artifacts as the cause for the crystalline inclusions, which are unrelated to mouse strain. In these studies blood from C57B6 mice was used to make several different EDTA:blood dilutions in vials from two different manufacturers, after which blood smears were made and then evaluated for the presence of erythrocytic inclusions. Data from these studies demonstrated a link between the EDTA:blood ratio and vial manufacturer in the formation of these inclusions as the presence and numbers of the inclusions increases with higher EDTA:blood ratios and appears to be dependent on the brand of the blood vial.

The second case was TEM of tissue in Wistar Han rats from a subchronic study. Electron microscopy of the tissue was requested to assess tissue changes and determine nanoparticle uptake. The type of tissue and tissue location was not revealed to the audience prior to voting. Two TEM photomicrographs (Figure 6D \& E) were shown to the audience with the following voting choices: (1) lipoma, (2) white fat, (3) brown fat, (4) oncocytoma and (5) other. The majority of the audience $(66 \%)$ chose the correct answer of brown fat. Characteristics of brown fat cells include multiple intracellular lipid droplets and a cytoplasm replete with mitochondria as this tissue is a source of energy for the body (Pavella and Roth, 2010; Vogel et al. 2011; Sengle et al. 2013). The adipocytes are intimately associated with capillaries as seen in Figures 6D \& E. Conversely, white fat cells have one large lipid droplet that flattens the nucleus and organelles against the cell membrane (Pavella and Roth, 2010). Oncocytomas are neoplasms that have cytoplasm filled with abnormal mitochondria and lack lipid droplets (Santos-Briz et al. 1977). Also discussed was the difference between unsaturated and saturated lipid droplets. On TEM, unsaturated lipid droplets appear medium to markedly electron dense (Figure 6D) while saturated lipid droplets are electron lucent to flocculent or finely pale gray and granular (Figure 6E) (Ghadially, 1997).

In conclusion, the authors note that the two main TEM distinguishing features of brown fat are the lipid droplets, which can vary in electron density according to type of lipid, and the abundance of mitochondria. This tissue may be useful for the examination of mitochondria, in terms of number and structure abnormalities, and as such may be a window into the state of the body's lipid metabolism.

\section{Cell Death: Always A Diagnostic Challenge}

Dr. Susan A. Elmore (NTP, NIEHS, Research Triangle Park, NC, USA) presented a liver lesion from an as yet unpublished NTP 28 day bioassay. Other pathologists involved in this study include Drs. Mark Cesta (NTP Pathologist for this study), Georgette Hill (ILS; PWG

Toxicol Pathol. Author manuscript; available in PMC 2015 January 01. 
Coordinator), Jim Morrison (CRL/PAI; EM evaluation), Connie Cummings (Ultrapath Imaging; EM consultation), Kyathanahalli Janardhan (ILS; immunohistochemistry) and the PWG participants.

Female Harlan Sprague Dawley rats were placed on study at 6-8 weeks of age and administered test article once daily by oral gavage for 28 days. There were 5 dose groups plus a vehicle control group and there were 8 animals per group. The audience was told that the liver lesion in question occurred in the 3 highest dose groups, increased in incidence and severity, and showed no specific lobular distribution. A series of low- and highmagnification images of $\mathrm{H} \& \mathrm{E}$ stained liver sections were viewed (Figures 7A\&B). These showed scattered, randomly distributed, single or small clusters of affected hepatocytes. Cytologically, the hepatocytes were shrunken and angular with hyperchromatic nuclei and hypereosinophilic cytoplasm. No inflammation was present. There were two electron micrographs (EM) that were also shown to the audience (Figures 7C\&D). The first showed a small, shrunken hepatocyte with angular features but an intact cell membrane. The nucleus was small and angular with condensed chromatin and there was an increased density of cytoplasmic organelles. Mixed between the clusters of mitochondria and endoplasmic reticulum (ER) were lakes of electron lucent regions that could be either distended ER or vacuolated cytoplasm (Figure 7C). The second EM showed a hepatocyte with an adjacent and impinging macrophage, more cytoplasmic and nuclear condensation, multiple clear vacuoles and myelin-like debris (Figure 7D). The voting choices and results were artifact (35\%) single cell necrosis (27\%), apoptosis (11\%), degeneration (8\%), single cell death (7\%), autophagy (5\%), oncotic necrosis (5\%), necrosis (2\%) and I don't know (2\%). The lack of clear consensus underscores the unusual nature of this lesion. However, "artifact" garnered the most votes despite the dose related increases in incidence and severity.

The study data is presented in Table 7. This chemical is a weak peroxisome proliferator and, when given at very low doses, causes minimal to mild centrilobular and periportal hepatocellular hypertrophy in the two highest dose groups and statistically significant increased liver weights in the three highest dose groups. By EM, the main change in the hypertrophied hepatocytes is increased mitochondria but no peroxisome proliferation (at these doses). This unusual hepatocellular lesion (scattered small, shrunken hepatocytes) was seen in the three highest dose groups with increasing incidence and severity. At the highest dose group, $100 \%$ of animals had this lesion.

To clarify the meaning of terms presented for voting, Dr. Elmore defined autophagic cell death, degeneration, apoptosis and necrosis. Oncotic necrosis is a synonym for necrosis that describes the cell swelling (oncosis) (Jaeschke and Lemasters 2003; Majno and Joris 1995; Trump et al. 1997). The term oncosis (derived from ónkos, meaning swelling) was proposed in 1910 by von Recklinghausen, precisely to mean cell death with swelling (von Recklinghausen 1910). In the literature, there are many other terms that have been used for cell death such as necrobiosis, necroapoptosis, aponecrosis, parapoptosis, pyroptosis, necroptosis, pyronecrosis, entosis, anoikis, cornification, eryptosis, etc. (Kroemer et al. 2009; Lang et al. 2006; http://www.merriam-webster.com/medical/necrobiosis; Cornillon et al. 1994; Ameisen et al. 1995; Frisch and Francis 1994). However, a discussion or definition 
of each was beyond the scope of this talk. Therefore only the major terms for cell death were discussed.

Consideration of autophagic cell death was first discussed. This process involves sequestration of cytoplasmic material with autophagosomes for bulk degradation by lysosomes (Abrams 2008; Hotchkiss et al. 2009; Gump and Thorburn 2011). H\&E evaluation would show autophagic vacuolization of the cytoplasm. EM evaluation would show autophagosomes, which are double-membrane bound structures, containing degenerating cytoplasmic organelles or cytosol. Myelin figures would be present and we did see those in this study (Figure 7E), but chromatin condensation would not be a feature. Most importantly, we did not see autophagosomes in this study.

Consideration of degeneration was next discussed. This is a form of reversible cell injury, also called hydropic change or vacuolar degeneration. Degenerating cells can have a different morphology depending on the cell/tissue/organ. Generally, cell swelling occurs due to hypoxia and the failure to maintain appropriate cellular osmotic balance, resulting in the gross appearance of pallor, increased turgor, and increased organ weight. Histologically, cell swelling and small, clear cytoplasmic vacuoles are common. Myelin figures, loosening of intercellular attachments, mitochondrial swelling, and dilatation of the RER and smooth endoplasmic reticulum (SER) are typical manifestations of degeneration as seen with EM. Since the cells have not passed the point of no return, there is no cell death or inflammation. In this case, the affected hepatocytes did not fit this classic picture of degeneration, especially since there was cell shrinkage and chromatin/cytoplasmic condensation rather than cell swelling.

Apoptosis and necrosis were discussed next, beginning with a table showing the similarities and differences between these two types of cell death (Table 8). In general, apoptosis involves single cells or small clusters of cells whereas necrosis often involves larger groups of contiguous cells (Elmore 2007). With apoptosis there is cell shrinkage and convolution with cytoplasmic/organelle condensation and hypereosinophilia whereas with necrosis there is cell and organelle swelling with loss of cellular detail. Apoptotic cells show pyknosis and karyorrhexis with chromatin condensation and peripheralization in the early stages and with necrosis, there is karyolysis, karyorrhexis and pyknosis although chromatin condensation is not a prominent feature. Most importantly, with apoptosis, there is an intact cell membrane with the cytoplasm retained within apoptotic bodies (seen singly or within tingible body macrophages) and therefore a lack of inflammation. Necrosis involves a disrupted cell membrane with cell rupture and release of pro-inflammatory mediators into the surrounding tissue and therefore inflammation is generally present.

To consider apoptosis as a potential mechanism, special stains, EM and H\&E sections were discussed. Caspase 3 (a marker for late apoptosis) and TUNEL (a nonspecific marker for apoptosis) were performed and both were negative. By EM, you would expect to see peripheralization of the chromatin in the early stages of apoptosis and this was not present. Also, H\&E evaluation showed that all of the cells appeared to be at or near the same stage. With apoptosis you would expect some cells in early apoptosis, some in late apoptosis with 
apoptotic debris within and outside of macrophages, and all stages in between, as illustrated in Figure 7F. Therefore, the changes seen did not fit the classic picture of apoptosis.

To consider necrosis as a potential mechanism, the H\&E sections and EM were discussed. By H\&E, the affected cells were either individual or in small clusters, and the morphology shrunken and angular. There was no inflammation. With necrosis, the cells would most likely occur in groups, with cell swelling and rupture, and result in inflammation, as illustrated in Figure 7G. If there were single cell necrosis, there would be cell swelling and, if cell rupture had occurred, there would likely be foci of inflammation, as illustrated in Figure 7H. Most importantly, the EM in this case showed small shrunken cells with an intact cell membrane and an increased density of cytoplasmic organelles, rather than cell swelling and rupture. Therefore, we were able to rule out necrosis as a potential mechanism.

Finally, consideration for artifact was discussed. It was noted that this lesion had a progressively increasing incidence and severity in the three highest dose groups, and was not present in the control or two lowest dose groups, which would suggest that it is not artifact but rather a true effect of treatment. Using kidney as an example, there was discussion that, with highly metabolic tissues, there can be small shrunken cells if the tissue is not processed immediately. It was argued that treatment might have somehow made the cells more susceptible to an artifactual change. However, tissue processing should not have been a factor since all tissues were processed in a similar fashion and if the lesion was due to processing artifact, it should also have been present in controls and the lower dose groups. Another argument against artifact is the presence of myelin figures in the more severely affected cells (Figure 7E). But there was some discussion that myelin figures could be considered an artifact. One audience member noted that myelin figures might be seen as artifact in tissues that are fixed in glutaraldehyde for a prolonged period of time. In this case, the tissues were fixed in formalin. But the chemical process is similar enough that if damage to the cells could occur with glutaraldehyde, it could also occur with formalin. According to this audience member, the occurrence of cytoplasmic myelin figures and irregular membranous profiles within lipid vacuoles is an "aldehyde fixation effect" that he routinely sees in tissue samples fixed and stored for extended periods of time in glutaraldehyde and formalin. If an antemortem effect, he would expect many of the myelin figures to be within phagocytic vacuoles and phagolysosomes, since autophagocytosis is the usual cell process that sequesters degenerated cell particulates and organelles. In hepatocyte images from the affected rats the myelin figures were intracytoplasmic multilamellar membranes that encircled organelles such as mitochondria and endoplasmic reticulum (e.g. Figure 7E).

After much discussion, a revote was taken and the results were artifact (54\%), single cell necrosis (15\%), I still don't know (12\%), apoptosis (6\%), degeneration (6\%), single cell death $(3 \%)$, necrosis $(2 \%)$, autophagy $(1 \%)$, and oncotic necrosis $(0 \%)$. Artifact continued to be the most popular diagnosis for this lesion despite the dose related increase in incidence and severity in treatment groups. The true cause of the lesion, or even if it is a lesion, remains an enigma. The final NTP diagnosis for this lesion was "cellular alteration".

In post-presentation discussions with the audience member that raised concerns about artifact, it was indicated that the myelin-like figures presented here are similar to those 
images where the effect was attributed to the drug treatment in a rat liver sample fixed with osmium tetroxide, supporting the theory that these myelin figures are in fact an effect of treatment (Burger and Herdson 1966). The changes in the hepatocytes in this report are also similar to a manifestation of "focal cytoplasmic degradation" as described by Hruban et al. (1963) for a rat hepatoma.

\section{Challenging Proliferative Uterine Lesions in The Rat}

Dr. Molly Boyle (Integrated Laboratory Systems, Inc., RTP, NC) and Dr. Susan Elmore (NTP, NIEHS, RTP, NC) presented an unusual uterine lesion from an as yet unpublished NTP chronic gavage and carcinogenicity bioassay in Wistar Han rats. In addition to the PWG, the pathologists involved in the review included Dr. Susan Elmore (NTP Pathologist), Dr. Crystal Johnson (Study Pathologist, Charles River Laboratories, PAI, RTP, NC), and reproductive pathologist, Dr. Darlene Dixon (NTP, NIEHS, RTP, NC).

The lesion of interest was presented for voting in a series of low- and high-magnification images from three female rats (Figures 8A-H). This lesion involved both the epithelium lining the glands and the epithelium lining the uterine lumen. Affected glands were separated by little to no stroma and lined by atypical stratified disorganized epithelium, which piled into glandular lumens (Figures 8A\&B). Atypical hyperplastic uterine luminal epithelium formed multiple branching papillary projections into the uterine cavity (Figures $8 \mathrm{C} \& \mathrm{D})$, but there were also hyperplastic regions that were similar to those seen in the affected glands (Figures 8E\&F). Affected glandular and luminal epithelium exhibited cellular pleomorphism, loss of nuclear polarization, karyomegaly, epithelial blebbing, and mitoses (Figures 8B,D,F,H). Voting choices made available to the audience were (1) adenoma, (2) adenocarcinoma, (3) carcinoma in situ, (4) endometrial hyperplasia, (5) focal glandular hyperplasia, (6) cystic endometrial hyperplasia, (7) atypical endometrial hyperplasia, (8) atypical cystic endometrial hyperplasia, and (9) normal (no diagnosis). Atypical endometrial hyperplasia received $37 \%$ of the votes. The other available diagnoses garnered $1 \%$ to $24 \%$ of the votes: adenoma (1\%), adenocarcinoma (3\%), carcinoma in situ $(4 \%)$, endometrial hyperplasia (12\%), focal glandular hyperplasia (9\%), cystic endometrial hyperplasia (9\%), atypical cystic endometrial hyperplasia (24\%), and normal (2\%).

This lesion has not previously been identified in NTP studies, which has used the F344/N rat as the default rat strain until recently. It is rarely observed as a spontaneous lesion in the F344 rat but has been seen with the administration of uterine carcinogens (Leininger and Jokinen, 1990). The PWG that was convened to evaluate this study considered the diagnosis and pathogenesis of this lesion with much discussion. Neoplastic differential diagnoses included adenoma and adenocarcinoma, but lack of a distinct mass and surrounding compression or invasion distinguished atypical endometrial hyperplasia from neoplasia. Although some of the glands exhibiting atypical endometrial hyperplasia could be described as cystic, cystic endometrial hyperplasia is characterized by normal appearing endometrial epithelium that becomes attenuated with ectasia. Cystic dilatation was not consistently present in affected glands, thus atypical cystic endometrial hyperplasia was not considered applicable. 
The differential diagnosis that received the most consideration was focal glandular hyperplasia. This lesion is described as a proliferation of (atypical) glands, but does not incorporate luminal epithelial changes. "Focal glandular hyperplasia" has previously been described in rodents (Dixon et al., 1999; Leininger and Jokinen, 1990) and the INHAND female reproductive Organ Working Group (OWG) is considering focal glandular hyperplasia with "atypical" as a modifier for affected glandular epithelium (personal communication). However, this is the first reported case of the uterine luminal epithelium also being affected, and the need for a distinction was considered. If atypical focal glandular hyperplasia was used, another term would have been needed to describe the uterine luminal changes. Since the glandular and luminal epithelium are continuous, it seemed that one term should encompass both. As a result, the PWG chose the term "atypical endometrial hyperplasia".

In women, this lesion is diagnosed as "complex atypical hyperplasia" and is considered preneoplastic (Kurman and Norris, 1994). Development of the lesion results from high levels of estrogens combined with insufficient levels of progesterone-like hormones. Risk factors include obesity, polycystic ovary syndrome, estrogen producing tumors such as a granulosa cell tumor, and some estrogen replacement therapies. It has also been associated with uterine carcinogens that are uterine estrogen agonists, such as Tamoxifen (Newbold et al. 1997) and is considered a significant risk factor for the development or even co-existence of endometrial cancer. One study reports that, in women with this lesion, $22 \%$ eventually developed cancer (Kurman et al. 1985).

The preliminary results of this yet-to-be-published 2-year bioassay reveal treatment-related statistically significant increased incidences of atypical endometrial hyperplasia, adenocarcinomas (including multiples), and adenomas. In this study, atypical endometrial hyperplasia appears to be pre-neoplastic based on histomorphology and incidence, as it relates to uterine tumors. Future mechanistic studies are warranted to better understand the pathogenesis of this lesion in rats.

\section{Challenging Rat Uterine Neoplasms}

Dr. Crystal Johnson (Charles River Laboratories, PAI, Durham, NC) presented an unusual uterine tumor from an as yet unpublished NTP chronic gavage toxicity and carcinogenicity bioassay, the same study as that previously presented by Dr. Molly Boyle. In addition to the PWG, the pathologists involved in the review of this study included the NTP pathologist (Dr. Susan Elmore, NTP, NIEHS, RTP, NC), the study pathologist (Dr. Michael Ryan, Battelle Memorial Institute, Columbus, $\mathrm{OH}$ ), and the QA pathologist (Dr. Terence Adams, Experimental Pathology Laboratories, RTP, NC). Additional residual uterine tissue was sectioned longitudinally and reviewed by Drs. Crystal Johnson and Molly Boyle (Integrated Laboratory Systems, RTP, NC). Reproductive pathologist, Dr. Darlene Dixon (NTP, NIEHS, RTP, NC) provided additional helpful consultation.

Male and female Wistar Han (Crl:WI[Han]) rats were dosed via gavage for either 14 weeks (interim sacrifice) or 105 weeks (terminal sacrifice) and an increased incidence of uterine tumors was noted. The first case presented for voting consisted of a series of five low- and 
high-magnification images of a uterine neoplasm with unusual morphology (9A and 9B as examples). The uterine tumor completely effaced the uterine architecture and appeared solid (Figure 9A). Neoplastic cells were arranged in solid sheets and streams without acinar formation. Individual neoplastic cells were large and pleomorphic with large round to elongate nuclei containing an open chromatin pattern and a single prominent magenta nucleolus (Figure 9B). Bizarre mitotic figures were frequent. Voting choices made available to the audience were (1) sarcoma, (2) adenoma, (3) carcinoma, (4) carcinosarcoma, (5) adenocarcinoma, and (6) malignant mixed Müllerian tumor. The majority of the voting attendees chose either carcinosarcoma (33\%) or malignant mixed Müllerian tumor (20\%). The other available diagnoses garnered from $1 \%-20 \%$ of the votes: adenoma (1\%), carcinoma (12\%), adenocarcinoma (16\%), and sarcoma (20\%).

A second neoplastic uterine mass with unusual morphology from the same study was presented as case 2 in a series of seven images. Microscopically, a portion of the tumor consisted of areas of well-differentiated glandular epithelium. The glandular epithelium was several layers thick in some areas ("piled up") with very little intervening stroma between glands, characteristic of a typical uterine adenocarcinoma (Figure 9C). Other portions of the same mass formed solid areas that contained a population of small darkly basophilic polygonal cells surrounded by eosinophilic amorphous material (osteoid) (Figure 9D) and scattered islands of more mature bone with evidence of mineralization and occasional multinucleated cells, likely osteoclasts. Voting choices made available to the audience were (1) sarcoma, (2) adenoma, (3) teratoma, (4) carcinoma, (5) osteosarcoma, and (6) carcinosarcomas, (7) adenocarcinoma, and (8) malignant mixed Müllerian tumor. The majority of the voting attendees chose either carcinosarcoma (31\%) or malignant mixed Müllerian tumor (24\%). The other available diagnoses garnered $0 \%-19 \%$ of the votes: sarcoma (0\%), adenoma (1\%), carcinoma (1\%), osteosarcoma (10\%), adenocarcinoma $(13 \%)$, and teratoma $(19 \%)$.

The preliminary results of this yet-to-be-published 2-year bioassay revealed treatmentrelated statistically significant increased incidences of atypical endometrial hyperplasia (see Molly Boyle's presentation), adenocarcinomas, and combined uterine tumors of epithelial origin (Table 9). A PWG was convened to evaluate these studies and determine the most appropriate diagnosis for the uterine neoplasms. The unusual solid appearance of some of the neoplasms generated much discussion and debate among pathologists. The PWG considered the terms 'sarcoma', 'carcinosarcoma' and 'adenocarcinoma, atypical', but recommended a panel of immunohistochemical markers to determine the neoplastic populations present. A subset of uterine tumors displaying solid growth patterns was selected for staining with cytokeratin and vimentin. Following immunohistochemistry, six neoplastic masses were found to contain areas of positive staining for both cytokeratin and vimentin. In some cases individual neoplastic cells stained with both cytokeratin and vimentin, indicating dual positivity. In all cases, the neoplastic epithelial and mesenchymal cells were intermingled, thus giving the impression of a carcinosarcoma.

After consideration of the tumor morphology, the immunohistochemical stains, and a review of the literature, the term 'malignant mixed Müllerian tumor' (MMMT) was selected as the most current and appropriate terminology for these specific neoplastic masses. Figures 9E 
and 9F show a side by side comparison of an adenocarcinoma and an MMMT stained with H\&E. Figures $9 \mathrm{G}$ and $9 \mathrm{H}$ show a side by side comparison of an MMMT stained with cytokeratin and vimentin to illustrate the neoplastic epithelial and mesenchymal components, respectively. The terms MMMT and 'carcinosarcoma' have been used interchangeably in the human literature and are considered to be synonymous. The female reproductive INHAND OWG may recommend using the term 'malignant mixed Müllerian tumor' as it is more descriptive of the neoplastic cell of origin (personal communication).

In the human literature, malignant mixed Müllerian tumor is synonymous with carcinosarcoma and is composed of both epithelial and mesenchymal neoplastic components (Scully et al. 1994). The mesenchymal component may be considered homologous if it arises from tissues normally present within the uterus, such as smooth muscle, fibrous tissue, or endometrial stroma (Figure 9B). Heterologous types contain mesenchymal tissues not normally present in the uterus, such as skeletal muscle, cartilage, or bone (Figure 9D). Malignant mixed Müllerian tumor is a very rare, spontaneous neoplasm in animals and has been previously diagnosed in one cat (Nicotina et al. 2002), one rabbit (Goto et al. 2006), five Lewis rats, and three Wistar rats (Takami et al 2011; Van den Brink-Knol et al. 2010), though it has never been reported as a treatment-related finding in animals.

MMMTs are believed to arise from the pluripotent cells of the Müllerian ducts, giving rise to both epithelial and mesenchymal elements. In the developing embryo, two sets of paired tubular reproductive organs develop from intermediate mesoderm, the Wolffian duct and the Müllerian duct. In males, anti-Müllerian hormone is secreted by Sertoli cells of the testes and the Müllerian duct regresses. In females, these ducts lead to development of uterus, Fallopian tubes, cervix, and cranial vagina. Persistent rests of the Müllerian duct are believed to be the structures from which malignant mixed Müllerian tumors arise.

In humans, MMMTs can arise in the vagina, cervix, Fallopian tubes, or ovaries and is most common in post-menopausal women with a mean age of 57.5 years. This is an uncommon tumor, accounting for only 2-5\% of all uterine cancers (Choijamts et. al 2011), though associated with a disproportionally higher mortality rate, with stage 1 tumor (confined to uterus) at a five-year survival rate of 50\%. In two human studies, $70-80 \%$ of cases were found to be clonal, that is the epithelial and mesenchymal portions are derived from the same neoplastic cell (Buza et al. 2009). Another study suggests that 20-30\% of human cases may be "collision tumors", arising from two different neoplastic cells and joining to form a single mass (El-Nashar et. al 2011).

In humans, metastases of these tumors are often composed of the epithelial component only. Previous treatment modalities were directed at the sarcomatous portion of tumor; however, this was found to be ineffective. Further studies determined that the primary source of tumor aggressiveness was the epithelial component, which is now the main focus of treatment.

Stem cell markers SALL4 and glypican-3 are expressed in 33\% and 88\% of human MMMT cases, respectively (Bing et. al 2012). Current NTP efforts are underway to better characterize the rat MMMTs from this study with stem cell markers. 


\section{Lesions From The Gastrointestinal Inhand Organ Working Group}

At the time of the symposium, the nomenclature and diagnostic criteria generated by the INHAND Digestive Tract OWG were in an advanced draft status. For the OWG Dr. Nolte presented three cases of gastrointestinal lesions centering around the nomenclature and differential diagnosis between infiltration in epithelial malignancies on the one hand and diverticula on the other. It was the aim of this presentation to point to the importance of this differential diagnostic challenge and to get input from the audience on the suggested nomenclature and diagnostic criteria.

The first in this series of three cases showed cyst like structures in the tunica muscularis of the glandular stomach and cecum of $\mathrm{B} 6 \mathrm{C} 3 \mathrm{~F} 1$ and $\mathrm{CD} 1$-mice, which were lined by essentially normal mucosa (Figure 10A). The mucosa consisted of characteristic surface epithelium with underlying glands lined by parietal and chief cells in the stomach (Figure 10B) and with crypts rich in Goblet cells in the cecum. The mucosa was sharply demarcated from the surrounding tissue indicating the presence of an intact basement membrane. The majority of the voting attendees (73\%) chose either diverticulum (30\%), diverticulum simple (28\%), or diverticulum atypical (15\%). Also herniation (of mucosa) attained a relevant percentage of votes (19\%). The other available diagnoses obtained 6\% (ectopic mucosa), $1 \%$ (hyperplasia mucosal), and 0\% (adenoma, adenocarcinoma).

Diverticulum simple was the term preferred by the INHAND OWG, while simple was considered as a modifier. The key diagnostic criteria suggested for this lesion are listed in Table 10.

The modifier "cystic" should be used if diverticula become dilated by secretory products or intestinal contents. In such cases the epithelium is usually attenuated and the surrounding tissue compressed. Diverticula of the stomach and intestine are more frequently observed in mice than in rats. Their development may be associated with local mucosal defects (e.g., post-ulcerative repair), suggesting opportunistic expansion. Diverticula may also occur associated with submucosal veins in the absence of mucosal defects, suggesting there may be a vascular route of penetration from the mucosa.

The second case was from the glandular stomach of an aryl hydrocarbon receptor knockout mouse. This proliferative epithelial lesion involved both, the mucosal and submucosal layers (Figure 10C). The sessile mucosal proliferation projected into the gastric lumen and altered the mucosal structure. Atypical glandular / crypt epithelium extended through the muscularis mucosae into the submucosa and tunica muscularis. The basement membrane integrity of these epithelial projections was always maintained (Figure 10D). The majority of attendees chose hyperplasia with diverticula, simple (58\%). The other voting choices attained between $2 \%$ and $15 \%$ of the votes: adenoma with diverticula, simple (15\%), hyperplasia with diverticula, atypical (12\%), adenoma with diverticula, atypical (4\%), diverticulum (4\%), adenoma (3\%), hyperplasia, mucosal (3\%), and adenocarcinoma (2\%). This result differed from the recommendation of the INHAND OWG, which favored the diagnosis adenoma with diverticula, atypical. This recommendation was based on the atypical epithelium of the 
diverticula and the key criteria for an adenoma (Table 11), in this case in particular, the distorted mucosal architecture and the sessile growth pattern with projection into the lumen.

The third case showed a nodular lesion projecting into the lumen of the colon of a F344 rat treated by once daily administration of 1,2-dimethylhydrazine for 20 weeks (Figure 10E). The nodular process was covered by an atypical mucosa with branched crypts and markedly increased epithelial basophilia and cellularity. The nodule itself was formed by a scirrhotic tissue with numerous scattered glandular profiles. Centrally, these profiles showed continuity with mucosal crypts. The muscularis mucosae was lost in this region. High magnification revealed indistinct demarcation of the epithelial profiles from the surrounding scirrhotic stroma, indicating loss of basement membrane integrity (Figure 10F).

The result of the voting was unequivocal with $83 \%$ of voting attendees favoring the diagnosis adenocarcinoma and $11 \%$ adenocarcinoma with atypical diverticula. The other diagnoses offered (hyperplasia atypical, hyperplasia atypical with diverticula atypical, diverticula atypical, adenoma, and adenoma with diverticula atypical) attained $1 \%$ or $2 \%$.

Adenocarcinoma was also the diagnosis recommended by the INHAND OWG. The key criteria identified for an adenocarcinoma are listed in Table 12.

During the subsequent discussion several comments addressed the terminology "hyperplasia, atypical": it was recommended that the diagnostic term should be "hyperplasia", while "atypical" should be handled as a modifier. Other comments suggested not using the modifier "simple" for all those hyperplasias that are not atypical. Furthermore, it was recommended not to record a diverticulum separately, if it occurs in association with another proliferative process, e.g. hyperplasia or adenoma.

\section{Foreign Material in Rat Kidney}

Dr. J. M. Ward (Global VetPathology, Montgomery Village, MD) presented unusual lesions with foreign material in a rat kidney. The 16-week-old male Sprague Dawley rat was exposed to a test material orally for 12 weeks. The case came from Dr. Jiunn-Wang Liao, Professor and Director, Graduate Institute of Veterinary Pathobiology, National ChungHsing University, Taichung, Taiwan, ROC.

The attendees were presented images for voting, including Figures $11 \mathrm{~A} \& \mathrm{~B}$, along with the following diagnostic options: mineralization, tubule; crystals, calculi; nephropathy; nephropathy, obstructive; or nephropathy, crystalline. The majority voted for nephropathy, crystalline (67\%), crystals (19\%), nephropathy, obstructive (8\%), calculi (4\%), mineralization, tubule (2\%), or nephropathy (1\%). The INHAND diagnostic criteria (Frazier et al. 2012) for such lesions would recommend a diagnosis of "Nephropathy, obstructive"; a synonym includes "crystal nephropathy" and in humans "crystalline nephropathy" has been suggested (Herlitz et al. 2012). Obstructive nephropathy is defined by the INHAND nomenclature as "renal damage caused by precipitation of chemicals as crystals in the tubule lumen" with inflammation, renal damage and other tubular lesions resulting from tubule blockage by the crystals (Frazier et al. 2012). The lesions in this case were obviously severe and tubular damage was most likely caused primarily by the crystalline aggregates. A milder 
lesion may be diagnosed as "crystals", with no or little tubular obstruction, lesions or disease (Frazier et al. 2012).

The renal lesions (Figures 11A-F) diffusely involved the cortex and medulla of the kidney. At low magnification, tubules were dilated, more severely in the cortex. Tubules also showed mild to severe epithelial atrophy and aggregates of intratubular aggregates of crystals (foreign material) filled many tubules. The crystals had a unique appearance resembling a shattered dinnerware plate with concentric rings (Figure 11B). Intra-tubular mineralization was often seen as solitary concretions or concretions associated with the crystalline aggregates (Figure 11C\&D). The crystals and mineralized concretions often filled dilated tubular lumens. The crystalline aggregates were birefringent with polarized light (Figure 11E). Focal regenerative renal tubular hyperplasia was also noted. The entire renal process appeared to occur due, in part, to tubular damage by obstruction of the crystals and mineral. Protein casts were not seen but intratubular aggregates of neutrophils were common. The glomerular space was dilated but glomeruli appeared mostly normal. Foci of inflammatory cells, including lymphocytes and neutrophils, were found throughout the interstitium of the kidney. Although we did not perform any special stains, it was reported that a 72 hour Oil red $\mathrm{O}$ will stain the aggregates of crystals in kidneys of rats exposed to the same material (Thompson et al. 2008). The rat was fed a diet of 50\% of a melamine and cyanuric acid-contaminated dog and cat diet for 8 weeks, which was increased to $100 \%$ for weeks 9-12 (Chen et al. 2009).

Causes of renal crystals or aggregates of crystals are mostly from exposure to toxins that cause such crystals due to excretion of the chemical and/or its metabolites or other breakdown products. Most commonly, antifreeze poisoning due to ethylene glycol ingestion is seen in domestic and experimental animals. Calcium oxalate crystals are formed in the nephron during excretion resulting in obstructive nephropathy (Frazier et al. 2012; Herlitz et al. 2012). The use of melamine (Mel) and cyanuric acid (CA) to increase measured protein concentrations in dietary products in the early 2000s and its toxicity for humans and animals was reviewed (Chen 2009; Lam et al 2009; Osborne et al. 2009). Other subsequent experimental studies have been reported (Chen et al. 2009; Gamboa da Costa et al., 2012; Jacob et al. 2012; Kobayaski et al. 2010; Park et al. 2011; Sprando et al. 2012). Melamine alone does not induce crystal formation or crystalline aggregates in rats (Hard et al. 2009).

Differentiation of renal crystal aggregates due to Mel-CA from other renal crystals has not been reported. In H\&E stained sections, one can see obvious typical crystalline aggregate structures in rats exposed to melamine and cyanuric acid (Figure 11A-D) and calcium oxalate in dogs (Figure 11F) and other animals (Khan 2010). It is likely that the distinct histologic appearance of the Mel-CA crystals in formalin fixed paraffin embedded tissue sections stained with H\&E are pathognomonic in rats and other species (Osborne et al. 2009; Thompson et al. 2008). No renal lesions have been reported in human kidneys, perhaps because no autopsies were reported, but renal stones have been reported clinically (Lam et al. 2009).

The author wishes to thanks Dr. Dr. Jiunn-Wang Liao, Professor and Director, Graduate Institute of Veterinary Pathobiology, National Chung-Hsing University, Taichung, Taiwan, 
ROC for providing the slide and information on the study. The dog ethylene glycol case (Figure 11F) was from a 1977 AFIP Wednesday slide conference slide, which was submitted by EPL to AFIP.

\section{Acknowledgments}

The authors wish to thank Eli Ney of the NIEHS for her unique and creative cover artwork for the symposium handouts as well as for her technical expertise in formatting the speaker's PowerPoint presentations. Thanks also to both Eli Ney and Beth Mahler of EPL for their assistance with manuscript image preparation and to Beth Mahler of EPL for assistance during the symposium. The authors are grateful to Drs. Erin Quist and Tanasa Osborne of the NIEHS for their critical review of this manuscript. Appreciation also goes to Sue Pitsch, Krystle Correll, Tierre Miller and Maureen Kettering of Association Innovation and Management, Inc. for their valuable help with annual advertising and meeting facilities. Also integral to the success of this meeting was the security provided by William Stoeffler of the Stoeffler Group, LLC.

This research was supported [in part] by the Intramural Research Program of the National Institutes of Health (NIH), National Institute of Environmental Health Sciences (NIEHS). This article may be the work product of an employee or group of employees of the NIEHS, NIH, however, the statements, opinions or conclusions contained therein do not necessarily represent the statements, opinions or conclusions of NIEHS, NIH or the United States government.

\section{References}

Albers TM, Simon MA, Clifford CB. Histopathology of naturally transmitted "rat respiratory virus": progression of lesions and proposed diagnostic criteria. Vet Pathol. 2009; 46:992-9. [PubMed: 19429985]

Ameisen JC, Idziorek T, Billaut-Mulot O, Loyens M, Tissier JP, Potentier A, Ouaissi A. Apoptosis in a unicellular eukaryote (Trypanosoma cruzi): implications for the evolutionary origin and role of programmed cell death in the control of cell proliferation, differentiation and survival. Cell Death Differ. 1995; 2:285-300. [PubMed: 17180034]

Bab, I.; Hajbi-Yonissi, C.; Gabet, Y.; Müller, R. Micro-Tomographic Atlas of the Mouse Skeleton. Springer Science + Business Media; LLC, New York, NY: 2007. p. 87-92.

Barger, AM. Erythrocyte Morphology. In: Weiss, Douglas J.; Jane Wardrop, K., editors. Schalm's Veterinary Hematology. Blackwell Publishing; Ames, IA: 2010. p. 144-151.

Barnett SA. Genotype and environment in the tail length of mice. Q J Exp Physiol. 1965; 50:417-32. [PubMed: 5177006]

Beckwith JB, Kiviat NB, Bonadio JF. Nephrogenic rests, nephroblastomatosis, and the pathogenesis of Wilms' tumor. PediatrPathol. 1990; 10:1-36.

Bing Z, Pasha T, Wang LP, Zhang PJ. Malignant mixed Müllerian tumor: an immunohistochemical study. Patholog Res Int. 2012 Epub 2012 Jul 10. 10.1155/2012/569609

Burger PC, Herdson PB. Phenobarbital-induced fine structural changes in rat liver. Am J Pathol. 1966; 48:793-809. [PubMed: 5937778]

Buza N, Tavassoli FA. Comparative analysis of P16 and P53 expression in uterine malignant mixed mullerian tumors. Int J Gynecol Pathol. 2009; 28:514-21. [PubMed: 19851197]

Cardesa, A.; Ribalta, T. Nephroblastoma, kidney, rat. In: Jones, TC.; Hard, GC.; Mohr, U., editors. Monographs on Pathology of Laboratory Animals. 2nd. Springer-Verlag; Berlin: 1998. p. 129-38.Urinary System

Cebesoy O, Mete A, Karsli B. Complete lumbar spine duplication in a neurologically intact man. J Spinal Cord Med. 2009; 32:99-102. [PubMed: 19264056]

Center EM. Morphology and embryology of duplicitas posterior mice. Teratology. 1969; 2:377-88. [PubMed: 5362428]

Chen, K. Toxicological and Health Aspects of Melamine and Cyanuric Acid. WHO; Geneva: 2009. WHO Expert Meeting Report; p. 66 
Chen KC, Liao CW, Cheng F, Chou CC, Chang SC, Wu JH, Zen JM, Chen YT, Liao JW. Evaluation of subchronic toxicity of pet food contaminated with melamine and cyanuric acid in rats. Toxicol Pathol. 2009; 37:959-68. [PubMed: 19801503]

Choijamts B, Jimi S, Kondo T, Naganuma Y, Matsumoto T, Kuroki M, Iwasaki H, Emoto M. CD133+ cancer stem cell-like cells derived from uterine carcinosarcoma (malignant mixed Müllerian tumor). Stem Cells. 2011; 29:1485-95. [PubMed: 21919130]

Cornillon S, Foa C, Davoust J, Buonavista N, Gross JD, Golstein P. Programmed cell death in Dictyostelium. J Cell Sci. 1994; 107:2691-704. [PubMed: 7876338]

Courtney CL, Hawkins KL, Meierhenry EF, Graziano MJ. Immunohistochemical and ultrastructural characterization of granular cell tumors of the female reproductive tract in two aged Wistar rats. Vet Pathol. 1992; 29:86-9. [PubMed: 1557868]

Cummings CA, Panciera RJ, Kocan KM, Mathew JS, Ewing SA. Characterization of stages of Hepatozoon americanum and of parasitized canine host cells. Vet Pathol. 2005; 42:788-796. [PubMed: 16301575]

Dias MS, Walker ML. The embryogenesis of complex dysraphic malformations: a disorder of gastrulation? Pediatr Neurosurg. 1992; 18:229-53. [PubMed: 1476931]

Dixon, D.; Leininger, JR.; Valerio, MG.; Johnson, AN.; Stabinski, LG.; Frith, CH. Guides for Toxicologic Pathology. STP/ARP/AFIP; Washington, DC; 1999. Proliferative Lesions of the Ovary, Uterus, Vagina, Cervix, and Oviduct in Rats, URG-5.

Dominguez R, Rott J, Castillo M, Pittaluga RR, Corriere JN. Caudal duplication syndrome. Am J Dis Child. 1993; 147:1048-52. [PubMed: 8213674]

Doolittle, DP.; Davisson, MT.; Guidi, JN.; Green, MC. Catalog of mutant genes and polymorphic loci. In: Lyon, MF.; Rastan, S.; Brown, SDN., editors. Genetic Variants and Strains of the Laboratory Mouse. 3rd. Vol. 1. Oxford University Press; Oxford; 1996. p. 17-854.

El-Nashar SA, Mariani A. Uterine carcinosarcomas. Clin Obstet and Gynaecol. 2011; 54:292-304.

Elmore S. Apoptosis: a review of programmed cell death. Toxicol Pathol. 2007; 35:495-516. [PubMed: 17562483]

Elwell MR, Mahler JF, Rao GN. "Have you seen this?" Inflammatory lesions in the lungs of rats. Toxicol Pathol. 1997; 25:529-531. [PubMed: 9323847]

Ernst, H.; Heinrichs, M.; Bargsten, G.; Kittel, B.; Rittinghausen, S.; Dungworth, DL.; Mohr, U. Neuroendocrine hyperplasias and tumors of the larynx and trachea in the Syrian hamster. In: Jones, TC.; Mohr, U.; Hunt, RD., editors. Monographs on Pathology of Laboratory Animals Respiratory System. 2nd. Springer-Verlag; Berlin: 1995. p. 107-116.

Frazier KS, Seely JC, Hard GC, Betton G, Burnett R, Nakatsuji S, Nishikawa A, Durchfeld-Meyer B, Bube A. Proliferative and Nonproliferative Lesions of the Rat and Mouse Urinary System. Toxicol Pathol. 2012; 40:14S-86S. [PubMed: 22637735]

Frisch SM, Francis H. Disruption of epithelial cell-matrix interactions induces apoptosis. J Cell Biol. 1994; 124:619-26. [PubMed: 8106557]

Gamboa da Costa G, Jacob CC, Von Tungeln LS, NR Hasbrouck, Olson GR, Hattan DG, Reimschuessel R, Beland FA. Dose-response assessment of nephrotoxicity from a twenty-eightday combined-exposure to melamine and cyanuric acid in F344 rats. Toxicol Appl Pharmacol. 2012; 262:99-106. [PubMed: 22579976]

Gerrish, K.; Malarkey, DE. Genomic profiles of liver injury. In: Sahu, S., editor. Hepatotoxicity: From genomics to in-vitro and in-vivo. Wiley \& Sons; Hoboken, NJ: 2007.

Ghadially, FN. Ultrastructural Pathology of the Cell and Matrix. 4th. Butterworth-Heinemann; Boston: 1997. p. 1034-1038.

Goto M, Nomura Y, Une Y, Goldschmidt MH. Malignant mixed Müllerian tumor in a rabbit (Oryctolagus cunicululs): case report with immunohistochemistry. Vet Pathol. 2006; 43:560-64. [PubMed: 16847001]

Greco TL, Takada S, Newhouse MM, McMahon JA, McMahon AP, Camper SA. Analysis of the vestigial tail mutation demonstrates that Wnt-3a gene dosage regulates mouse axial development. Genes Develop. 1996; 10:313-24. [PubMed: 8595882]

Gump JM, Thorburn A. Autophagy and apoptosis: what is the connection? Trends Cell Biol. 2011; 21:387-92. [PubMed: 21561772] 
Handrigan GR. Concordia discors: duality in the origin of the vertebrate tail. J Anat. 2003; 202:25567. [PubMed: 12713266]

Hansen LA, Malarkey DE, Wilkinson JE, Rosenberg M, Woychik RE, Tennant RW. Effect of the viable-yellow (A(vy)) agouti allele on skin tumorigenesis and humoral hypercalcemia in v-Ha-ras transgenic TGxAC mice. Carcinogenesis. 1998; 1837; 19

Hara H, Miyao M, Moriki T, Kutsukake F, Yamane T. Histological and ultrastructural studies, of nephroblastoma in rats induced transplacentally by ethylnitrosurea. Acta Pathol Jpn. 1982; 32:385-398. [PubMed: 6285663]

Hard GC. Differential renal tumor response to N-ethylnitrosourea and dimethylnitrosamine in the $\mathrm{Nb}$ rat: Basis for a new rodent model of nephroblastoma. Carcinogenesis. 1985; 6:1551-58. [PubMed: 2996800]

Hard GC, Flake GP, Sills RC. Re-evaluation of kidney histopathology from 13-week toxicity and two-year carcinogenicity studies of melamine in the F344 rat: morphologic evidence of retrograde nephropathy. Vet Pathol. 2009; 46:1248-57. [PubMed: 19605901]

Hard GC, Grasso P. Nephroblastoma in the rat: Histology of a spontaneous tumor, identity with respect to renal mesenchymal neoplasms, and a review of the previously recorded cases. J Natl Cancer Inst. 1976; 57:323-9. [PubMed: 187769]

Heinloth AN, Irwin RD, Boorman GA, Nettesheim P, Fannin RD, Sieber SO, Snell ML, Tucker CJ, Li L, Travlos GS, Vansant G, Blackshear PE, Tennant RW, Cunningham ML, Paules RS. Gene expression profiling of rat livers reveals indicators of potential adverse effects. Toxicol Sci. 2004; 80:193-202. [PubMed: 15084756]

Herlitz LC, D'Agati VD, Markowitz GS. Crystalline nephropathies. Arch Pathol Lab Med. 2012; 136:713-20. [PubMed: 22742545]

Homer MJ, Aguilar-Delfin I, Teleford S III, Krause PJ, Persing DH. Babesiosis. Clin Microbiol Rev. 2000; 13:451-469. [PubMed: 10885987]

Hotchkiss RS, Strasser A, McDunn JE, Swanson PE. Cell death. N Engl J Med. 2009; 361:1570-83. [PubMed: 19828534]

Hruban Z, Spargo B, Swift H, Wissler RW, Kleinfeld RG. Focal cytoplasmic degradation. Am J Pathol. 1963; 42:657-83. [PubMed: 13955261]

Jacob CC, Von Tungeln LS, Vanlandingham M, Beland FA, Gamboa da Costa G. Pharmacokinetics of melamine and cyanuric acid and their combinations in F344 rats. Toxicol Sci. 2012; 126:317-24. [PubMed: 22228804]

Jaeschke H, Lemasters JJ. Apoptosis versus oncotic necrosis in hepatic ischemia/reperfusion injury. Gastroenterology. 2003; 125:1246-57. [PubMed: 14517806]

Jamison, RL. Urinary Concentrating Mechanism. In: Layton, Harold E.; Weinstein, Alan M., editors. Membrane Transport and Renal Physiology. Springer; 2002. p. 177

Johnson EM, Kelly AE, Pancierr RJ, Ewing SA, Little SE, Reichard MV. Field survey of rodents for Hepatozoon infections in an endemic focus of American canine hepatozoonosis. Vet Parasitol. 2007; 150:27-32. [PubMed: 17942230]

Khan SR. Nephrocalcinosis in animal models with and without stones. Urol Res. 2010; 38:429-38. [PubMed: 20658131]

Kamino K, Tillmann T, Boschmann E, Mohr U. Age-related incidence of spontaneous non-neoplastic lesions in a colony of Han:AURA hamsters. Exp Toxicol Pathol. 2001; 53:157-64. [PubMed: 11484834]

Kaspareit-Rittinghausen J, Deerberg F. Spontaneous malignant mixed Müllerian tumors and rhabdomyosarcoma of the uterus in rats. Toxicol Pathol. 1990; 18:417-22. [PubMed: 2176344]

Klootwijk R, Franke B, Van der Zee CEEM, De Boer RT, Wilms W, Hol FA, Mariman ECM. A deletion encompassing Zic3 in Bent tail, a mouse model for X-linked neural tube defects. Human Mol Gen. 2000; 9:1615-22.

Kobayashi T T, Okada A, Fujii Y, Niimi K, Hamamoto S, Yasui T, Tozawa K, Kohri K. The mechanism of renal stone formation and renal failure induced by administration of melamine and cyanuric acid. Urol Res. 2010; 38:117-25. [PubMed: 20179916]

Kroemer G, Galluzzi L, Vandenabeele P, Abrams J, Alnemri ES, Baehrecke EH, Blagosklonny MV, El-Deiry WS, Golstein P, Green DR, Hengartner M, Knight RA, Kumar S, Lipton SA, Malorni W, 
Nunez G, Peter ME, Tschopp J, Yuan J, Piacentini M, Zhivotovsky B, Melino G. Classification of cell death: recommendations of the Nomenclature Committee on Cell Death 2009. Cell Death Differ. 2009; 16:3-11. [PubMed: 18846107]

Kurman, RJ.; Norris, HJ. Endometrial hyperplasia and related cellular changes. In: Kurman, RJ., editor. Blaustein's Pathology of the Female Genital Tract. 4th. Springer Verlag; New York: 1994. p. 441

Kurman RJ, Kaminski PF, Norris HJ. The behavior of endometrial hyperplasia. A long-term study of "untreated" hyperplasia in 170 patients. Cancer. 1985; 56:403-12. [PubMed: 4005805]

Lam CW, Lan L, Che X, Tam S, Wong SS, Chen Y, Jin J, Tao SH, Tang XM, Yuen KY, Tam PK. Diagnosis and spectrum of melamine-related renal disease: plausible mechanism of stone formation in humans. Clin Chim Acta. 2009; 402:150-5. [PubMed: 19171128]

Lang F, Lang KS, Lang PA, Huber SM, Wieder T. Mechanisms and significance of eryptosis. Antioxid Redox Signal. 2006; 8:1183-92. [PubMed: 16910766]

Leininger, JR.; Jokinen, MP. Oviduct, uterus, and vagina. In: Boorman, GA.; Eustis, SL.; Elwell, MR.; Montgomery, CA., Jr; MacKenzie, WF., editors. Pathology of the Fischer Rat. Academic Press; San Diego, CA: 1990. p. 447

Levine B, Abrams J. p53: The Janus of autophagy? Nat Cell Biol. 2008; 10:637-9. [PubMed: 18521069]

Livingston RS, Besch-Williford CL, Myles MH, Franklin CL, Crim MJ, Riley LK. Pneumocystis carinii infection causes lung lesions historically attributed to rat respiratory virus. Comp Med. 2011; 61:45-59. [PubMed: 21819681]

Majno G, Joris I. Apoptosis, oncosis, and necrosis. An overview of cell death. Am J Pathol. 1995; 146:3-15. [PubMed: 7856735]

Markovits JE, Sahota PS. Granular cell lesions in the distal female reproductive tract of aged Sprague Dawley rats. Vet Pathol. 2000a; 37:439-48. [PubMed: 11055867]

Markovits JE, Sahota PS. Aromatase inhibitors precent spontaneous granular cell tumors in the distal female reproductive tract of Sprague Dawley rats. Toxicol Pathol. 2000b; 28:799-801. [PubMed: 11127293]

Matsuura T, Narama I, Nishikawa T, Nishimura M, Imagawa T, Kitagawa H, Uehara M. Morphological and morphometric features of the deformed cervical and caudal vertebrae in a new mutant knotty-tail (knt/knt) mouse. Ann Anat. 1997; 179:277-83. [PubMed: 9229083]

McInnes, EF. Chapter 5. Hamsters and guinea pigs. In: McInnes, EF., editor. Background Lesions in Laboratory Animals: A Color Atlas. Saunders; Edinburgh: 2011.

Mesfin GM. Intralobar nephroblastemosis: Precursor lesions of nephroblastoma in the SpragueDawley rat. Vet Pathol. 1999; 36:379-90. [PubMed: 10490205]

Miyajima R, Hasegawa K, Yasui Y, Kihara T, Hosoi M, Yamakawa S, Iwata H, Enomoto M. Nine cases of granular cell tumors in B6C3F1 mice. J Vet Med Sci. 2001; 63:449-52. [PubMed: 11346182]

Murakami U, Kameyama Y. Vertebral malformation in the mouse foetus caused by maternal hypoxia during early stages of pregnancy. J Embryol Exp Morphol. 1963; 11:107-18.

Murakami U, Kameyama Y. Vertebral malformation in the mouse foetus caused by X-radiation of the mother during pregnancy. J Embryol Exp Morphol. 1964; 12:841-50. [PubMed: 14251489]

Newbold RR, Jefferson WN, Padilla-Burgos E, Bullock BC. Uterine carcinoma in mice treated neonatally with tamoxifen. Carcinogenesis. 1997; 18:2293-2298. [PubMed: 9450472]

Nicotina PA, Zanghi A, Catone G. Uterine malignant mixed Müllerian tumor (metaplastic carcinoma) in the cat: clinicopathologic features and proliferation indices. Vet Pathol. 2002; 39:158-60. [PubMed: 12102212]

Noel JF, Wright EA. The effect of environmental temperature on the growth of vertebrae in the tail of the mouse. J Embryol Exp Morphol. 1970; 24:405-10. [PubMed: 5491989]

Osborne CA, Lulich JP, Ulrich LK, Koehler LA, Albasan H Sauer L, Schubert G. Melamine and cyanuric acid-induced crystalluria, uroliths, and nephrotoxicity in dogs and cats. Vet Clin North Am Small Anim Pract. 2009; 39:1-14. [PubMed: 19038647]

Padmanabhan R. Retinoic acid-induced caudal regression syndrome in the mouse fetus. Repro Toxicol. 1998; 12:139-51. 
Padmanabhan R, Abdulrazzaq YM, Bastaki SMA, Shafiullah MM. Intrauterine growth and skeletal variations in mouse fetuses induced by vigabatrin administered at preimplantation stages of development. Congen Anomal. 2008; 48:29-39.

Park D, Kim TK, Choi YJ, Lee SH, Bae D, Yang G, Yang YH, Joo SS, Choi E, Ahn B, Kim JC, Kim KS, Kim YB. Increased nephrotoxicity after combined administration of melamine and cyanuric Acid in rats. Lab Anim Res. 2011; 27:25-8. [PubMed: 21826156]

Pavelka, M.; Roth, J. Functional Ultrastructure. Springer-Verlag; Wien, Austria: 2010. Adipose Tissue; p. 290-292.

Pour, PM. Clear cell carcinoma in the larynx of the Syrian Hamster. In: Jones, TC.; Mohr, U.; Hunt, RD., editors. Monographs on Pathology of Laboratory Animals, Respiratory system. SpringerVerlag; Berlin: 1985. p. 75-77.

Pour P, Althoff J, Cardesa A. Granular cells in tumours and in non-tumorous tissues. Arch Pathol. 1973; 95:135-38. [PubMed: 4345666]

Pour P, Mohr U, Althoff J, Cardesa A, Kmoch N. Spontaneous tumors and common diseases in two colonies of Syrian hamsters. III. Urogenital system and endocrine glands. J Natl Cancer Inst. 1976; 56:949-961. [PubMed: 994205]

Renne R, Brix A, Harkema J, Herbert R, Kittel B, Lewis D, March T, Nagano K, Pino M, Rittinghausen S, Rosenbruch M, Tellier P, Wohrmann T. Proliferative and nonproliferative lesions in the rat and mouse of the respiratory tract. Toxicol Pathol. 2009; 37:5S-73S. [PubMed: 20032296]

Rutledge JC, Shourbaji AG, Hughes LA, Polifka JE, Cruz YP, Bishop JB, Generoso WM. Limb and lower-body duplications induced by retinoic acid in mice. Proc Natl Acad Sci USA. 1994; 91:5436-40. [PubMed: 8202504]

Santos-Briz A, Terrón J, Sastre R, Romero L, Valle A. Oncocytoma of the Lung. Cancer. 1977; 40:1330-1336. [PubMed: 198093]

Schrick JJ, Dickinson ME, Hogan BLM, Selby PB, Woychik RP. Molecular and phenotypic characterization of a new mouse insertional mutation that causes a defect in the distal vertebrae of the spine. Genetics. 1995; 140:1061-7. [PubMed: 7672577]

Scully, RE.; Bonfiglio, TA.; Kurman, RJ.; Silverberg, SG.; Wilkinson, EJ. Histological Typing of Female Genital Tract Tumors. 2nd. Springer-Verlag; New York, NY: 1994. p. 23-24.World Health Organization

Sengle G, Tufa TS, Sakai LY, Zulliger MA, Keene DR. A Correlative Methods for Imaging Identical Regions of Samples by Micro-CT, Light Microscopy, and Electron Microscopy: Imaging Adipose Tissue in a Model System. J Histochem Cytochem. 2013; 61(4):263-271. [PubMed: 23264636]

Slaoui M, Dreef HC, van Esch E. Inflammatory lesions in the lungs of Wistar rats. Toxicol Pathol. 1998; 26:712-13. [PubMed: 9789962]

Smith JE, Moore K, Arens M, Rinderknecht GA, Ledet A. Hereditary elliptocytosis with protein band 4.1 deficiency in the dog. Blood. 1983; 61:373-377. [PubMed: 6821703]

Sonoda T, Shozo O, Ohba KI, Okishima T, Haykawa K. Teratogenic effects of sodium valproate in the Jcl:ICR mouse fetus. Acta Paediatr Jpn. 1990; 32:502-7. [PubMed: 2284927]

Sprando RL, Reimschuessel R, Stine CB, Black T, Olejnik N, Scott M, Keltner Z, Bandele O, Ferguson M, Nemser SM, Tkachenko A, Evans E, Crosby T, Woodling K, Loukotková L, da Costa GG. Timing and route of exposure affects crystal formation in melamine and cyanuric exposed male and female rats: gavage vs. feeding. Food Chem Toxicol. 2012; 50:4389-97. [PubMed: 22963836]

Takami S, Ogawa K, Umemura T, Hibi D, Ishii Y, Okamura T, Tasaki M, Inoue T, Suzuki Y, Jin M, Cho YM, Nishikawa A. Uterine carcinosarcoma in a 2-year old female Wistar Hannover GALAS rat. J Toxicol Pathol. 2011; 24:63-67. [PubMed: 22272045]

Theiler K, Gluecksohn-Waelsch S. The morphological effects and the development of the fused mutation in the mouse. Anat Rec. 1956; 125:83-103. [PubMed: 13340237]

Thompson ME, Lewin-Smith MR, Kalasinsky VF, Pizzolato KM, Fleetwood ML, McElhaney MR, Johnson TO. Characterization of melamine-containing and calcium oxalate crystals in three dogs with suspected pet food-induced nephrotoxicosis. Vet Pathol. 2008; 45:417-26. [PubMed: 18487505] 
Torchinsky A, Savion S, Gorivodsky M, Shepshelovich J, Zaslavsky Z, Toder V. Cycylophosphamideinduced teratogenesis in ICR mice: the role of apoptosis. Teratogen Carcin Mutagen. 1995; 15:179-90.

Trump BF, Berezesky IK, Chang SH, Phelps PC. The pathways of cell death: oncosis, apoptosis, and necrosis. Toxicol Pathol. 1997; 25:82-8. [PubMed: 9061857]

Turusov VS, Alexandrov VA, Timoshenko IV. Nephroblastoma and renal mesenchymal tumour induced in rats by N-nitrosoethyl- and N-nitrosomethylurea. Neoplasma. 1980; 27:229-35. [PubMed: 6256671]

Turusov VS, Torii M, Sills RC, Willson GA, Herbert RA, Hailey JR, Haseman JK, Boorman GA. Hepatoblastomas in mice in the US National Toxicology Program (NTP) studies. Toxicol Pathol. 2002; 30:580-91. [PubMed: 12371667]

Van den Brink-Knol H, van Esch E. Spontaneous malignant mixed Müllerian tumor in a Wistar rat: a case report including immunohistochemistry. Vet Pathol. 2010; 47:1105-10. [PubMed: 20587687]

Veit AC, Painter JT, Miller RA, Hardisty JF, Dixon D. Characterization of uterine granular cell tumors in B6C3F1 mice: a histomorphic, immunohistochemical and ultrastructural study. Vet Pathol. 2008; 45:654-62. [PubMed: 18725470]

Vogel P, Read R, Hansen G, Wingert J, DaCosta CM, Buhring LM, Shadoan M. Pathology of Congenital Generalized Lipodystrophy in Agpat $2^{-/-}$Mice. Vet Pathol. 2011; 48:642-654. [PubMed: 21051554]

Wellik DM. Hox genes and vertebrate axial pattern. Curr Top Develop Biol. 2009; 88:257-78.

Zani DD, De Zani D, Morandi N, Biggi M, Bellioli AG, Riccaboni P, Rondena M, Di Giancamillo M, Praevettoni D. Imaging diagnosis: split cord malformation. Vet Radiol Ultrasound. 2010; 51:5760. [PubMed: 20166395]

\section{Abbreviations}

$\begin{array}{ll}\text { Avy } & \text { Agouti viable yellow mutant mouse model } \\ \text { CA } & \text { cyanuric acid } \\ \text { CGRP } & \text { calcitonin gene-related peptide } \\ \text { EDTA } & \text { ethylenediaminetetraacetic acid } \\ \text { EM } & \text { electron micrograph } \\ \text { ER } & \text { endoplasmic reticulum } \\ \text { F344 } & \text { Fischer 344 } \\ \text { GMS } & \text { Grocott's methenamine silver stain } \\ \text { H\&E } & \text { hematoxylin \& eosin } \\ \text { INHAND } & \text { International Harmonization of Nomenclature and Diagnostic Criteria } \\ \text { MEL } & \text { melamine } \\ \text { MMMT } & \text { malignant mixed Müllerian tumor } \\ \text { MRI } & \text { magnetic resonance imaging } \\ \text { NB } & \text { nephroblastoma } \\ \text { NTP } & \text { National Pathology Program } \\ \text { NOTEL } & \text { no observable transcriptomic effect level }\end{array}$




$\begin{array}{ll}\text { OWG } & \text { Organ Working Group } \\ \text { PAS } & \text { periodic acid-Schiff } \\ \text { PTHrP } & \text { parathyroid hormone-related peptide } \\ \text { PWG } & \text { pathology working group } \\ \text { QA } & \text { quality assurance } \\ \text { SALL4 } & \text { Sal-like protein } 4 \\ \text { SER } & \text { smooth endoplasmic reticulum } \\ \text { TEM } & \text { transmission electron microscopy } \\ \text { TPA } & \text { 12-O-tetradecanoylphorbol-13-acetate } \\ \text { TUNEL } & \text { Terminal deoxynucleotidyl transferase dUTP nick end labeling }\end{array}$



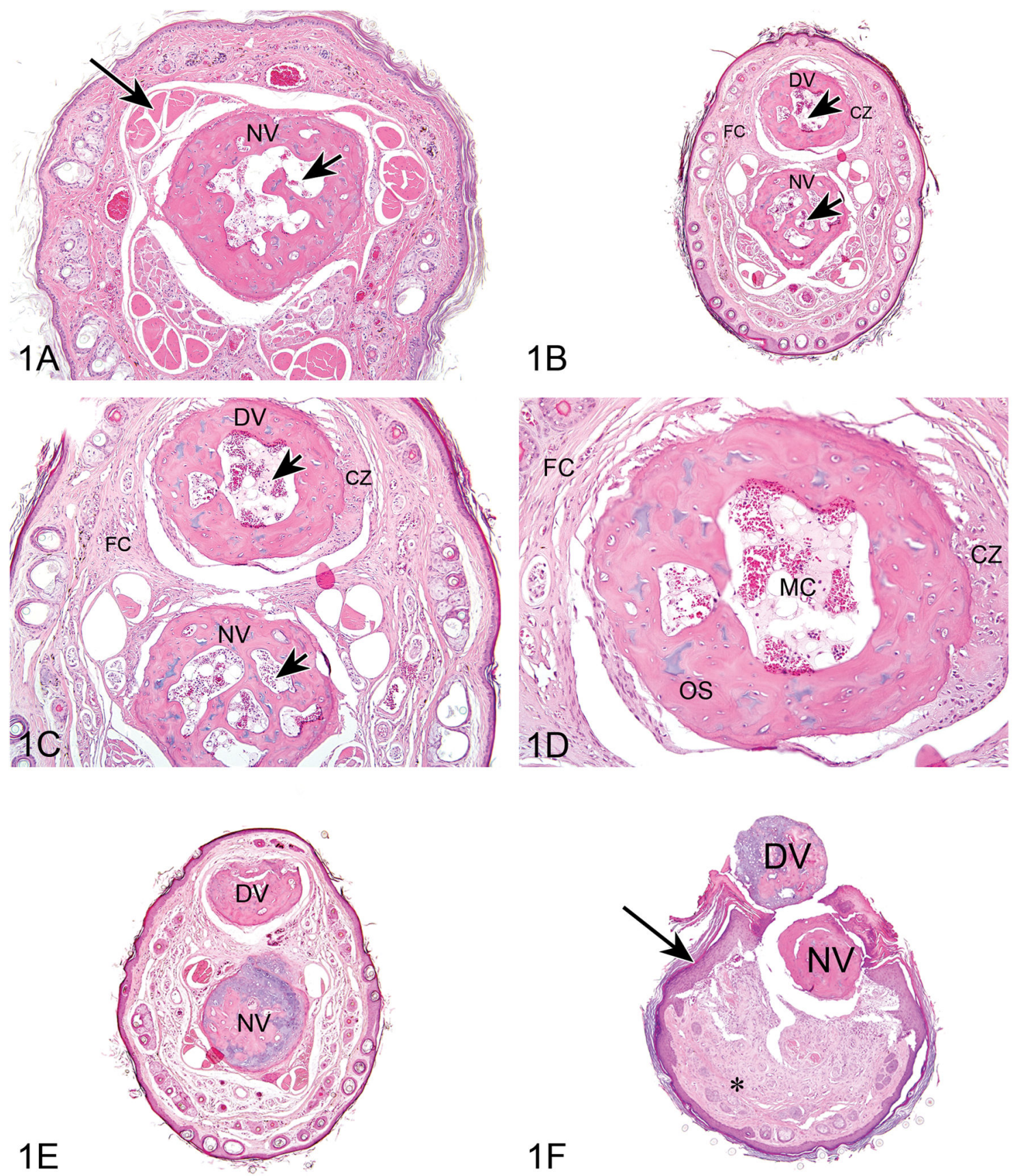

Figure 1.

Duplicate caudal vertebra in adult B6C3F1 mice (A-F). Vehicle-control unaffected male B6C3F1 mouse (A). Transverse distal tail section exhibits single, normal distal caudal vertebra (NV) lacking processes and a vertebral arch. Note the small medullary cavity (short arrow) and normal sacrocaudal tendon/muscle bundles (long arrow). Figure B illustrates an affected male B6C3F1 mouse (low-dose group). Transverse distal tail section exhibits a supernumerary (duplicate) caudal vertebra (DV) situated dorsal to the normal vertebra (NV). Both vertebrae have small medullary cavities (arrows). The duplicate vertebra (DV) has a peripheral cartilaginous zone (CZ) and is surrounded by a fibrous capsule (FC). Figure $\mathrm{C}$ illustrates an affected male B6C3F1 mouse (low-dose group). Higher magnification of the tail section from (B) shows that the normal (NV) and duplicate vertebra 
(DV) are similarly composed of well-differentiated bone with central medullary cavities (arrows); the duplicate vertebra (DV) also has a peripheral cartilaginous zone (CZ) and is surrounded by a fibrous capsule (FC). Figure D is a higher magnification of the duplicate caudal vertebra from (B) and (C) and shows the well-differentiated bone (OS), a peripheral cartilaginous zone (CZ), and a medullary cavity (MC) containing small blood vessels and adipocytes. The duplicate vertebra is surrounded by a fibrous capsule (FC). Figure E is from an affected male B6C3F1 mouse (vehicle-control group). Transverse distal tail section exhibits a supernumerary (duplicate) caudal vertebra (DV) situated dorsal to the normal vertebra (NV). Both vertebrae lack a medullary cavity. Figure F is a transverse section of the distal tail of another affected male B6C3F1 mouse (low-dose group) and shows dorsal displacement of the supernumerary (duplicate) caudal vertebra (DV) through a dorsal skin ulceration to the external surface of the tail. The underlying normal vertebra (NV) is also displaced dorsally. Both vertebrae lack a medullary cavity. The tail subcutis (asterisk) exhibits reactive fibrosis and inflammation, and the epidermis bordering the ulcer is hyperplastic (arrow). 

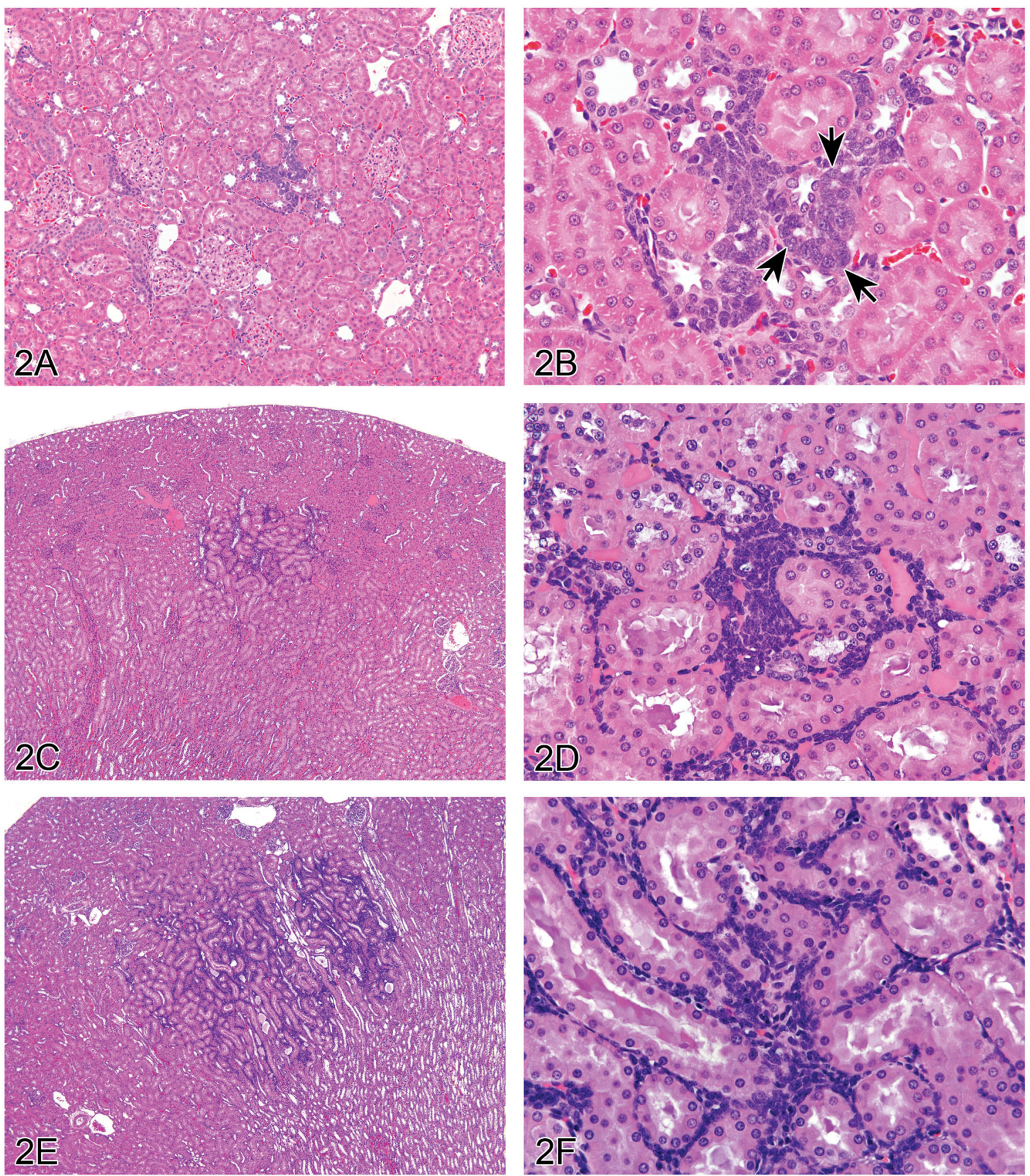

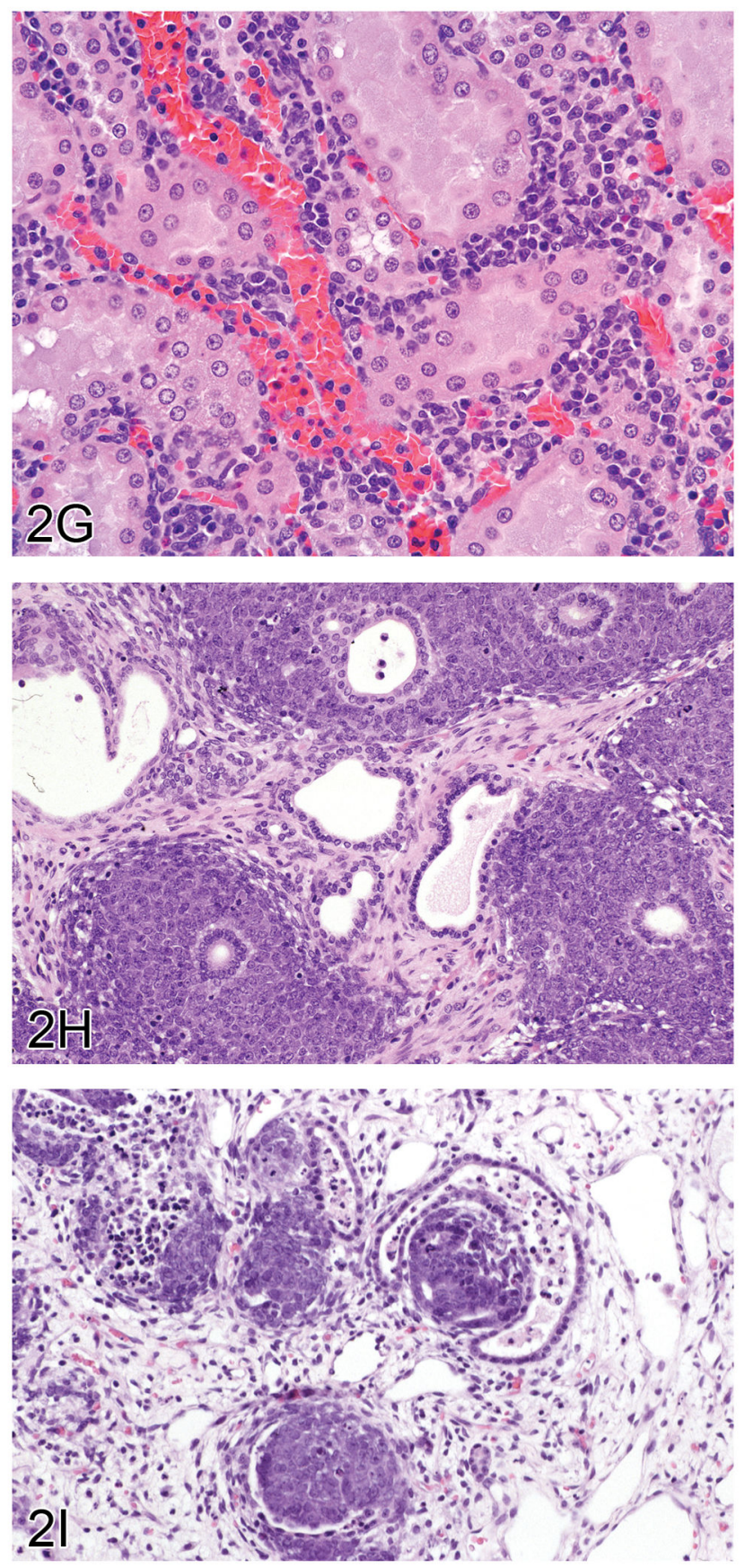

Figure 2.

Nephroblastematosis and nephroblastoma in rat kidney. A-F, show low to high magnification views of nephroblastematosis in female Sprague Dawley rats depicting location in deep renal cortex (A,C,E), and relatively small size of focal dense interstitial accumulations of intensely staining basophilic blastema cells (B,D,F). See attempts at rosette formation in B (arrows).. Example of a differential diagnosis of focal lymphocyte accumulation $(\mathrm{G})$ characterized by a population of interstitial mononuclear inflammatory cells. Well-developed nephroblastoma $(\mathrm{H})$ comprised of blastema cells arranged primarily in dense mantles around ductules supported by fibrous stroma. Well-developed nephroblastoma (I) comprised of blastema cells organized into tubules that are similar to immature tubules that occur in the outer cortex of pre- and postnatal rats. The tumor is supported by a 
fibromyxomatous stroma. Example of a differential diagnosis of focal lymphocyte accumulation $(\mathrm{G})$ characterized by a population of interstitial mononuclear inflammatory cells. Well-developed nephroblastoma $(\mathrm{H})$ comprised of blastema cells arranged primarily in dense mantles around ductules supported by fibrous stroma. Well-developed nephroblastoma (I) comprised of blastema cells organized into tubules that are similar to immature tubules that occur in the outer cortex of pre- and postnatal rats. The tumor is supported by a fibromyxomatous stroma. 

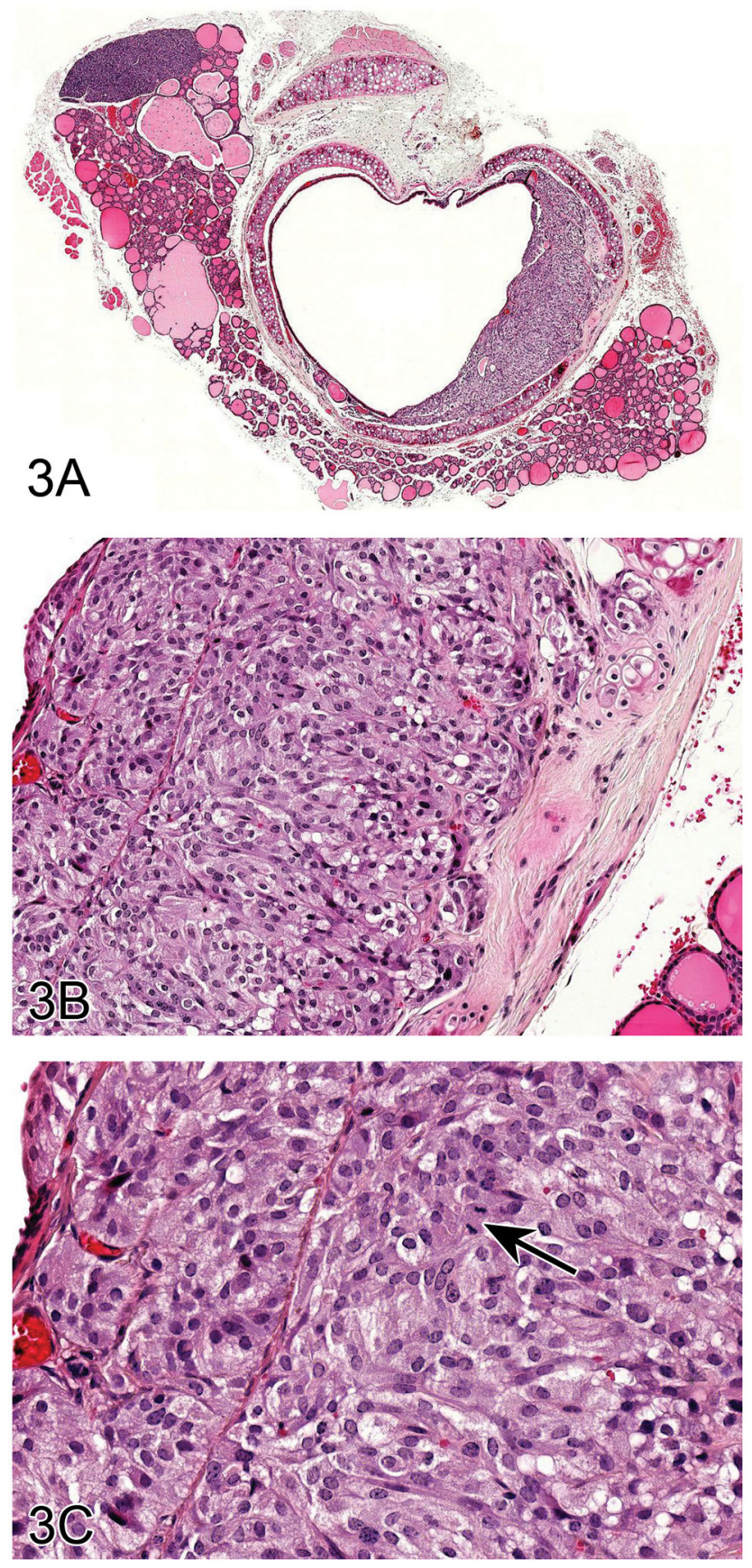

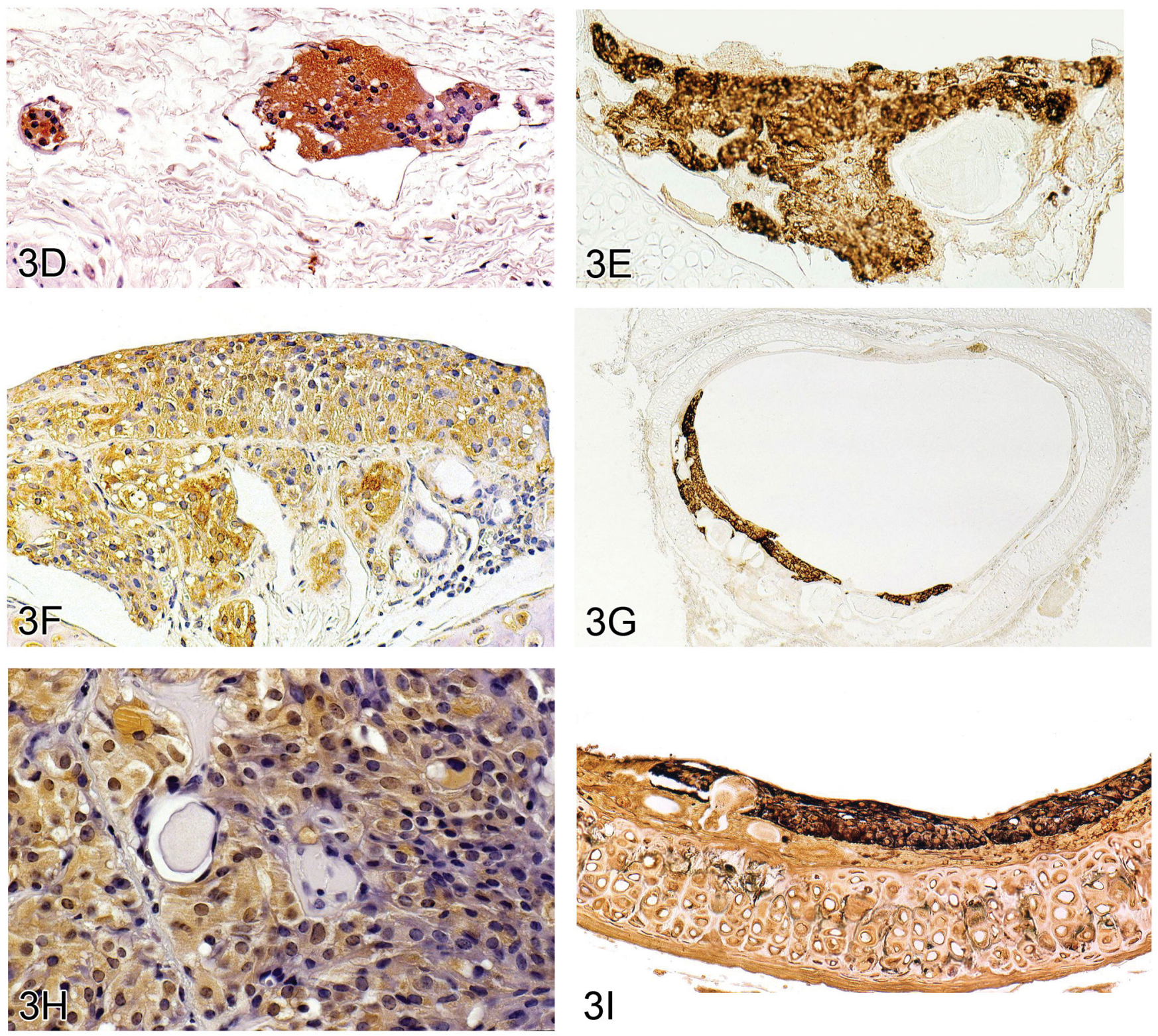

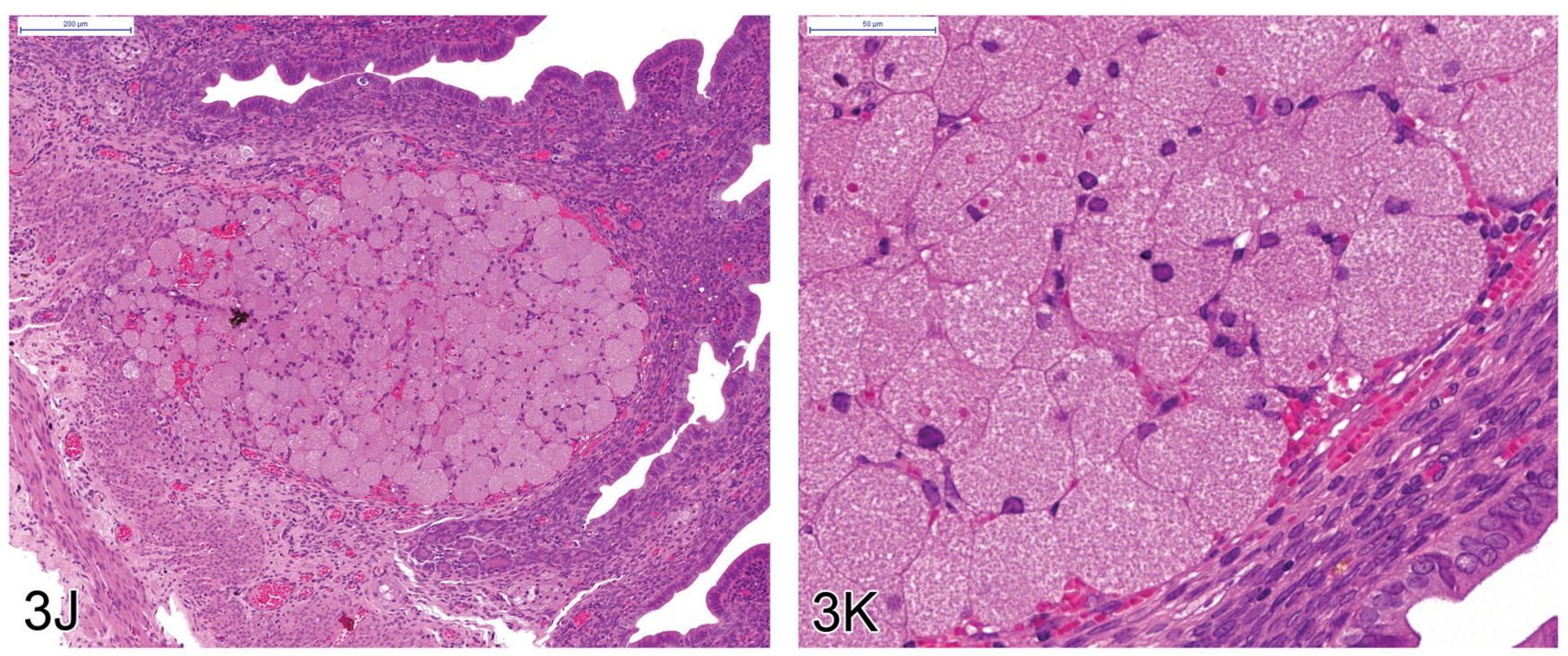

Figure 3.

Ectopic C cell tumor in the trachea of a male Syrian (Han:AURA) hamster (A-I). A luminal cellular mass extends through the lamina propria to the level of the tracheal cartilage, adjacent to the thyroid gland (A). This mass is composed of sheets of medium-sized, polygonal to elongated cells with abundant amounts of eosinophilic, often vacuolated cytoplasm (B). The nuclei are predominantly medium-sized, round and central with coarse chromatin and occasional mitotic figures (C).

Immunohistochemical stains were used to better characterize the lesion and show that the neuroendocrine cells are positive for calcitonin (D), calcitonin gene-related peptide (E), neuron-specific enolase (F), serotonin (G), and synaptophysin (H). In addition, neuroendocrine or ectopic $\mathrm{C}$ cells are positive with a silver stain (Grimelius) (I). A uterine granular cell lesion in a female Syrian (Han:AURA) hamster (J\&K). This lesion is characterized by a large focal group of polygonal cells in the lamina propria of the uterus $(\mathrm{J})$ with abundant eosinophilic granular cytoplasm and small, eccentric, nuclei with coarse chromatin (K). 

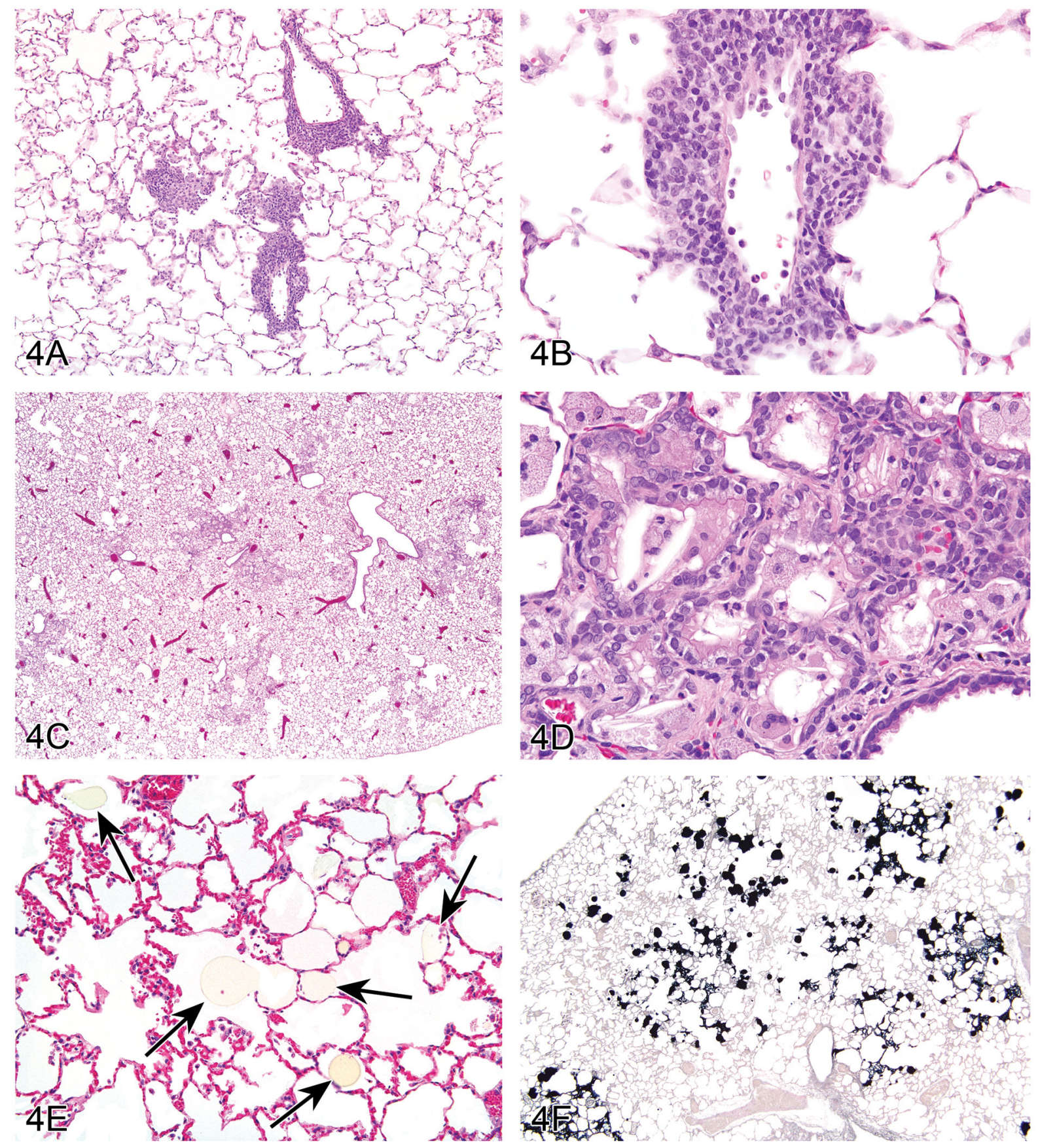

Figure 4.

Lung lesions in F344/N control male rats from chronic oral gavage studies. For Case 1, images A and B were used to illustrate a lesion that is morphologically similar to Pneumocystis carinii infection with chronic perivascular inflammation (A) and multifocal lymphohistiocytic interstitial inflammation (B). Images C-F were presented for Case 2, which involved an oral gavage study in which corn oil served as the vehicle control. A centriacinar lesion (C) is comprised of chronic inflammation, type II epithelial hyperplasia, and bronchiolar metaplasia (D). Figure E illustrates numerous pale yellow homogeneous droplets within the alveolar spaces of a F344/N male control rat. There is positive staining of the droplets for Sudan Black indicating that the foreign material may be corn oil (F). 

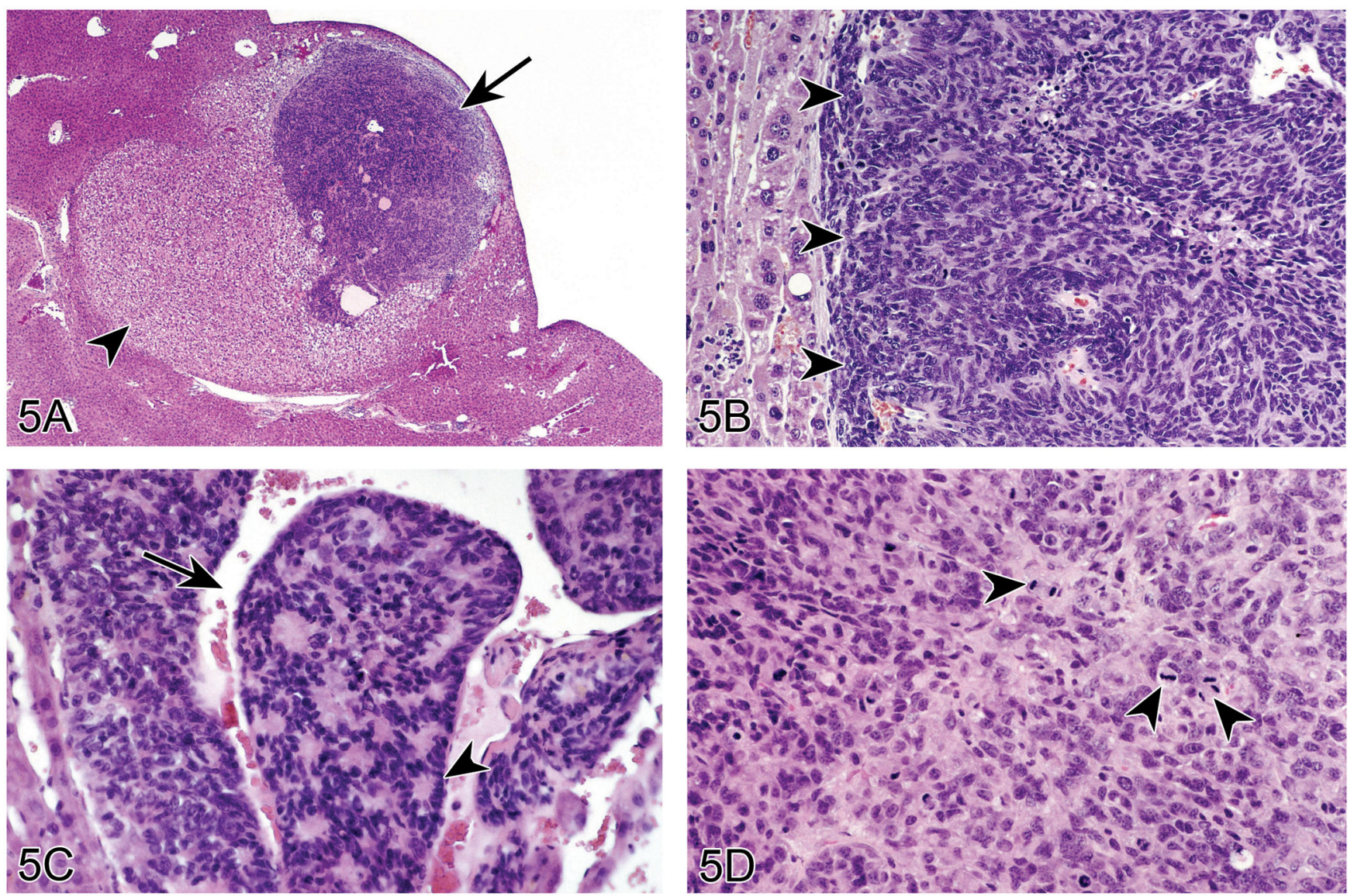

Figure 5.

An hepatoblastoma arising within a pre-existing hepatic adenoma in a $\mathrm{B} 6 \mathrm{C} 3 \mathrm{~F} 1$ mouse. Figure 5A shows an hepatoblastoma (arrow) associated with an expansive and well-circumscribed hepatocellular adenoma (arrowhead). Higher magnification (B) shows the two morphologically distinct neoplasms; the hepatoblastoma (arrowheads) is composed of small cells with scant

cytoplasm and hyperchromatic irregular nuclei as compared to the neoplastic adenoma cells on the left. (C) The hepatoblastoma exhibits palisading of nuclei (arrowhead) and areas with widened endothelial-lined spaces containing blood (arrow) (C), and mitotic figures are frequent (arrowheads) (D). 

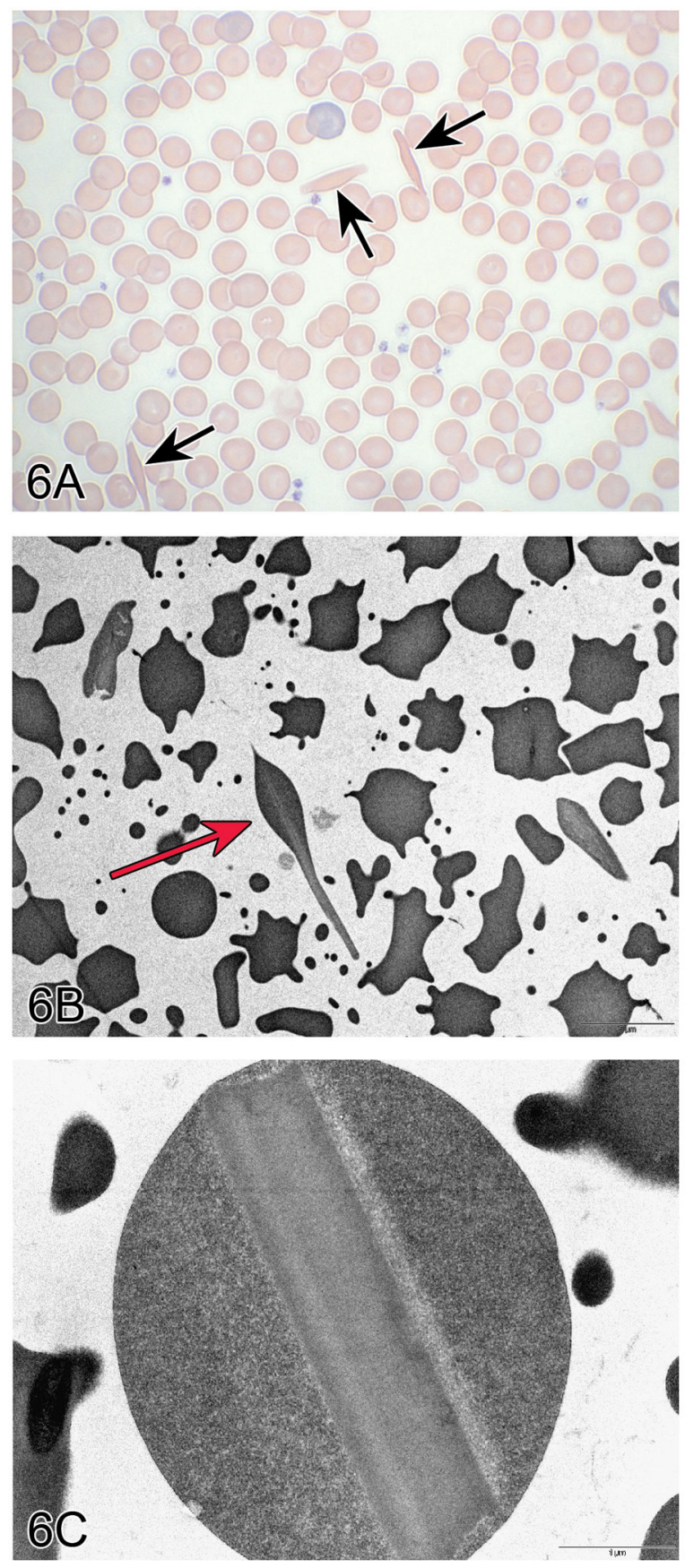

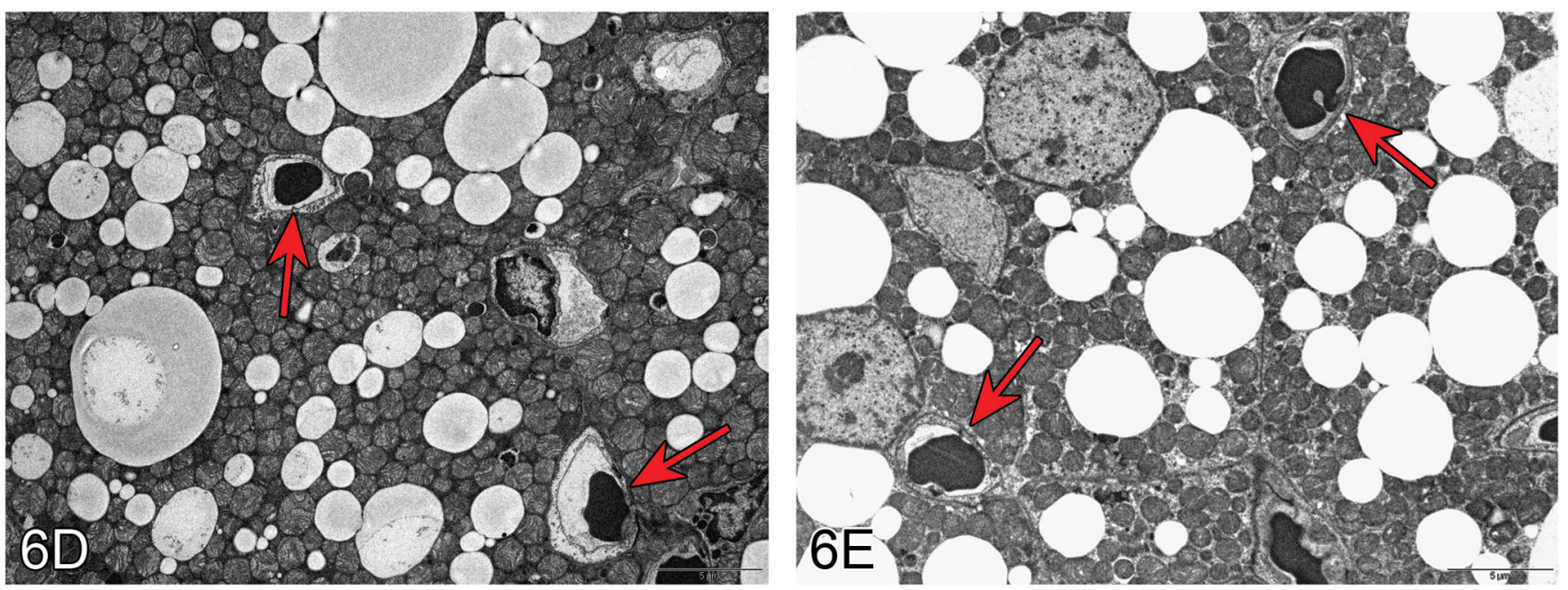

Figure 6.

Preanalytical artifact in red blood cells in genetically engineered mice. Peripheral blood smear (A) from a genetically engineered mouse shows several abnormally shaped erythrocytes (arrows). Figures 6B and 6C are TEMs that better define the abnormally shaped erythrocytes with intracellular crystalline-like inclusions (arrows), thought to be a preanalytical artifactual change.

Transmission electron microscopy (TEM) of brown fat in Wistar Han rats. Figures In these TEMs, brown fat cells characterized by fat droplets and numerous cytoplasmic mitochondria. The close proximity of the adipocytes to capillaries is illustrated in these images (arrows). Unsaturated lipid droplets appear medium to markedly electron dense (D) while saturated lipid droplets are electron lucent to flocculent or finely pale gray and granular (E). 

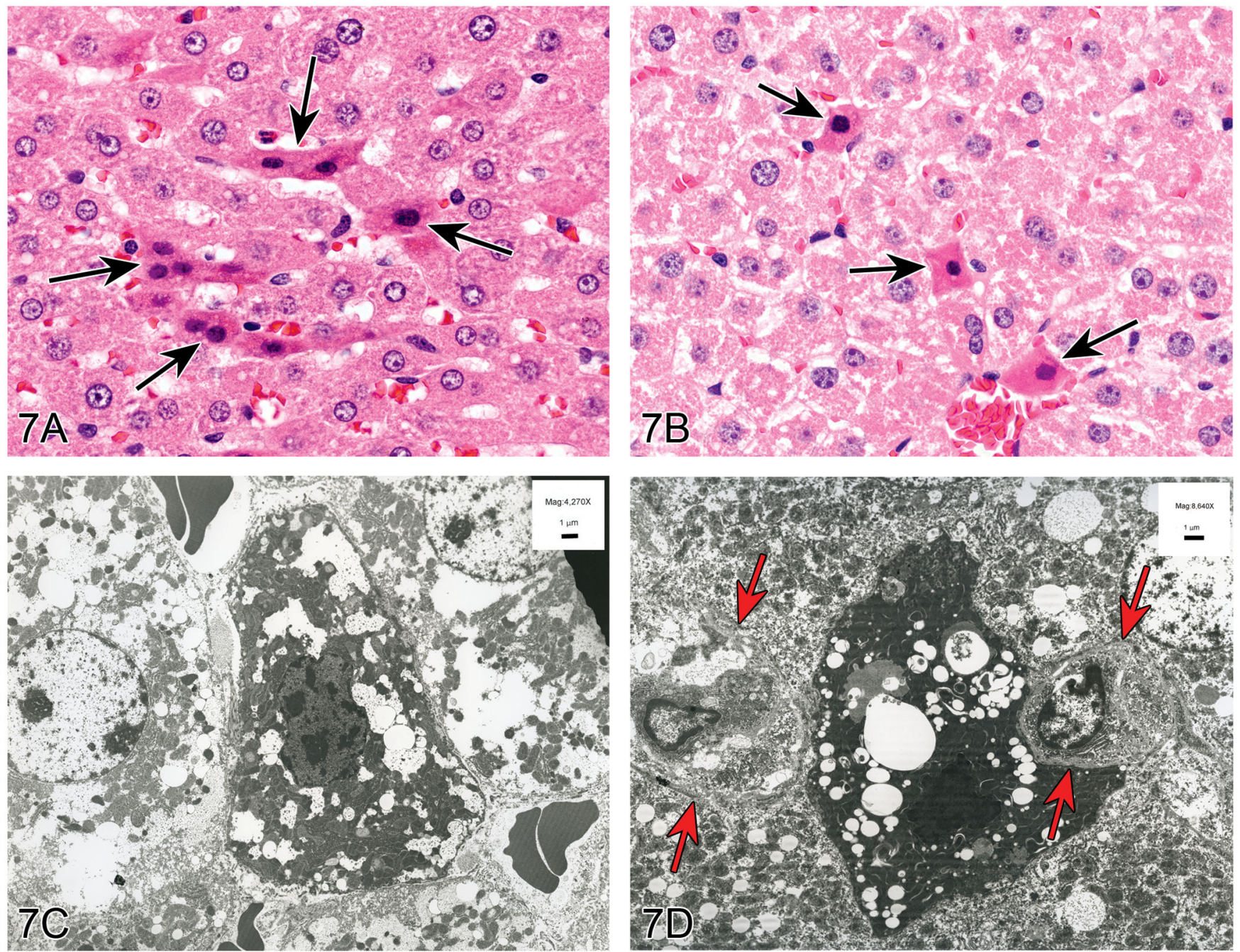

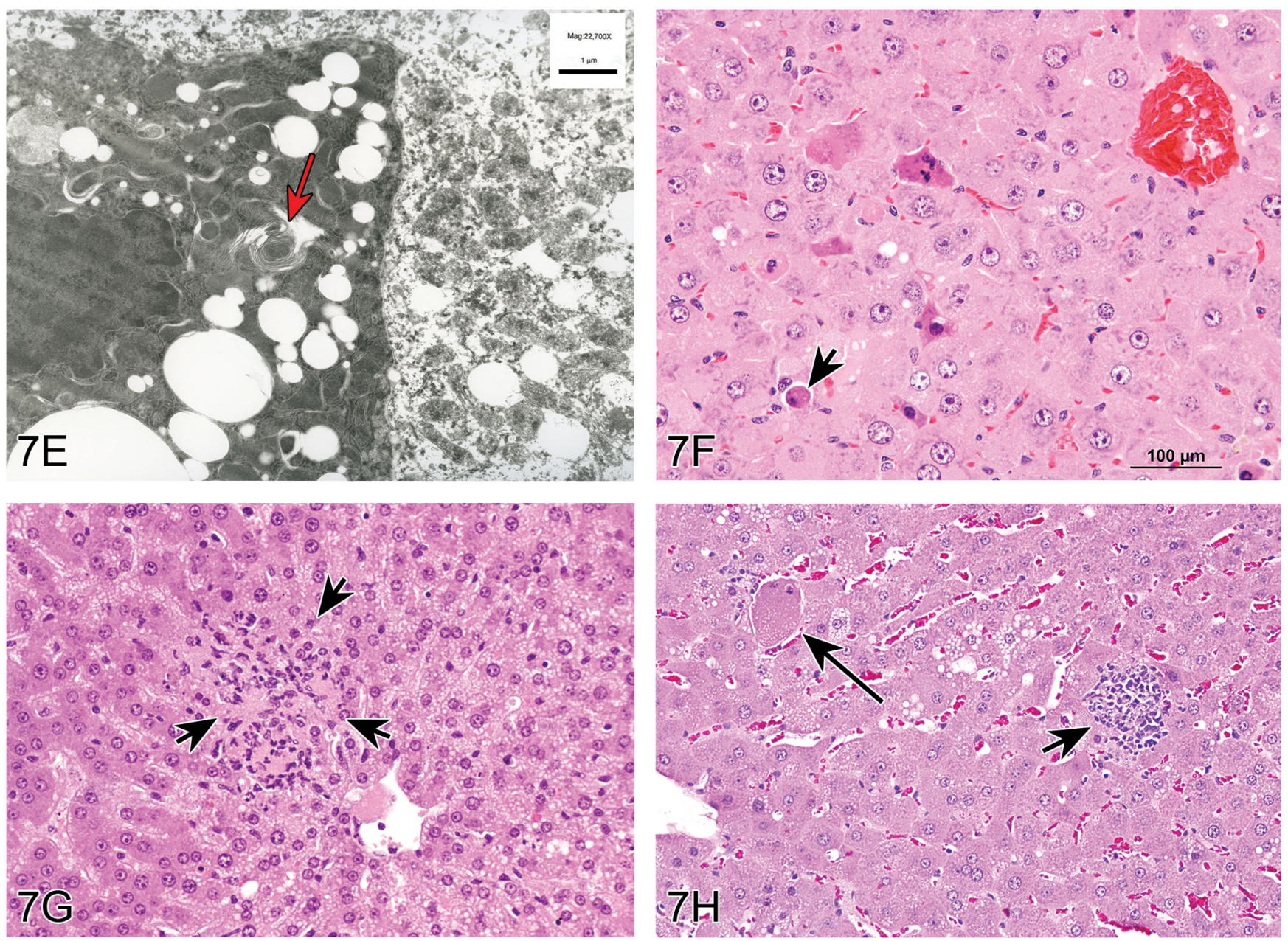

Figure 7.

Small hypereosinophilic hepatocytes in female Sprague Dawley rats treated with a weak peroxisome proliferator. Figures 7A\&B show medium and high magnification images of the scattered, randomly distributed, single or small clusters of affected hepatocytes (arrows). These cells are shrunken and angular with hyperchromatic nuclei and hypereosinophilic cytoplasm. Figures 7C-E are transmission electron micrographs of the affected hepatocytes. Figure 7C is an example of a hepatocyte that appears to be in an earlier stage. Note the lack of peripheralized chromatin, which would be a hallmark of early apoptosis. Also not the lack of cell swelling, which would be a hallmark of necrosis. Figure 7D is a later stage, with more condensed chromatin and cytoplasm, larger vacuoles, and adjacent/encroaching macrophages (Kupffer cells) (arrows). Figure 7E is a higher magnification of (D) showing a myelin figure that is neither within a lipid vacuole nor an autophagosome. Figure 7F is an example of classic hepatocellular apoptosis characterized by single scattered hepatocytes that are small and shrunken with hypereosinophilic cytoplasm and occasional nuclear debris. Various stages of apoptosis can be seen, including apoptotic bodies (arrows). Figure 7G is an example of classic hepatocellular necrosis, characterized by a focal group of contiguous cells with cell swelling, loss of cellular features, cell debris and inflammation. Figure $7 \mathrm{H}$ is an example of single cell necrosis in the liver. The affected cell (long arrow) shows marked cell swelling and karyorrhexis. The ultimate fate of such a cell is cell rupture with release of proinflammatory mediators and eventually inflammation as indicated by the short arrow. 

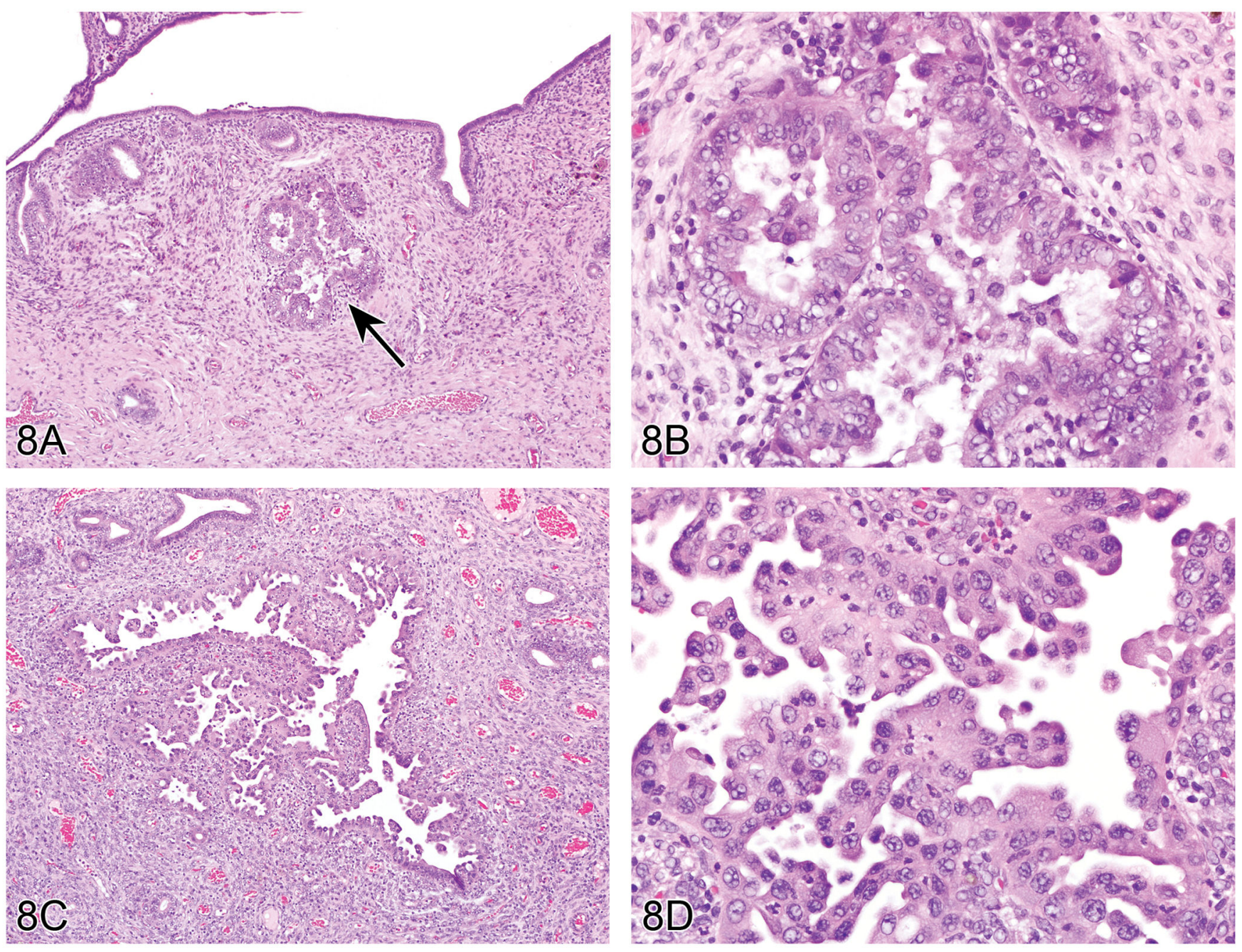

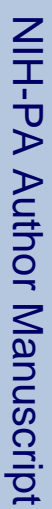

Toxicol Pathol. Author manuscript; available in PMC 2015 January 01. 

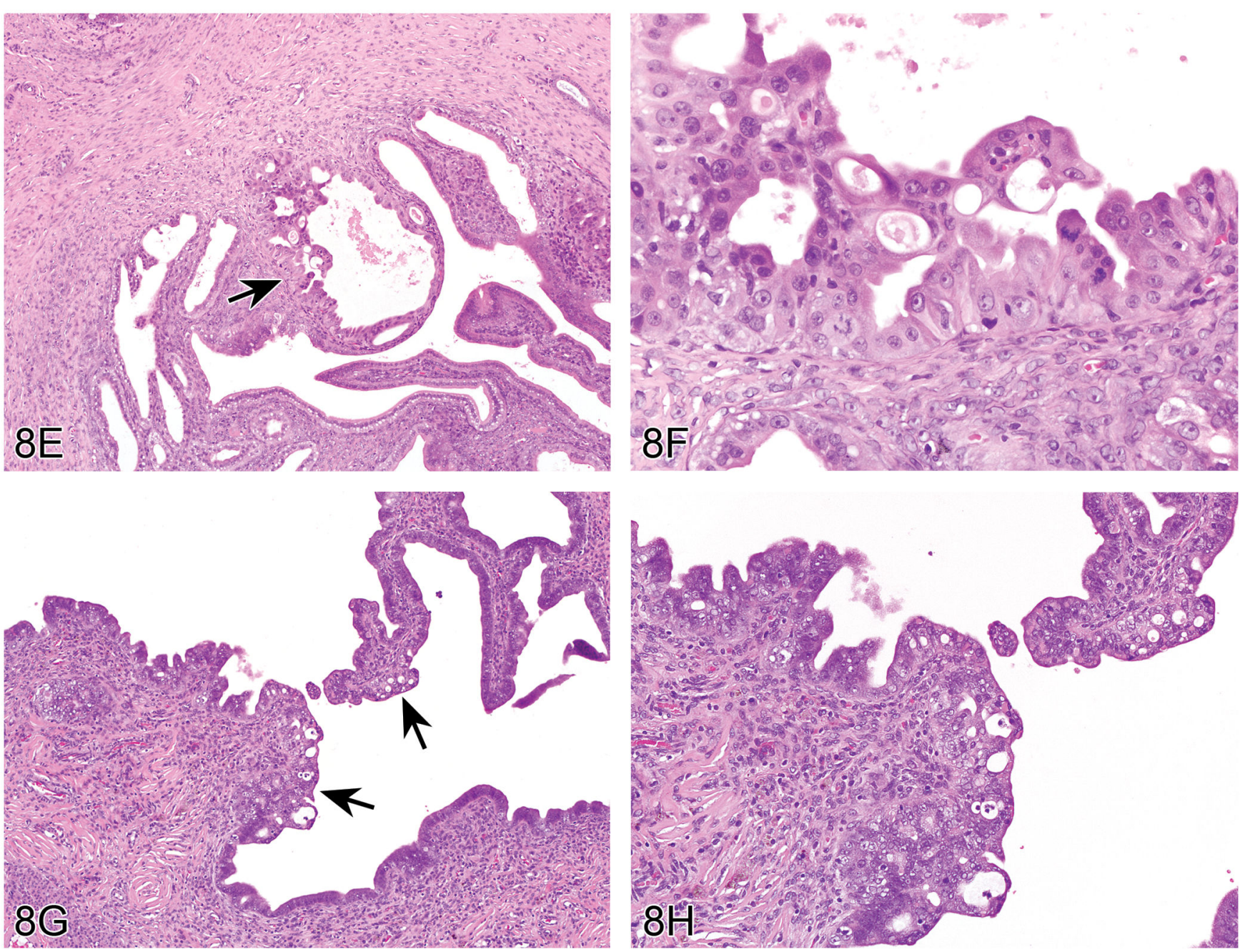

Figure 8.

Atypical endometrial hyperplasia in the uteri of Wistar Han rats from a 2-yr toxicity/carcinogenicity bioassay. Clusters of affected glands are separated by little to no stroma (A) and lined by atypical stratified disorganized epithelium that piles up to

six cell layers thick and protrudes into glandular lumens forming multiple thickened infoldings and projections (B). The epithelial cells display loss of nuclear polarization, karyomegaly, mitoses, and cellular pleomorphism (B). Also identified in this study was a papillary type of atypical hyperplasia (C) characterized by numerous small branching projections of epithelium that extend into the uterine lumen with epithelial blebbing and loss of nuclear polarization (D). Occasionally large cystic glands (E) would also show areas of similar cellular atypia $(F)$. Focal areas of the uterine lumen $(\mathrm{G})$ were also affected by atypical endometrial hyperplasia $(\mathrm{H})$. 

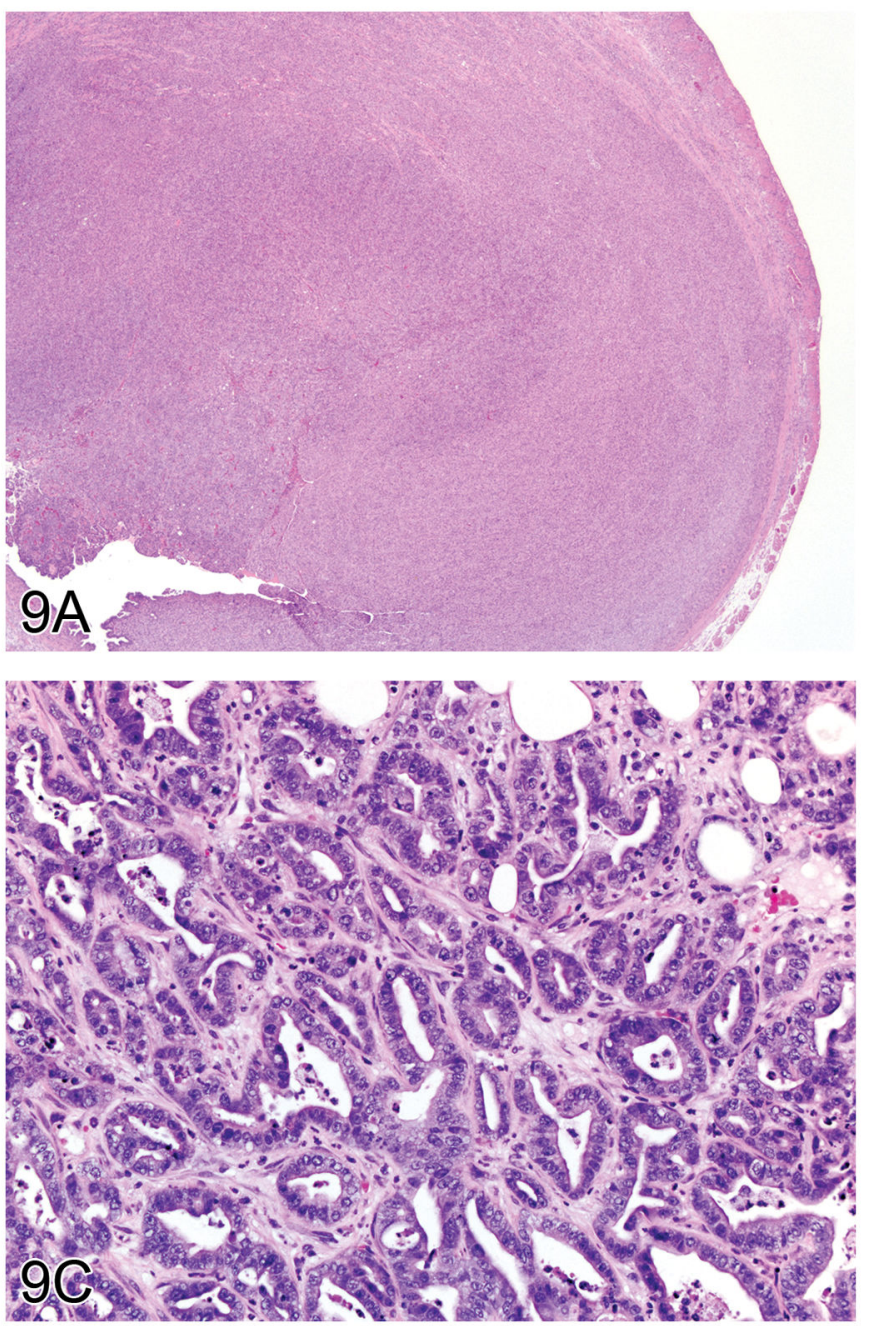
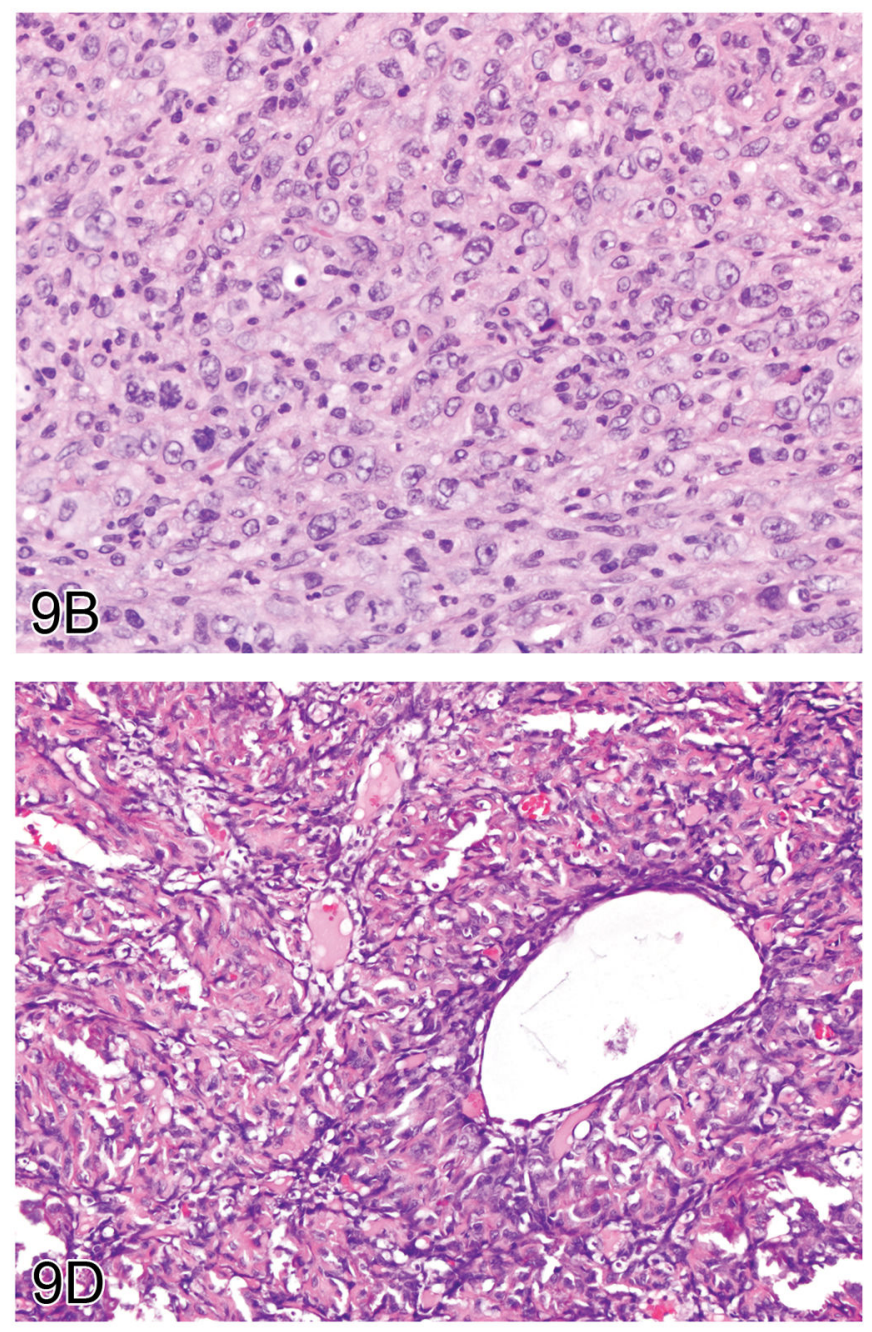

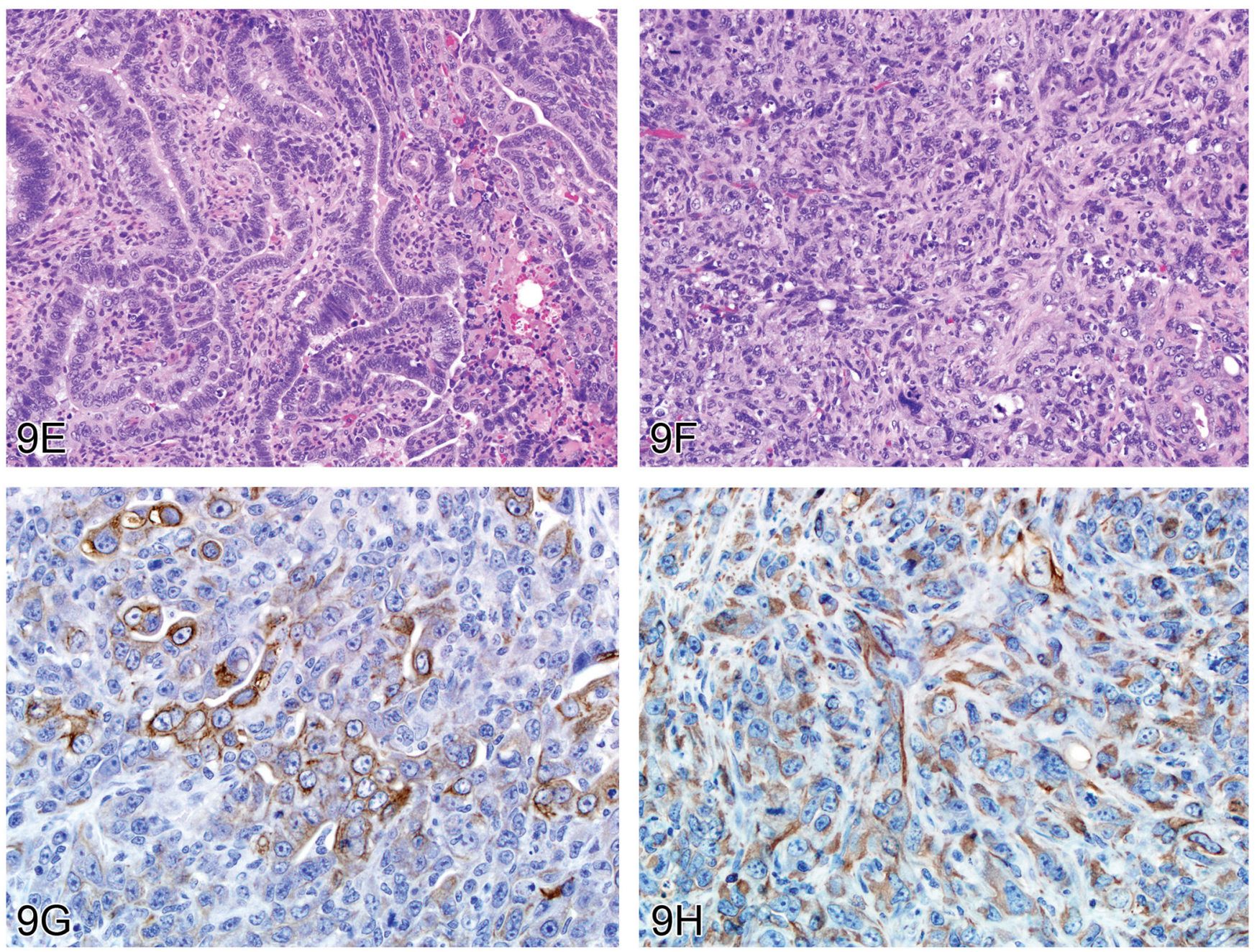

Figure 9.

Malignant mixed Müllerian tumors (MMMTs) in female Wistar Han rats from a 2-year toxicity/carcinogenicity bioassay. The lesion presented for voting as Case 1 depicts a large solid neoplastic mass (homologous MMMT) that effaces the normal uterine architecture (A). Higher magnification of the lesion in (A) shows neoplastic cells arranged in solid sheets without the typical adenocarcinoma acinar formation (B). Neoplastic epithelium arranged in acinar structures comprises a portion of the heterologous MMMT presented in Case 2 (C). The glandular epithelium is several layers thick in some areas with very little intervening stroma between glands, characteristic of a typical uterine adenocarcinoma (C). Other portions of the mass from figure 9C are composed of small angular basophilic neoplastic cells surrounded by abundant eosinophilic material (osteoid) and islands of mature bone (D). Figures 9E\&F were used to illustrate the differences in cellular morphology between a classic uterine adenocarcinoma and an MMMT. The adenocarcinoma is composed of acinar formation lined by well-differentiated neoplastic epithelium (E). The MMMT is densely cellular and solid (F). The cells contain a moderate amount of cytoplasm, indistinct cell borders, and variably sized round to oval nuclei with coarse to stippled chromatin and one to several prominent nucleoli. Cytokeratin $(\mathrm{G})$ and vimentin $(\mathrm{H})$ were used to illustrate the epithelial and mesenchymal components of this neoplasm, respectively. 


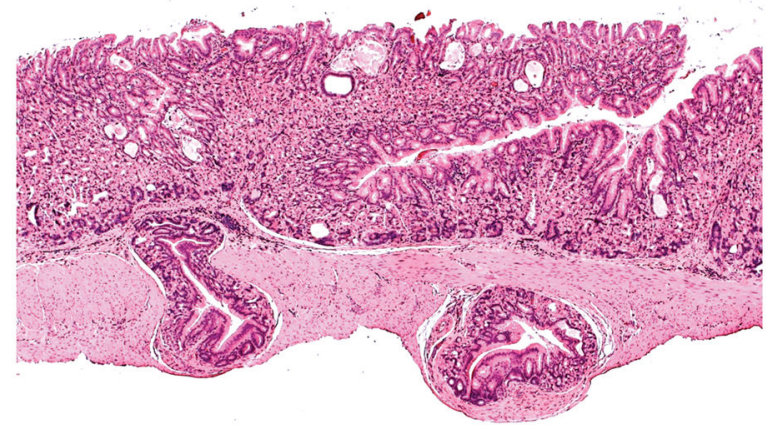

$10 \mathrm{~A}$
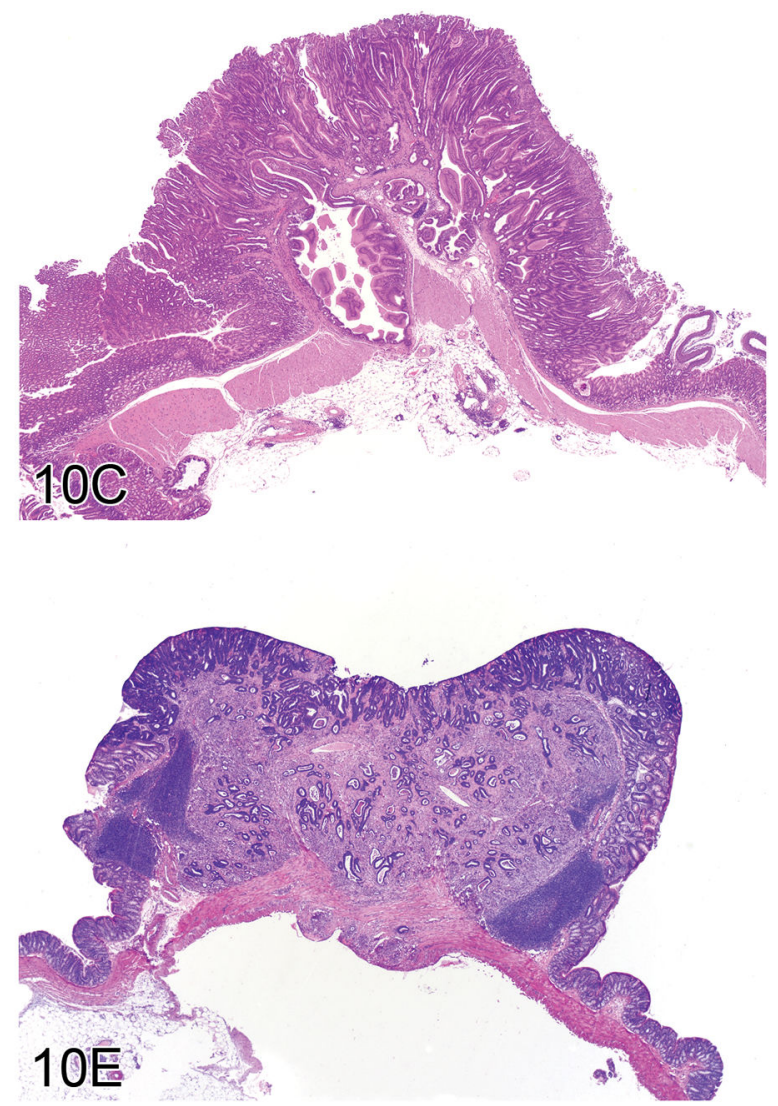
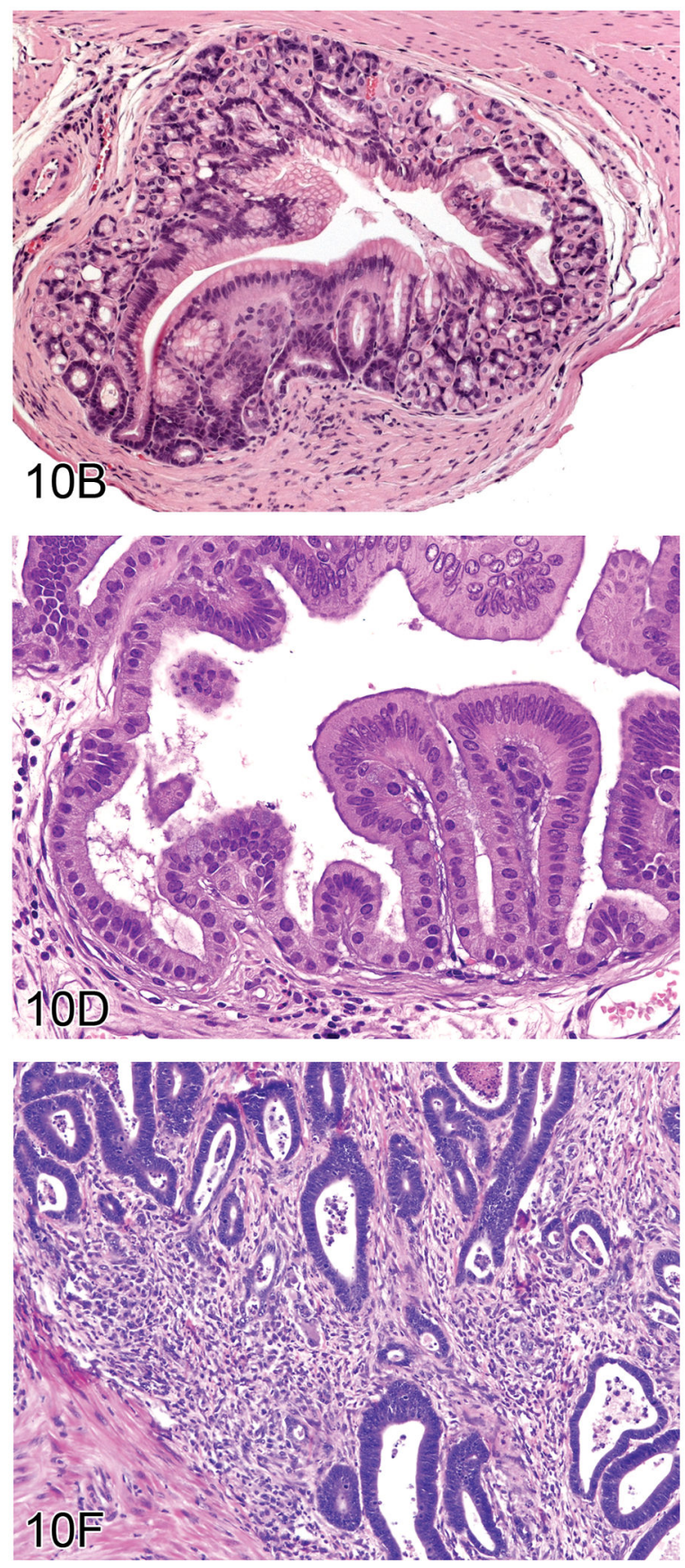

Figure 10.

Three cases of gastrointestinal lesions with questions about nomenclature and differential diagnosis of both infiltration in epithelial malignancies and diverticula. Case 1 illustrates diverticula in the glandular stomach of a male CD-1 mouse characterized by cyst like structures in the tunica muscularis (A). Higher magnification (B) shows the regular differentiation of the mucosa lining the diverticulum; note also the maintained basement membrane integrity. Case 2 is illustrated by a sessile adenoma with atypical diverticula in the pyloric region of a male aryl hydrocarbon receptor knockout mouse (C) with a higher magnification (D) demonstrating the atypical character of the epithelium lining the diverticulum; note that basement membrane integrity is maintained. Case 3 was presented as an adenocarcinoma of the colon in a male F344 rat treated with once weekly 
subcutaneous injections of $26.6 \mathrm{mg} / \mathrm{kg}$ 1,2-dimethylhydrazine for 20 weeks; note composition of the tumor is scirrhous stroma with scattered glandular profiles covered by atypical mucosa (E). Higher magnification (F) shows areas of indistinct demarcation of the epithelial profiles from the surrounding scirrhous stroma, indicating loss of basement membrane integrity. 

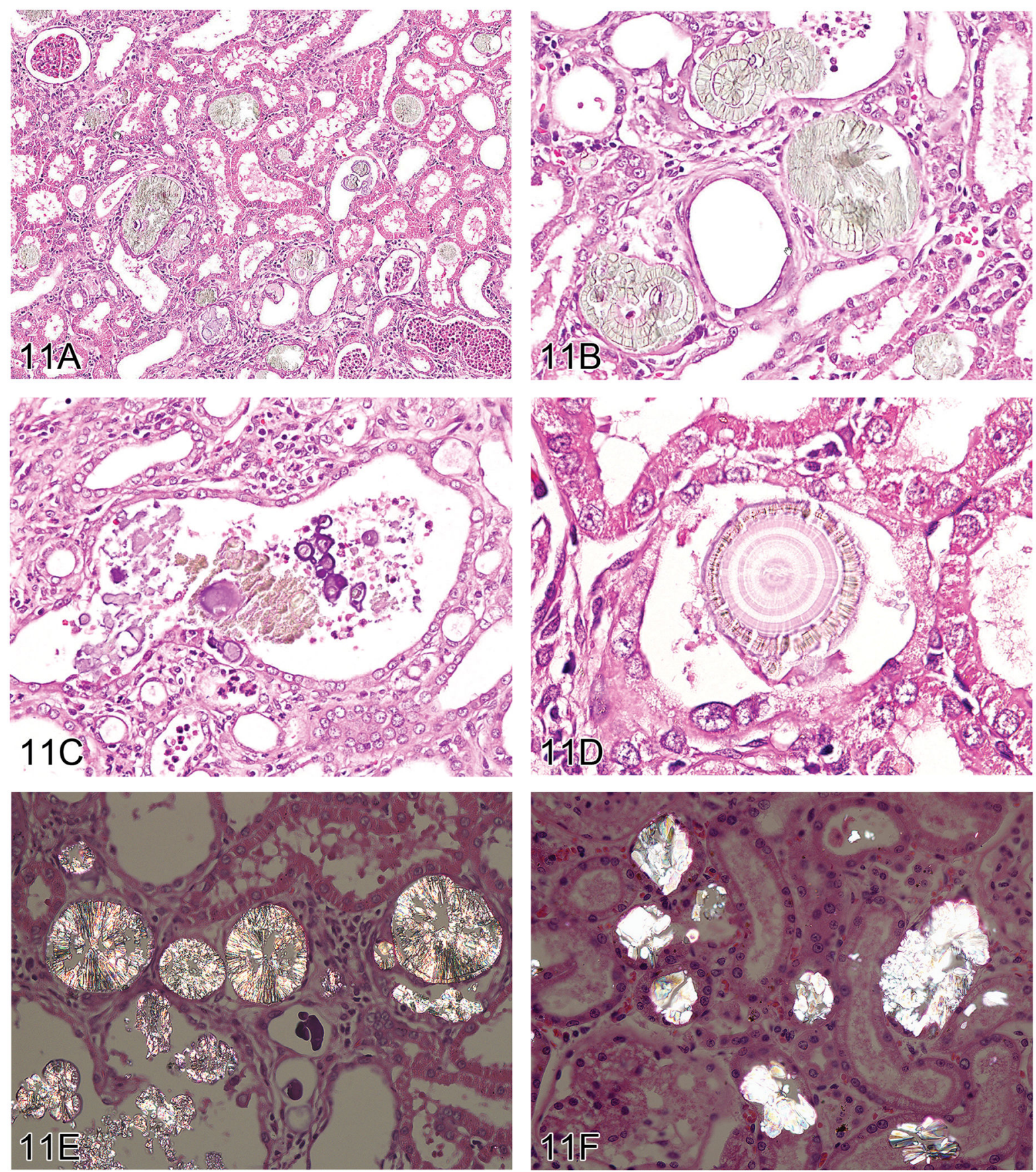

Figure 11.

Foreign material in the kidney of a rat exposed to melamine and cyanuric acid orally for 12 weeks. Both the cortex and medulla show dilated renal tubules and crystalline aggregates (A). Crystalline aggregates have a characteristic "shattered plate" morphology (B). In a dilated renal tubule, foci of mineralized concretions, granular material and smaller crystals can be seen (C). Intra-tubular mineralization was often seen as concretions or concretions associated with the crystalline aggregates and (D) shows a more unusual crystalline aggregate with a structured center, possibly mineralization. Polarized light was used to show the characteristic appearance of melamine-cyanuric acid crystalline aggregates in a rat kidney (E). For comparison, polarized 
light was also used to show the characteristic appearance of crystalline aggregates in a dog kidney with ethylene glycol toxicity (F). Note the differences in aggregate morphology when compared to (E). 


\section{Table 1}

Ectopic C cell hyperplasia and tumors in control hamsters.

\begin{tabular}{|c|c|c|c|c|}
\hline & \multicolumn{2}{|c|}{6 month study } & \multicolumn{2}{|c|}{12 month study } \\
\hline & Male & Female & Male & Female \\
\hline No. examined & 50 & 50 & 50 & 50 \\
\hline \multicolumn{5}{|l|}{ Trachea } \\
\hline \multirow[t]{3}{*}{ Hyperplasia } & 0 & 1 & 0 & 1 \\
\hline & \multicolumn{2}{|c|}{104 week study } & \multicolumn{2}{|c|}{104 week study } \\
\hline & Male & Female & Male & Female \\
\hline No. examined & 100 & 98 & 30 & 30 \\
\hline \multicolumn{5}{|l|}{ Trachea } \\
\hline \multirow[t]{3}{*}{ Hyperplasia } & 1 & 0 & 1 & 1 \\
\hline & \multicolumn{4}{|c|}{3 combined 104 week studies } \\
\hline & \multicolumn{2}{|c|}{ Male } & \multicolumn{2}{|c|}{ Female } \\
\hline No. examined & \multicolumn{2}{|c|}{250} & \multicolumn{2}{|c|}{250} \\
\hline \multicolumn{5}{|l|}{ Larynx } \\
\hline Benign tumor & \multicolumn{2}{|c|}{0} & \multicolumn{2}{|c|}{1} \\
\hline Malignant tumor & \multicolumn{2}{|c|}{1} & \multicolumn{2}{|c|}{0} \\
\hline \multicolumn{5}{|l|}{ Trachea } \\
\hline Benign tumor & \multicolumn{2}{|c|}{0} & \multicolumn{2}{|c|}{1} \\
\hline
\end{tabular}




\section{Table 2}

Voting choices and results for case 2.
A. Inflammation, chronic
B. Infiltration cellular, histiocyte
C. Type II epithelial hyperplasia
D. Bronchioloalveolar hyperplasia, mixed
E. Bronchiolar metaplasia / bronchiolization
1. A
2. D
3. A, D
4. B, D
5. A, C, E
6. B, C, E
7. None of the above 


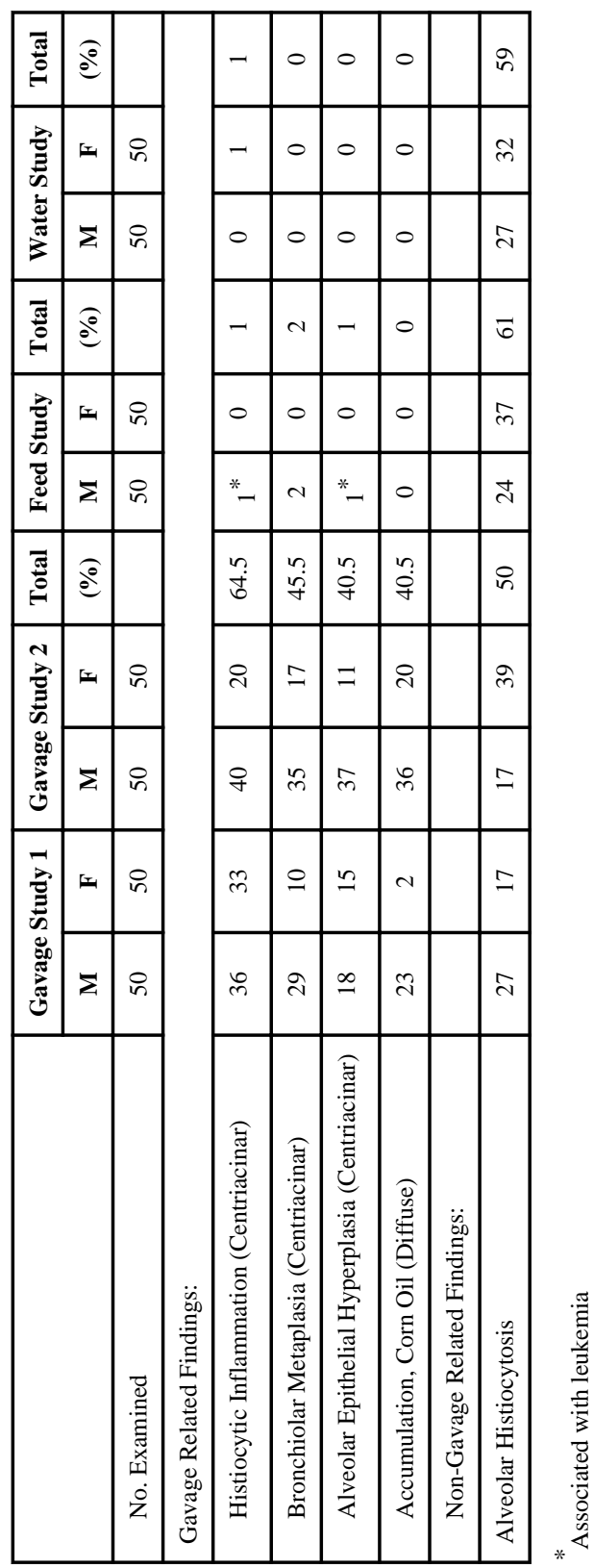


Table 4

Mutation Spectrum of H-ras and $\beta$-catenin in Liver Tumors ${ }^{+}$

\begin{tabular}{|c|c|c|c|c|}
\hline & \multicolumn{2}{|c|}{ H-ras 1} & \multicolumn{2}{|c|}{$\beta$-catenin 2} \\
\hline & $\mathrm{HCC}^{*}$ & $\mathrm{HB}^{*}$ & $\mathrm{HCC}^{*}$ & $\mathrm{HB}^{*}$ \\
\hline \multicolumn{5}{|c|}{ Animal \# } \\
\hline 1 & $61 \mathrm{CAA} \rightarrow \mathrm{CGA}$ & - & - & - \\
\hline 2 & $61 \mathrm{CAA} \rightarrow \mathrm{CGA}$ & - & $\begin{array}{c}34 \mathrm{GGA} \rightarrow \text { GTA } \\
37 \mathrm{TCT} \rightarrow \mathrm{TTT}\end{array}$ & $37 \mathrm{TCT} \rightarrow \mathrm{TTT}$ \\
\hline 3 & $61 \mathrm{CAA} \rightarrow \mathrm{CGA}$ & - & - & $32 \mathrm{GAT} \rightarrow \mathrm{GTT}$ \\
\hline 4 & $61 \mathrm{CAA} \rightarrow \mathrm{CTA}$ & - & - & - \\
\hline 5 & - & $61 \mathrm{CAA} \rightarrow \mathrm{CTA}$ & - & - \\
\hline 6 & - & $61 \mathrm{CAA} \rightarrow \mathrm{CTA}$ & - & $52 \mathrm{CCT} \rightarrow \mathrm{CAT}$ \\
\hline 7 & - & - & - & $32 \mathrm{GAT} \rightarrow \mathrm{AAT}$ \\
\hline 8 & - & - & $41 \mathrm{ACC} \rightarrow \mathrm{GCC}$ & $\begin{aligned} 32 \mathrm{GAT} & \rightarrow \text { GGT } \\
33 \mathrm{TCT} & \rightarrow \text { TTT }\end{aligned}$ \\
\hline 9 & - & - & - & $5 \mathrm{GCT} \rightarrow \mathrm{TCT}$ \\
\hline 10 & - & - & - & $35 \mathrm{ATC} \rightarrow \mathrm{AGC}$ \\
\hline 11 & - & - & 19-46 deletion & - \\
\hline
\end{tabular}

${ }^{+}$Unpublished data courtesy of Dr. Hiroaki Nagai

${ }^{1}$-ras codon 61 defects for are separated

${ }^{2} \beta$-catenin codon $34,37,32,52,41,33,5,35$

*HCC, hepatocellular carcinoma; HB, hepatoblastoma 
Table 5

Serum Calcium Analysis Between Groups

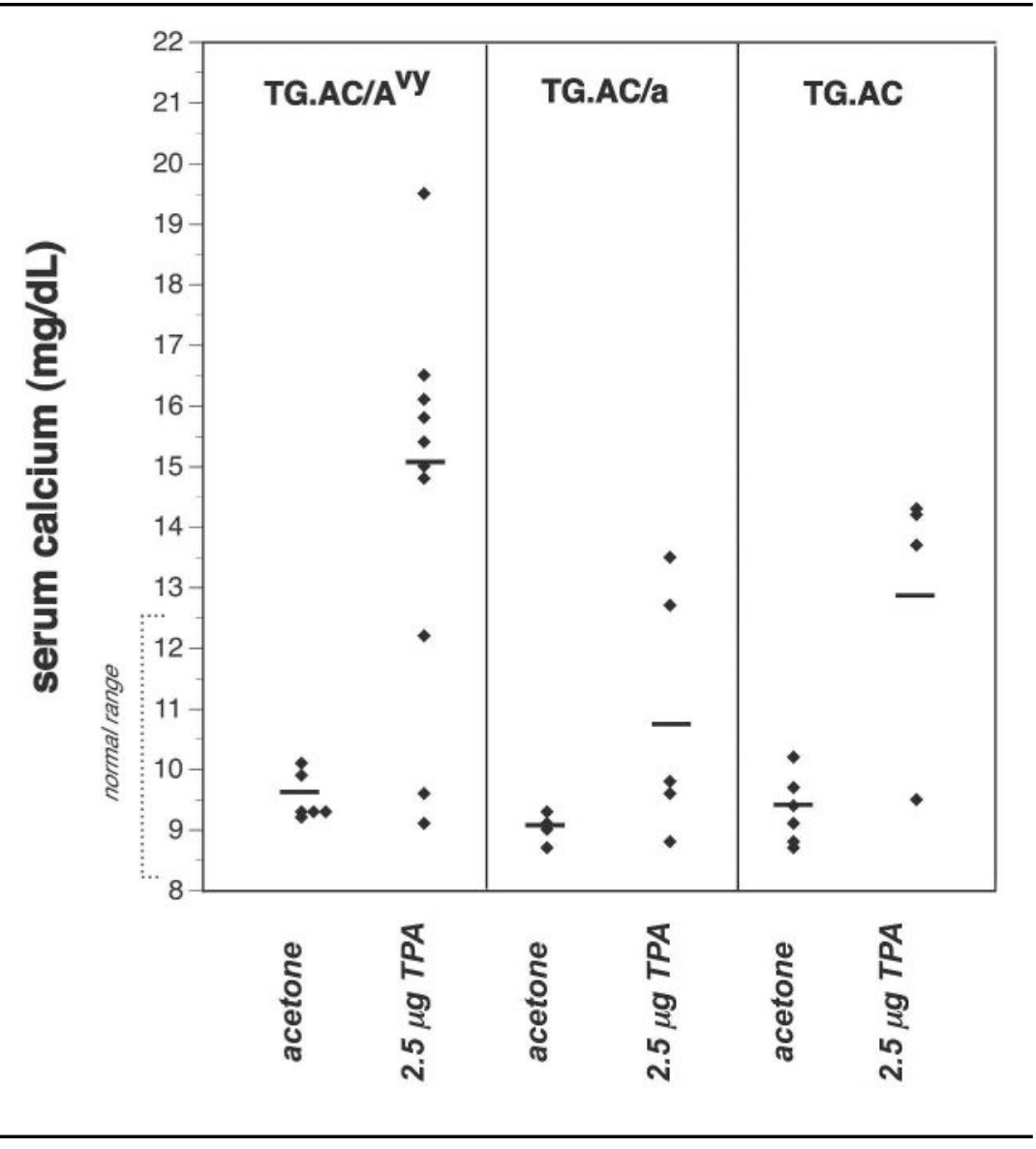


Table 6

Absolute Numbers of Differentially Expressed Genes in Rat Livers

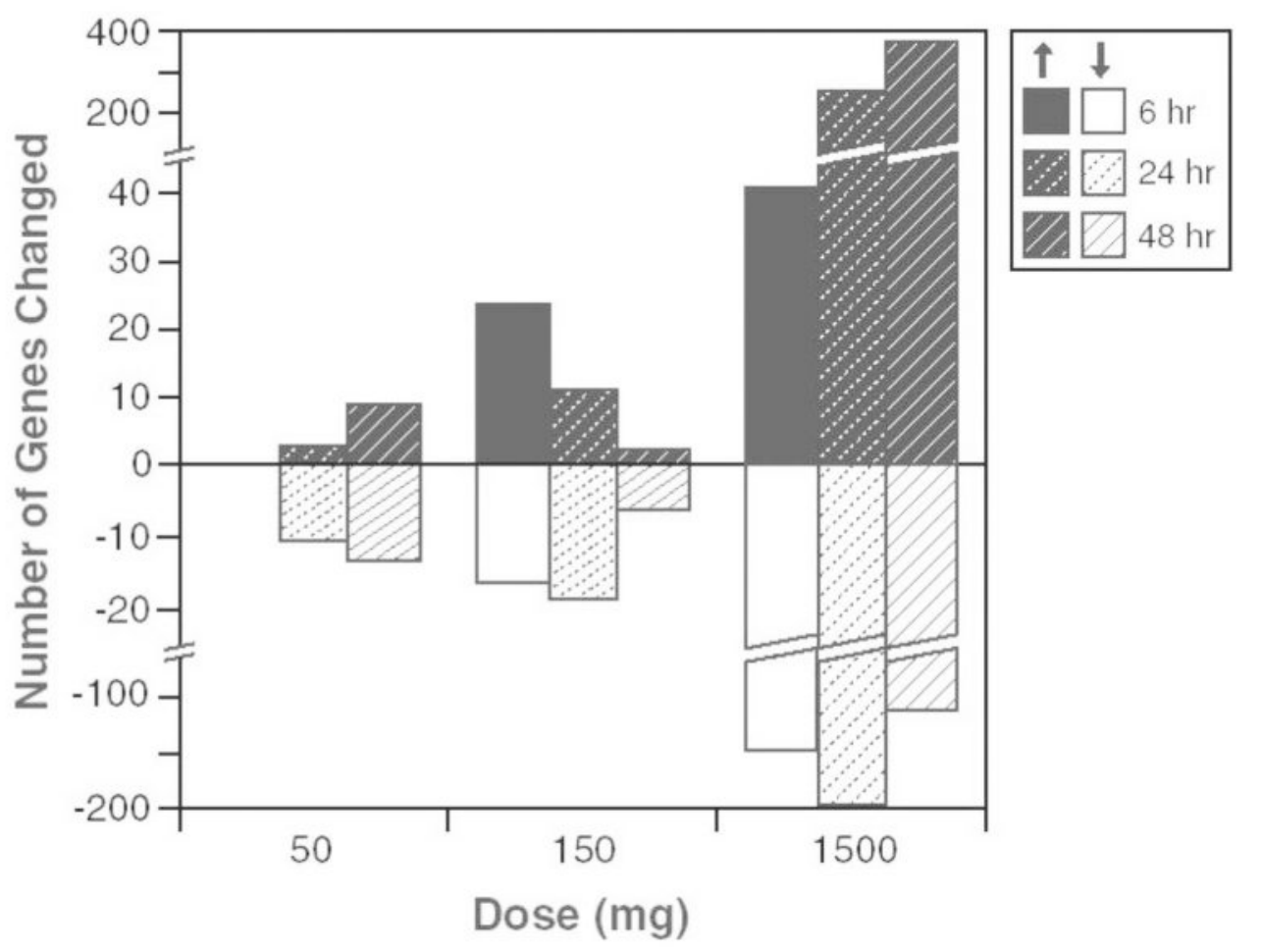




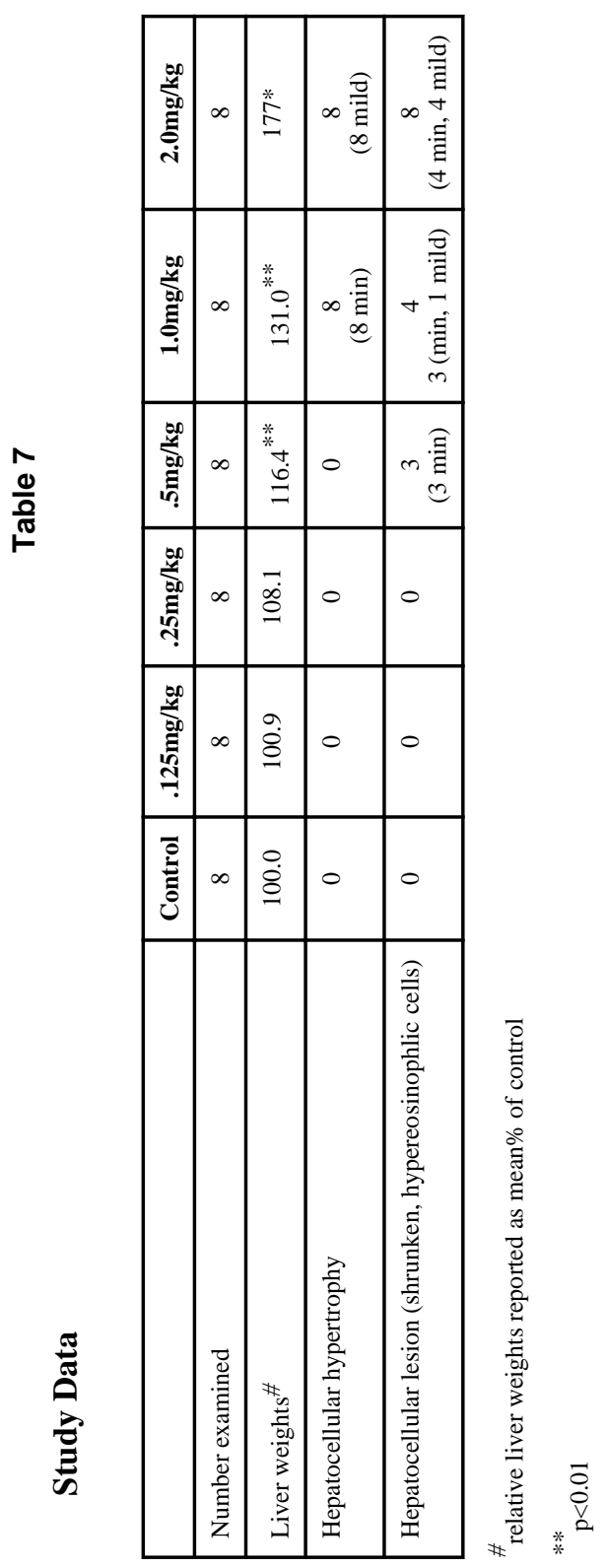

Toxicol Pathol. Author manuscript; available in PMC 2015 January 01. 
Table 8

Morphology of apoptosis versus necrosis

\begin{tabular}{|l|l|}
\hline Apoptosis & Necrosis \\
\hline Single cells or small clusters of cells & Often contiguous cells \\
\hline Cell shrinkage and convolution & Cell swelling with loss of cell detail* \\
\hline Cytoplasmic/organelle condensation & Organelle swelling \\
\hline Chromatin condensation with peripheralization in early stages & Chromatin condensation not a prominent feature \\
\hline Hypereosinophilia & Pale eosinophilic staining \\
\hline Pyknosis and karyorrhexis & Karyolysis, pyknosis, and karyorrhexis \\
\hline Intact cell membrane & Disrupted cell membrane \\
\hline $\begin{array}{l}\text { Tingible body macrophages with engulfed apoptotic bodies in some tissues } \\
\text { (i.e. lymphoid) }\end{array}$ & No tingible body macrophages \\
\hline Cytoplasm retained in apoptotic bodies & $\begin{array}{l}\text { Cell rupture with release of cytoplasm and pro-inflammatory } \\
\text { mediators }\end{array}$ \\
\hline Inflammation usually not present & Inflammation (esp. neutrophils) usually present \\
\hline
\end{tabular}

* One of the easiest ways to distinguish these two forms of cell death with H\&E. 
Table 9

Incidences of malignant mixed Müllerian tumors, adenomas, and adenocarcinomas

\begin{tabular}{|l|c|c|c|c|}
\hline & Control & Low Dose & Mid Dose & High Dose \\
\hline Females \# ex. & 50 & 50 & 50 & 50 \\
\hline Malignant mixed Müllerian tumor & 0 & 4 & 0 & 2 \\
\hline Adenoma & 3 & 2 & 4 & 6 \\
\hline Adenocarcinoma, including multiples & $4^{* *}$ & 10 & $15^{* *}$ & $16^{* *}$ \\
\hline MMMT, adenoma, or adenocarcinoma & $6^{* *}$ & 11 & $16^{* *}$ & $19^{* *}$ \\
\hline
\end{tabular}

** Positive trend test or significantly different ( $\mathrm{p} \leq .001)$ from the control group by Poly 3 test 


\section{Table 10}

INHAND Digestive Tract Organ Working Group: Key criteria suggested for diverticulum of stomach / intestine:

- Extension of glands / crypts through muscularis mucosae, into submucosa and further in some cases.

- Morphology of epithelial lining is variable, ranging from single layer cuboidal or columnar cells to complete mucosa.

- Epithelium may show features of regeneration-like increased basophilia, increased nucleus-to-cytoplasm ratio and gradual loss of polarity, but atypia is minimal at the most.

- $\quad$ Basement membrane integrity is always maintained. 
Table 11

INHAND Digestive Tract Organ Working Group: Key criteria suggested for adenoma of stomach / intestine:

- Mucosal architecture distorted.

- Growth pattern polypoid, sessile, or papillary with or without a fibrovascular stalk projecting into the lumen.

- Focal penetration by glandular diverticula into lamina propria or deeper layers may be present but basement membrane is always intact.

- $\quad$ The epithelium may contain foci of varying degrees of dysplasia. 


\section{Table 12}

INHAND Digestive Tract Organ Working Group: Key criteria suggested for adenocarcinoma of stomach / intestine:

- Regular mucosal structure is lost.

- Varying degrees of cellular atypia.

- $\quad$ Many mitotic figures.

- Invasion of nests and cords of neoplastic cells into lamina propria or deeper layers, loss of basement membrane integrity.

- Often scirrhous response in areas of invasion. 